\title{
VARIABILIDADE DOS PARÂMETROS DA EQUAÇÃO DA CONDUTIVIDADE HIDRÁULICA EM FUNÇÃO DA UMIDADE DE UM LATOSSOLO SOB CONDIÇÕES DE CAMPO
}

\author{
José Fernandes de MELO FiLHO
}

\author{
Tese apresentada à Escola Superior de Agricultura \\ "Luiz de Queiroz", Universidade de São Paulo, para \\ obtenção do título de Doutor em Agronomia, Área de \\ Concentração: Solos e Nutrição de Plantas.
}

P I R A C I C A B A

Estado de São Paulo - Brasil

Janeiro - 2002 


\title{
VARIABILIDADE DOS PARÂMETROS DA EQUAÇÃO DA CONDUTIVIDADE HIDRÁULICA EM FUNÇÃO DA UMIDADE DE UM LATOSSOLO SOB CONDIÇÕES DE CAMPO
}

\section{JOSÉ FERNANDES DE MELO FILHO}

Engenheiro Agrônomo

\author{
Orientador: Prof. Dr. PAULO LEONEL LIBARDI
}

\begin{abstract}
Tese apresentada à Escola Superior de Agricultura "Luiz de Queiroz", Universidade de São Paulo, para obtenção do título de Doutor em Agronomia, Área de Concentração: Solos e Nutrição de Plantas.
\end{abstract}

P I R A C I C A B A

Estado de São Paulo - Brasil

Janeiro - 2002 


\section{Dados Internacionais de Catalogação na Publicação (CIP)}

DIVISÃO DE BIBLIOTECA E DOCUMENTAÇÃO - ESALQ/USP

\section{Melo Filho, José Femandes de}

Variabilida de dos parâmetros da equa ção da condutividade hidrá ulica em função da umida de de um la tossolo sob condições de campo / J osé Femandes de Melo Filho. - - Piracic aba, 2001.

145 p. : il.

Tese (doutora do) - Escola Superior de Agric ultura Luiz de Queiroz, 2002. Bibliografia.

1. Água do solo 2. Condutivida de hidráulic a I. Título

CDD 631.432 
$\mathcal{D A} I-\mathcal{N} O S \quad \mathcal{A} \mathcal{A B D} D$ RI $\mathcal{A}$

Dai-nos forças, Sentior, para aceitar com serenidade tudo o que não possa ser mudado.

Dai-nos coragem para mudar o que pode e deve ser mudado.

$\mathcal{E}$ dai-nos sabedoria para distinguir uma coisa da outra.

\section{$O$ FERE $C ̧ O$}

À minha mãe, Vanda,

por todo esforço e de dic ação

para minha formação pessoal e profissional.

Aos meus irmãos $\mathcal{N}$ ey, Aialdo, gerry e $\mathcal{N}$ eto.

$\grave{A}$ minha querida esposa e amiga, Tilma, companteira de todas as horas, cujo apoio foi fundamental para estarmos aqui.

Aos meus filhos, Luiz Fernando e Thamires, pela dedicação e amor que sempre demonstraram pelo pai 


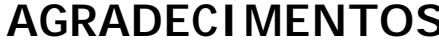

Ao professor Paulo Leonel Libardi, meu orientador e amigo, cuja dedicação, eficiência e humildade, dignificam a existência fumana;

À Escola S uperior de Agricultura "Luiz de Queiroz", a melhor, mais be la e centenária, pela oportunidade de desenvolvimento profissional;

À Escola de Agronomia da Universidade Federal da Bahia, berço da Ciênc ia Agronômica Brasile ira, pela formação e oportunidade de treinamento;

À Unive rsidade Federal da Bahia e a CAPES, cuja bols a viabilizou me u Curso e vivência em Piracicaba;

À Fundação de Amparo à Pesquisa do Estado de São Paulo (FAPESP), financiadora do proje to de pesquisa no qual desenvolve mos esta $\mathcal{T} e s e$;

Ao Curso de Pós-Graduação em Solos e Nutriçãa de Plantas da ES ALQ/ULP e seus professores, pela oportunidade e acolfimento para realização deste treinamento;

Ao professor Quirijn de Iong van Lier, pela amizade e dedicação para implantação do proje to no campo;

Ao professor Nilson Augusto Villanova, "o number one", pela confiança e carintio;

Ao professor Sérgio de Olive ira Moraes, cuja biblioteca me foi muito útil;

Ao professor Álvaro Pires da Silva, cuja amizade e apoio será sempre lembrada;

Ao casal Pedro e Edna Louça, por nossa eterna amizade; 
Ao professor gosé Torquato, meu procurador, por todo o apoio para garantir minha tranqüilidade aqui e m Piracicaba;

Aos amigos Welinton, Lílian, Estevão, Ze zé, Onildo, Maria Angélica, Guto, Aurora, Manoel, Glaudes, Heury, Lea, Washington, Carla, Elvis, Candinha, I aenes, Cândida, Genelício e Laércio, conviver com vocês foi muito gratificante, aquele abraço;

À Maria Iosé, I amile e gaqueline, admiráve is batalhadoras, minha primeira família aqui em Piracicaba;

Aos amigos da ESALQ, Silvia Inhoff, Miguel Cooper, Célia Regina Monte, Marcos Soares e Dêmora, pelas de monstrações de apreço e carintio;

Aos colegas de curso, I ean Dalmo, Marcelo Biassusi, Maria da Glória, Iosé Ronaldo, Cláudia, Luciana; Toninho, Rogério, Ana Lúcia, Ricardo Rome ro e Thiago, cujo convívio e ajuda foram importantes durante o Curso;

À Eliana Garcia, pela amizade e eficiência;

$\mathcal{A} M a^{2}$ e lo e $\mathcal{T}$ elma, pela re taguarda, cuidando de nossas coisas na Bafia;

À Mais a S ales, nossa guardiã na $\mathcal{U F B \mathcal { F }}$

$\mathcal{A}$ Fernando Novello, Vladimir, Luciano, Chiquinho, Flávia Morales e Lurdes Gandra, funcionários da $\mathcal{E S} \mathcal{A} L Q$, sempre disponíve is e solícitos;

$\mathcal{A}$ todos aqueles que contribuíram em algum momento e lugar para que este trabalho se tornasse uma realidade concre ta. 


\section{SUMÁRIO}

RESUMO .................................................................... ix

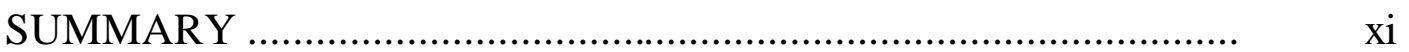

1 INTRODUÇÃ

2 REVISÃO DE LITERATURA ........................................... 3

2.1 Movimento da á gua no solo ........................................... 3

2.2 Variabilidade espacial do solo .......................................... 15

3 MATERIAL E MÉTODOS .................................................. 40

3.1 Localização da área experimental ........................................ 40

3.2 Características do solo ...................................................... 40

3.3 Parcela experimental ....................................................... 41

3.4 Ensaio de perfil instantâneo ................................................. 45

3.5 Calibração TDR ........................................................... 48

3.6 Análise computacional .................................................. 48

3.7 Análise estatística dos resultados ...................................... 51

4 RESULTADOS E DISCUSSÃO .......................................... 55

4.1 Estatística descritiva e análise exploratória dos dados................ 55

4.1.1 Umidade do solo ................................................................ $\quad 56$

4.1.2 Potencial mátrico ........................................................... 66

4.1.3 Coeficiente angular $(\beta)$ da relação $\ln K=\beta \theta+\ln K_{\theta=0} \ldots \ldots \ldots \ldots \ldots . \quad 80$ 
4.1.4 Coeficiente linear $\left(\ln \mathrm{K}_{\mathrm{o}}\right)$ da relação $\ln \mathrm{K}=\beta \theta+\ln \mathrm{K}_{\theta=0} \ldots \ldots \ldots \ldots . .90$

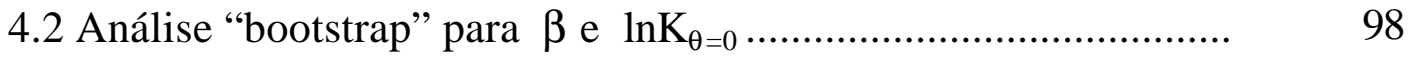

4.3 Análise da estabilidade temporal para umidade e potencial mátrico ...................................................................... 104

5 CONCLUSÕES ............................................................. 117

REFERÊNCIAS BIBLIOGRÁFICAS ..................................... 119

APÊNDICES ................................................................ 141 


\section{CURRICULUM VITAE}

Iosé Fernandes de Melo Filho, nascido em 11 de março de 1961, na cidade de Cruz das Almas, Estado da Bahia, Engentieiro Agrônomo pela Escola de Agronomia da Universidade Federal da Bafia em 1983, Mestre em Solos e Nutrição de Plantas pela Universidade Federal do Ceará em 1991, pesquisador da Empresa Baiana de Desenvolvimento Agrícola até 1996.

Professor da Disciplina Manejo e Conservação de Solo e Água no Departamento de Química Agrícola e Solos da Escola de Agronomia da Universidade Federal da Bafia, localizada em Cruz das Almas - BA. 


\title{
VARIABILIDADE DOS PARÂMETROS DA EQUAÇÃO DA CONDUTIVIDADE HIDRÁULICA EM FUNÇÃO DA UMIDADE DE UM LATOSSOLO SOB CONDIÇÕES DE CAMPO
}

\author{
Autor: JOSÉ FERNANDES DE MELO FILHO \\ Orientador: Prof. Dr. PAULO LEONEL LIBARDI
}

\section{RESUMO}

O presente trabalho foi realizado com o objetivo de quantificar e caracterizar a variabilidade espacial dos parâmetros equação $K=K_{\theta=0} \exp (\beta \theta)$, determinada pelo método do perfil instantâneo. Nessa equação, $K_{\theta=0}$ é $o$ coeficiente linear da reta $\operatorname{lnK}$ versus $\theta$ ou a condutividade hidráulica $(\mathrm{K})$ para $\mathrm{o}$ teor de água no solo $(\theta)$ igual a zero e $\beta$ o coeficiente angular. $O$ experimento foi realizado no campus da "Escola Superior de Agricultura Luiz de Queiroz" ESALQ/USP, localizado no município de Piracicaba (SP), em um Latossolo Vermelho Amarelo, álico, A moderado, textura média, (Typic Hapludox), moderadamente a bem drenado. A parcela experimental tinha um comprimento de $70 \mathrm{~m}$ e uma largura de $20 \mathrm{~m}$; na sua linha central ao longo do comprimento foram considerados 50 pontos de observação, distanciados de $1 \mathrm{~m}$ entre si e, em cada um deles, instalados 5 tensiômetros eqüidistantes com suas cápsulas porosas localizadas às profundidades de 0,$15 ; 0,30 ; 0,45 ; 0,60 ; 0,75 \mathrm{~m}$. No ponto central de cada circunferência de $0,10 \mathrm{~m}$ de raio, na qual foram equidistantemente instalados 5 tensiômetros, foi instalada uma sonda de TDR para medida da 
umidade nas mesmas cinco profundidades em cada ponto de observação. As medições de umidade e potencial mátrico foram feitas durante 62 dias ou 1.370 horas, escolhendo se para este estudo o período compreendido entre os tempos de redistribuição 78 a 604 horas. Os resultados de umidade no solo $\boldsymbol{\theta})$, potencial mátrico $\left(\phi_{\mathrm{m}}\right), \operatorname{lnK}_{\theta=0}$ e $\beta$, foram submetidos à análise estatística exploratória e descritiva para verificação da distribuição e identificação de valores extremos. Também se calculou o número mínimo de subamostras necessárias para estimar o valor médio representativo dos parâmetros avaliados, para um nível de probabilidade de 95\%, nos valores de 5, 10, 20 e 30\% de coeficiente de variação em torno da média. Para os parâmetros $\ln _{\theta=0}$ e $\beta$ a análise do número de amostras foi também feita pela técnica "bootstrap". Análise da estabilidade temporal foi realizada com os dados de umidade no solo e potencial mátrico. Os resultados indicaram que o padrão de variabilidade dos parâmetros hídricos estudados $\left(\theta, \phi_{\mathrm{m}}, \beta\right.$ e $\left.\ln K_{\theta=0}\right)$ aumentou em profundidade, sendo os maiores coeficientes de variação aqueles apresentados pelo $\beta$. A variabilidade da umidade $(\theta)$ foi baixa e aumentou com o tempo de redistribuição, enquanto que o potencial mátrico $\left(\phi_{\mathrm{m}}\right)$, apresentou comportamento oposto, qual seja, variabilidade alta no início da redistribuição diminuindo para média no final da avaliação. Não houve relação entre os parâmetros quanto ao número de amostras necessárias para estimar a média, indicando que a utilização dos métodos para determinação de número de amostras pode gerar valores bem diferentes e que sua aplicação deve ser feita com prudência. Tanto a umidade do solo quanto o potencial mátrico apresentaram estabilidade temporal, o que permitiu identificar quais os locais mais indicados para a realização de amostragens com reduzido esforço e grande precisão. 


\title{
VARIABILITY OF THE PARAMETERS OF THE HYDRAULIC CONDUCTIVITY AS A FUNCTION OF SOIL-WATER CONTENT EQUATION FOR A FIELD LATOSOL
}

\author{
Author: JOSÉ FERNANDES DE MELO FILHO \\ Adviser: Prof. Dr. PAULO LEONEL LIBARDI
}

\section{SUMMARY}

This work was carried out with the objective of quantifying and characterizing the spatial variability of the $K=K_{\theta=0} \exp (\beta \theta)$ equation parameters, determined by means of instantaneous profile method. In this equation, $\beta$ is the slope and $K_{\theta=0}$ the intercept of the linear regression of $\operatorname{lnK}$ versus $\theta$. The experiment site is located at the Campus "Luiz de Queiroz", University of São Paulo, county of Piracicaba (SP), Brasil (22 42'30" S e $47^{\circ} 38^{\prime} 00^{\prime}$ ' W) in a Typic Hapludox. The experimental plot dimensions were: length $=70 \mathrm{~m}$ and width $=20 \mathrm{~m}$. In the central line of the length, 50 observation points $1 \mathrm{~m}$ among themselves were considered each one with i) 5 mercury manometer tensiometers equally spaced in a $0.10 \mathrm{~m}$ radius circumference with their porous cups installed at $0.15,0.30,0.45,0.60$ and $0.75 \mathrm{~m}$ soil depths and ii) one TDR probe in the central point of the above circumference to measure soil-water content at the same five soil depths. Measurements of soil-water content and matric potential were made during 62 days of soil water redistribution, but the study was carried 
out using the redistribution time range from 78 to 604 hours. Results of soil-water content $(\theta)$, matric potential $\left(\phi_{\mathrm{m}}\right), \ln K_{\theta=0}$ and $\beta$ were analyzed by the exploratory and descriptive statistics in order to verify the data distribution and to identify outliers values. The minimum number of samples necessary to estimate the mean value of the assessed parameters was also calculated at a probability level of 5\%, for variation coefficient values of 5,10, 20 and $30 \%$. For the parameters $\ln K_{\theta=0}$ and $\beta$, the analysis of number of samples was also made by using the "bootstrap" technique. Time stability analysis was used for soil-water content and matric potential data. The results have indicated that the variability of the studied hydric parameters $\left(\theta, \phi_{\mathrm{m}}, \beta\right.$ and $\left.\ln \mathrm{K}_{\theta=0}\right)$ increased with soil depth, being the higher variation coefficients those of the parameters $\beta$. The soil water-content $(\theta)$ variability was low and increased with the soil water redistribution time, whereas the matric potential had an inverse behavior, that is, high variability at the beginning of the soil water redistribution, decreasing to a medium one at the end of evaluation. There was no relation among parameters in terms of number of samples needed to estimate the mean, indicating that the use of methods to determine the number of samples can led to values very differents; hence the appliance of these methods should be done with caution. Both soil-water content and matric potential presented time stability, which permitted to identify the best points for future samplings with less effort and high precision. 


\section{INTRODUÇÃO}

No contexto das Ciências Agronômicas e Ambientais, a função condutividade hidráulica $K(\theta)$, isto é a condutividade hidráulica de um solo em função da umidade desse solo, tem especial importância para os estudos e solução de problemas práticos relacionados, entre outros, com a irrigação, a drenagem e a lixiviação de nutrientes e de poluentes. Conseqüientemente, para o eficiente uso e manejo do solo e da água, para grandes áreas, tornam-se necessários o conhecimento e a análise, no tempo e no espaço, das propriedades do solo que quantifiquem a condução de água ao longo do perfil.

O solo é um material poroso, cuja heterogeneidade determina uma grande sensibilidade entre a condutividade hidráulica $(\mathrm{K})$ e a umidade $(\theta)$ resultando, normalmente, em uma função $K=K_{o} \exp \left[\beta\left(\theta-\theta_{0}\right)\right]$ para valores não muito baixos de $\theta$, cujos parâmetros, $\theta_{\mathrm{o}}$ (valor máximo de umidade), $\mathrm{K}_{\mathrm{o}}$ (valor máximo de condutividade) e $\beta$, apresentam-se com elevado grau de variabilidade.

O método do perfil instantâneo é o mais utilizado para determinar a função $K(\theta)$ no campo. A vantagem do método está no fato de ele basear-se em medições diretas no campo. A desvantagem está no alto investimento de tempo e mão-de-obra. Por essa razão existem poucos resultados experimentais para determinações da função $K(\theta)$ pelo método de perfil instantâneo com grande número de repetições. A realização de um experimento desta natureza, com um 
grande número de repetições, torna-se, entretanto, fundamental para esclarecer a natureza e a magnitude da variabilidade dos fatores que influenciam a função $\mathrm{K}(\theta)$.

O trabalho que se apresenta foi desenvolvido, exatamente com o intuito de avaliar a variabilidade de um grande número de medidas da função $\mathrm{k}(\theta)$, pelo método do perfil instantâneo, por meio da variabilidade dos parâmetros da equação representativa desta função e relacionar o comportamento dessa variabilidade, como número de medidas realizadas. Além disso, tendo em vista a variabilidade temporal das medidas de umidade $(\theta)$ e potencial mátrico $\left(\phi_{\mathrm{m}}\right)$, exigidas pelo método do perfil instantâneo, fez-se também um estudo da estabilidade temporal de $\theta$ e $\phi_{\mathrm{m}}$, também com o intuito de avaliar a redução do número de medidas da função $K(\theta)$. 


\section{REVISÃO DE LITERATURA}

\subsection{Movimento da água no solo}

O movimento de água no perfil do solo é um importante componente no estudo de problemas relacionados à agricultura e ao ambiente. Para tanto é indispensável uma adequada caracterização das propriedades hídricas do solo, dentre as quais pode-se citar a condutividade hidráulica.

A condutividade hidráulica do solo foi definida, empiricamente, por Henry Darcy em 1856, identificando-a como a constante de proporcionalidade, K, que aparecia nas relações matemáticas resultantes de seus experimentos de infiltração vertical em colunas de areia, completamente saturadas, para a filtragem e purificação de água para abastecimento urbano da cidade de Dijon na França. Atualmente é um dos principais parâmetros utilizados para estudos agrícolas e ambientais que envolvem o fluxo de água no solo, tais como, planejamento de sistemas de irrigação e drenagem, rebaixamento de lençol freático, movimento de água no interior do perfil do solo, nutrição de plantas, controle de erosão e poluição da água (Jones \& Wagenet, 1984; Freeze, 1994; Filizola et al., 1997; Queiroz et al., 1997; Jong van Lier \& Libardi, 1999; Libardi, 2000; Radcliffe \& Rasmussen, 2000). 
Libardi (2000) faz uma análise pormenorizada da equação de Darcy. Considerando a notação vetorial no sistema cartesiano, ela pode ser escrita como:

$$
\vec{q}=-K \vec{\nabla} \phi_{t}
$$

em que $\vec{q}$ é o vetor densidade de fluxo para qualquer direção no espaço e $\vec{\nabla} \phi_{t}$ o vetor resultante dos componentes cartesianos triortogonais do vetor $\overrightarrow{g r a d} \phi_{t}$ de mesma direção que o vetor $\vec{q}$.

Em conseqüência das condições experimentais de seu trabalho, a equação de Darcy foi desenvolvida e aplica-se para quantificar o movimento de um líquido em condições de saturação, no entanto, a condição mais comum no meio poroso de nosso interesse, o solo, é a não saturação. Atento a esta realidade Buckingham (1907) tentou e conseguiu quantificar o movimento da solução no solo não saturado. De acordo com Libardi (2000), a equação, também atualizada, proposta por Buckingham tem a seguinte forma:

$$
\vec{q}=-K(\boldsymbol{\theta}) \vec{\nabla} \phi_{m}(\theta)
$$

sendo $\vec{q}$ a densidade de fluxo da solução; $\mathrm{K}(\theta)$ a função condutividade hidráulica; $\phi_{\mathrm{m}}(\theta)$ a função potencial mátrico e $\theta$ a umidade volumétrica do solo. 
A equação de Buckingham (1907) apresenta a limitação de ser válida apenas para o movimento da solução no solo na direção horizontal, então Richards (1928) definiu um potencial total, $\phi_{t}$, como resultante da soma do "potencial capilar" de Buckingham e o potencial gravitacional $\phi_{z}$, reescrevendo a equação do movimento da solução no solo como:

$$
\vec{q}=-K(\boldsymbol{\theta}) \vec{\nabla} \phi_{t}
$$

a qual é denominada atualmente de equação de Darcy-Buckingham.

A função condutividade hidráulica do solo, $\mathrm{K}(\theta)$, é, conforme Libardi (2000), com base na eq. (3), numericamente, igual ao volume de água ou solução que atravessa, numa unidade de tempo, uma unidade de área de uma amostra de uma unidade de comprimento de um meio poroso (solo) sob uma diferença unitária de potencial total. Em termos práticos, a constante $\mathrm{K}$ é um índice que expressa a facilidade com que o solo transporta a água através dos seus poros.

Quando se substitui a equação de Darcy-Buckingham (3) na equação da continuidade (4)

$$
\frac{\partial \theta}{\partial t}=-\vec{\nabla} \cdot \vec{q}
$$


gera-se um novo modelo matemático que é a equação diferencial geral que rege o movimento da solução em solos isotrópicos com relação a $K(\theta)$ e conhecida pelo nome de equação de Richards, cuja expressão para o fluxo na direção vertical (Libardi, 2000) é:

$$
\frac{\partial \theta}{\partial t}=\frac{\partial}{\partial z}\left(K(\boldsymbol{\theta}) \frac{\partial \phi_{t}}{\partial z}\right)
$$

sendo $\theta$ a umidade $\left(\mathrm{m}^{3} \mathrm{~m}^{-3}\right), \mathrm{t}$ o tempo (horas) e $\mathrm{z}$ a coordenada vertical de posição (metros).

A determinação da condutividade hidráulica do solo pode ser feita por métodos de laboratório e de campo. No laboratório é possível atingir um grau de precisão e refinamento muito superior ao campo, devido ao elevado grau de controle das condições experimentais. Por outro lado, nas condições de campo, não obstante o grau de complexidade, as medidas são feitas em condições naturais e com perturbação mínima do solo. Existem também os métodos indiretos que tentam quantificar a condutividade hidráulica a partir de outras propriedades do meio poroso cuja determinação seja mais fácil.

De forma geral pode-se citar os seguintes métodos para determinação da condutividade hidráulica dos solos: Permeâmetro de carga constante; permeâmetro de carga decrescente; método das colunas grandes; método das colunas pequenas; método das condições transientes; infiltrômetro de tensão; método do furo do trado e método do perfil instantâneo. A escolha do método depende de alguns fatores como disponibilidade de equipamentos, 
natureza do solo, tipo de amostra disponível, experiência e conhecimento do pesquisador, faixa de tensão a ser estudada e objetivo das determinações (Richards \& Weeks, 1953; Gardner, 1956; Ogata \& Richards, 1957; Gardner \& Miklich, 1962, Childs, 1969; Hillel et al., 1972; Klute, 1972; Reichardt et al., 1975; Libardi et al., 1980; Van Genuchten, 1980; Jones \& Wagenet, 1984; Amoozegar \& Warrick, 1986; Green et al., 1986; Klute \& Dirksen, 1986; Shouse et al., 1992; Prevedello, 1996; Radcliffe \& Rasmussen, 2000; Libardi, 2000).

Dentre os métodos de campo o mais utilizado é o método do perfil instantâneo. É um método que foi inicialmente desenvolvido e testado para condições de laboratório em estudos de drenagem em colunas homogêneas de solo. Posteriormente foi aperfeiçoado por contribuições de vários autores, sendo também aplicável para determinar a condutividade hidráulica de solos não saturados in situ, mesmo para perfis heterogêneos, desde que o lençol freático seja ausente ou esteja bem profundo. É um método prático que não necessita de equipamentos sofisticados para sua aplicação, que tem como principal limitação o fato de não ser útil para áreas nas quais o movimento lateral de água seja significativo.

Richards e Weeks (1953) foram, provavelmente, os primeiros pesquisadores a utilizarem a técnica do perfil instantâneo em experimentos de laboratório com utilização de colunas de solo e Richards et al. (1956) em condições de campo. Um novo aperfeiçoamento ao método, qual seja a eliminação do fluxo na superfície do solo com a colocação de uma lona plástica, foi determinado por Ogata e Richards (1957), enquanto que Watson (1966) melhorou a técnica para obtenção dos dados tornando o método mais preciso.

Para aplicação do método do perfil instantâneo, uma parcela de campo deve ser delimitada e inundada até a saturação. Dentro desta área, 
suficientemente grande para que os processos em seu centro não sejam afetados pelos seus limites, um tubo de acesso para medida da umidade do solo com sonda de nêutrons e uma série de tensiômetros para medida do potencial mátrico a diversas profundidades, são instalados. Atingida a condição de saturação interrompe-se a infiltração e cobre-se a superfície do solo com uma lona plástica para evitar a evaporação e a entrada de água através da superfície. Também assume-se que as condições internas sejam isotérmicas durante o processo. A água contida no perfil redistribui-se pelo processo de drenagem interna e à medida que este ocorre, medidas periódicas de umidade e de potencial mátrico são feitas (Green et al., 1986; Libardi, 2000).

Com este procedimento experimental, procura-se uma solução para a equação de Richards (1928) na direção vertical (eq. 5), isto é, integrando-se a equação de Richards (1928) com relação à profundidade $Z$, entre os limites $Z=0$ e $\mathrm{Z}=\mathrm{Z}$ com as seguintes condições de contorno:

$$
\begin{aligned}
& Z=0 ; \mathrm{t} \geq 0 ; \mathrm{q}=0 \\
& Z=\mathrm{Z} ; \mathrm{t}>0 ; \mathrm{q}=\mathrm{q}_{\mathrm{Z}}
\end{aligned}
$$

obtém-se:

$$
-\int_{0}^{Z} \frac{\partial \boldsymbol{\theta}}{\partial t} d Z=\left.K(\boldsymbol{\theta}) \frac{\partial \phi_{t}}{\partial z}\right|_{Z}=q_{Z}
$$

ou, rearranjando 


$$
\left.K(\boldsymbol{\theta})\right|_{Z}=\frac{-\int_{0}^{Z} \frac{\partial \theta}{\partial t} d Z}{\left.\frac{\partial \phi_{t}}{\partial z}\right|_{Z}}=\left.\frac{-\frac{\partial h_{Z}}{\partial t}}{\frac{\partial \phi_{t}}{\partial z}}\right|_{Z}
$$

sendo $\mathrm{h}_{\mathrm{z}}\left(\mathrm{m}^{3} \mathrm{~m}^{-2}\right)$ a armazenagem de água no solo entre a superfície $(Z=0)$ e a profundidade Z. Por meio de medidas simultâneas de umidade e de potencial total ao longo do perfil de solo durante a redistribuição da água, determina-se a variação de armazenagem $\mathrm{h}_{\mathrm{Z}}$ com o tempo t e o gradiente de $\phi_{\mathrm{t}}$ ao longo de $\mathrm{Z}$ que aparecem na eq. (7) e, então, o valor de $K(\theta)$.

Para a medida da umidade, com o tempo, ao longo do perfil é recomendável a utilização de equipamentos não destrutivos, como por exemplo, a sonda de nêutrons (Greacen, 1981) e o TDR (Smith \& Mullins, 1991). Igualmente o mesmo deve ser considerado para determinação do potencial total, soma dos potenciais mátrico e gravitacional. Nesse sentido, o tensiômetro é um equipamento consagrado de medida da tensão ou potencial mátrico da água no solo, sob condições de campo (Or \& Wraith, 2000) e, muito embora tentativas tenham sido feitas para automatizá-lo, o tipo tradicional com manômetro de mercúrio ainda é o mais adequado e utilizado para estudos da função $K(\theta)$.

Normalmente, os valores de $\mathrm{K}(\boldsymbol{\theta})$ apresentam uma relação exponencial com a umidade (Hillel et al., 1972; Libardi, 2000), de maneira que a função $K(\theta)$ pode ser expressa pela eq. (13), cuja dedução pode ser feita a partir da regressão $\ln K$ vs $\theta$ : 


$$
\begin{gathered}
\ln K=K_{\theta=0}+\beta \theta \\
\ln K_{o}=K_{\theta=0}+\beta \theta_{o}
\end{gathered}
$$

Subtraindo a eq. (9) da eq. (8) tem-se:

$$
\ln K-\ln K_{o}=\boldsymbol{\beta} \boldsymbol{\theta}-\boldsymbol{\beta} \boldsymbol{\theta}_{o}
$$

ou

$$
\ln \left(\frac{K}{K_{O}}\right)=\beta\left(\theta-\theta_{O}\right)
$$

com

$$
\frac{K}{K_{O}}=e^{\beta\left(\theta-\theta_{0}\right)}
$$

e, portanto, resultando em: 


$$
K=K_{o} e^{\beta\left(\theta-\theta_{o}\right)}
$$

sendo $\beta$ o coeficiente angular da reta $\operatorname{lnK}$ versus $\theta$ e $\mathrm{K}_{\mathrm{o}}$ a condutividade hidráulica para o tempo zero de redistribuição da água.

Hillel et al. (1972) simplificaram bastante esta metodologia. Estes autores sugerem um roteiro simples para a determinação da função $K(\theta)$ com base na elaboração de duas tabelas. A primeira para determinação da densidade de fluxo de água no solo nas diversas profundidades e para diversos tempos a partir da integral da eq. (7) com relação a profundidade do solo, aproximada para um somatório e $\partial \theta / \partial t$ medida graficamente em pontos particulares no tempo em curvas de $\theta \times \mathrm{t}$. A segunda tabela, para cálculo da condutividade hidráulica em cada profundidade e para diferentes umidades, dividindo-se os fluxos q da primeira tabela pelos gradientes de potencial também obtidos graficamente a partir dos perfis de potencial total para os diversos tempos (Libardi, 2000).

Uma alternativa na técnica do perfil instantâneo é a de se considerar o gradiente de potencial hidráulico como unitário. Com esta proposição Libardi et al. (1980) simplificaram mais ainda o procedimento para se determinar à função $\mathrm{K}(\theta)$ a partir de medidas de umidade apenas durante o processo de redistribuição.

As medidas da umidade do solo são feitas de várias formas. Dentre as técnicas mais utilizadas para este fim estão o método termogravimétrico, tido como o padrão, a tensiometria, a técnica da atenuação de raios gamas e o método da atenuação de nêutrons. No entanto, novas técnicas, alternativas, foram e estão sendo desenvolvidas. Neste caso citamse as técnicas de tomografia computadorizada, ressonância magnética, indução eletromagnética, capacitância 
elétrica e time domain reflectrometry (TDR) (Smith \& Mullins, 1991; Hanks, 1992; Tommasselli \& Bacchi, 1996; Gee \& Ward, 1999).

A técnica do TDR foi inicialmente desenvolvida para outros usos, porém logo utilizada para estudos e investigações em pedologia, inclusive com aplicações para o desenvolvimento de métodos para determinação da condutividade hidráulica do solo (Hudson et al., 1996). Devido à facilidade para obtenção de medidas não destrutivas e sem riscos para o homem e o ambiente, o TDR tem sido bastante utilizado para quantificar a umidade do solo. Como desvantagens, pode-se citar o seu alto custo, a complexa calibração e a existência de alguns erros inerentes à própria técnica (Hook \& Livingston, 1995; Hook \& Livingston, 1996; Frueh \& Hopmans, 1997; Tommaselli, 1997).

O princípio de funcionamento do método está baseado na velocidade de propagação de uma onda eletromagnética de alta freqüência $(>50$ $\mathrm{MHz}$ ) ao longo de hastes de metal, paralelas, introduzidas no solo. O intervalo de tempo entre a entrada da onda no solo e a reflexão do sinal depois de alcançada o final das hastes, possibilita a determinação da umidade (Baker \& Lascano, 1989; Dalton, 1992).

A velocidade de propagação do pulso eletromagnético no meio é função de uma constante $(\varepsilon)$, denominada constante dielétrica. Assim, o método do TDR depende da determinação do valor do $\varepsilon$ para o solo. Esta determinação é feita com referência a propagação de um pulso no ar. Para a água a constante dielétrica é estimada em 80. Para a maioria dos materiais de solo está entre 2 a 5 , sendo, neste caso, muito afetada pelo seu conteúdo de água e pelos componentes da matriz do solo (Smith \& Mullins, 1991; Hanks, 1992). A diferença significativa entre a constante dielétrica da água e a constante dielétrica dos componentes da matriz do solo permite calcular o conteúdo de água no solo. 
Topp et al. (1980) foram os primeiros pesquisadores que aplicaram o princípio do TDR para determinar o conteúdo de água no solo. Em seu trabalho, os autores mediram o tempo de trânsito do pulso eletromagnético em um cabo coaxial de comprimento conhecido e correlacionaram o valor da constante dielétrica, $\varepsilon$, do solo com o seu conteúdo de água, $\theta$. Desde então a técnica passou por diversos aperfeiçoamentos e melhorias que resultaram em sensível aumento tanto da precisão quanto das possibilidades de aplicação (Tommaselli, 1997; Or $\&$ Wraith, 2000).

A velocidade de propagação $\mathrm{v}$, de um pulso eletromagnético ao longo de uma linha de transmissão em um meio como o solo é igual a:

$$
v=\frac{c}{\sqrt{\varepsilon}}
$$

em que c é a velocidade da luz no vácuo $\left(3 \times 10^{8} \mathrm{~m} \mathrm{~s}^{-1}\right)$ e $\varepsilon$ é a constante dielétrica do meio. Embora a velocidade de propagação do pulso não seja diretamente medida é possível deduzi-la, em função do comprimento $L$ da haste ao longo da qual ela se propaga, pela da equação:

$$
v=\frac{2 L}{t}
$$


sendo que o tempo t de propagação corresponde ao intervalo entre a entrada do pulso no solo e o seu retorno após atingir o final da haste (Dalton, 1992; Kutilek $\&$ Nielsen, 1994). Substituindo a eq. (15) na eq. (14) tem-se:

$$
\varepsilon=\left(\frac{c t}{2 L}\right)^{2}
$$

Desta forma, conhecendo-se o tempo $t$ de propagação do pulso, pode-se facilmente calcular o valor da constante dielétrica $\varepsilon$. Considerando que a constante dielétrica é uma característica altamente correlacionada com o teor de água torna-se possível estabelecer uma relação entre ambas de forma que se possa a partir de uma determinar-se a outra.

A principal proposição para estabelecer a relação $\varepsilon$ vs $\theta$ e calcular o conteúdo de água no solo foi feita por Topp et al. (1980). Estes autores sugerem a seguinte equação empírica de terceiro grau aplicável para solos minerais:

$$
\theta_{v}=-5,3 \times 10^{-2}+2,92 \times 10^{-2} \varepsilon-5,5 \times 10^{-4} \varepsilon^{2}+4,3 \times 10^{-6} \varepsilon^{3}
$$

$\mathrm{Na}$ equação original, sugerida pelos autores, $\varepsilon$ aparece como Ka, "constante dielétrica aparente" que, para materiais homogêneos, é igual à constante dielétrica real. 
No entanto, outros autores encontraram limitações para a aplicação da eq. (17) e sugerem modelos, também empíricos, que levam em consideração as influências de diversos fatores do solo (textura, matéria orgânica, conteúdo de elementos metálicos) na constante dielétrica, $\varepsilon$, sugerindo um modelo misto ou calibrações específicas para cada condição e tipo de solo (Tommaselli \& Bacchi, 1995; Silva \& Gervásio, 1999; Or \& Wraith, 2000).

Considerando que o tempo de trânsito do pulso eletromagnético é muito pequeno, da ordem de $10^{-9}$ segundos, a técnica de quantificação necessita ser sofisticada e precisa, exigindo, portanto, equipamento eletrônico complexo e conseqüentemente caro. Gee \& Ward (1999) relatam que o desenvolvimento de sondas em forma de lança, tipo MP 917, iguais as que foram utilizadas neste trabalho, com diodos ligados em série, permitiu grandes avanços na determinação da variação temporal da umidade do solo, ampliando, sobremodo, as possibilidades de uso do TDR em estudos sobre dinâmica da água no solo.

\subsection{Variabilidade espacial do solo}

O solo é um corpo natural e complexo, resultante da interação dos seus fatores de formação (material de origem, clima, organismos, relevo e tempo) que o torna um sistema dinâmico e variável, fundamental para a sustentação das diversas formas de vida do planeta. Os processos de formação determinam, portanto, as características químicas, físicas e biológicas do solo, conferindo-lhe variabilidade espacial elevada. Esta heterogeneidade natural, reconhecida desde o início do século vinte, é também acentuada pelas técnicas de manejo do solo decorrentes de seu uso agrícola (Alvarenga \& Sousa, 1995; Souza, 1992; Mata, 
1997; Souza et al., 1997a; Alvarenga \& Davide, 1999; Borges et al., 1999; Oliveira et al., 1999).

Dentre as propriedades do solo, seguramente, a condutividade hidráulica está entre aquelas que apresentam maior índice de variabilidade. $\mathrm{Na}$ medida em que ocorre no espaço livre do solo, a condutividade hidráulica é influenciada por todas as propriedades que afetam a distribuição, o tamanho e a forma dos poros. Assim, propriedades do solo como a textura, a estrutura, a densidade, qualidade das argilas e a matéria orgânica exercem influência sobre a sua condutividade hidráulica. Outro fator importante que afeta a condutividade hidráulica é a umidade do solo $\theta)$, estando implícito nesta relação que $K(\theta)$ é função direta de $\theta$ e apresenta, na condição do solo saturado, a forma exponencial da eq. (13) (Buckingham, 1907; Gardner, 1958; Hillel et al., 1972; Libardi et al., 1980; Reichardt, 1996; Libardi, 2000).

De acordo com Falleiros et al. (1998) a relação entre K e $\theta$ é tão sensível que alterações muito pequenas, da ordem de 1 a $2 \%$, nos teores de água podem gerar coeficientes de variação superiores a $170 \%$ no valor da condutividade hidráulica do solo não saturado.

Bouma et al. (1989) sugerem efeitos do processo de gênese na heterogeneidade e conseqüente variabilidade dos parâmetros hídricos do solo. Para estes autores, o processo de desenvolvimento do perfil influencia no padrão de porosidade, afetando a condutividade hidráulica do solo saturado. Baseando-se no exame de amostras micromorfológicas, eles concluíram que o desenvolvimento de microestrutura massiva resulta em baixos valores de $\mathrm{K}_{0}$, ao passo que quando o processo resulta em poros de grãos simples e fissurais ocorre exatamente o contrário. 
Outros fatores como sistemas de uso, manejo e erosão, que interferem nas propriedades físicas do solo, também afetam as suas propriedades hídricas e, conseqüentemente, a condutividade hidráulica. Nestes casos, geralmente ocorre um aumento na densidade do solo e redução da porosidade total, da infiltração e da condutividade hidráulica em relação à condição natural (Vieira \& Muzilli, 1984; Centurion \& Demattê, 1985; Corrêa, 1985; Silva et al., 1986; Comegna et al., 2000).

Utilizando amostras compactadas artificialmente, Silva et al. (1986) verificaram a influência do aumento da densidade nas propriedades físicas de dois Latossolos. Em ambos os casos verificaram que a compactação alterou a porosidade e a condutividade hidráulica do solo saturado. Quanto ao tamanho dos poros, observaram que o aumento da densidade elevou a percentagem de microporos com conseqüente redução dos macroporos. Quanto à condutividade hidráulica observaram uma acentuada queda nos valores, certamente relacionada com a diminuição do espaço poroso que foi constatada.

Carvalho et al. (1995) determinaram a condutividade hidráulica de um Latossolo Roxo distrófico (Latosssolo Vermelho (EMBRAPA (1999)) pelo método do perfil instantâneo. Eles concluíram que a função $K=K(\theta)$ possui uma clara tendência de aumentar com a profundidade em consequiência do efeito do preparo periódico. De outra forma, Dechen \& Vieira (1997) apresentam resultados diferentes das conclusões de Carvalho et al. (1995), quando analisam o impacto de erosão induzida, pela remoção da camada superficial, em atributos físicos e químicos do solo. Neste caso, eles concluíram que há um decréscimo significativo na condutividade hidráulica do solo saturado com a profundidade e atribuem este fato à estratificação dos horizontes, diminuição do teor de matéria orgânica e alterações da estrutura do solo. 
Silva (1988), estudando a variabilidade espacial de alguns atributos físicos de um Latossolo Roxo, concluiu, tendo como base teórica a estatística clássica, que propriedades do solo como areia, argila, densidade do solo e porosidade, apresentaram pequeno coeficiente de variação. Porém, o autor faz uma importante consideração quando afirma que para os parâmetros físicos do solo influenciados pelas alterações na estrutura a sensibilidade é muito grande. Desta forma, pequenas alterações em propriedades como a densidade do solo, podem acarretar grandes modificações em parâmetros que dela dependam, tipo distribuição de poros, retenção e movimentação de água, aqui entendida como condutividade hidráulica.

Flühler et al. (1976) incluem como fatores de variação da condutividade hidráulica do solo não saturado, os erros decorrentes e associados aos métodos experimentais (erros de leitura, experimentais, sistemáticos, calibração e equipamentos). Estudando a propagação desses erros na determinação da condutividade hidráulica pelo método do perfil instantâneo, estes autores informam que na faixa úmida os mesmos são responsáveis por 20 a 30\% da variação dos valores de K. Informam também que os erros originados da leitura dos tensiômetros são mais importantes que outros e ocorrem no início do processo de drenagem, quando o gradiente hidráulico é menor que $0,3 \mathrm{mbar} \mathrm{cm}^{-1}$, enquanto que os erros de medida da umidade são dominantes durante o processo de secagem do solo, quando a drenagem é muito lenta.

De forma semelhante Maheshwari (1997) constatou diferenças entre valores de $\mathrm{K}_{\mathrm{o}}$ em estudo de comparação das inter-relações entre parâmetros físicos e hidráulicos do solo. Seus resultados mostram que as determinações de laboratório podem superestimar os valores de $\mathrm{K}_{\mathrm{o}}$, introduzindo erros, em relação a medidas de campo, devido a alterações nas amostras e ocorrência de fluxo 
preferencial durante o processo de medida. O autor sugere, então, que medidas de laboratório não podem ser usadas como estimativa de valores de campo para o parâmetro condutividade hidráulica do solo saturado, $\mathrm{K}_{\mathrm{o}}$.

Banton (1993) comparou valores de $\mathrm{K}_{\mathrm{o}}$, determinados por métodos de laboratório e campo, examinando seus efeitos na estimativa da média, da variância e na distribuição deste parâmetro hídrico para um mesmo solo. Neste caso, as características estatísticas diferiram significativamente e não houve correlação entre os resultados de campo e laboratório, cuja magnitude de variação foi dez vezes maior do que no método de campo.

Prevedello et al. (1994), analisaram a magnitude dos erros envolvidos no cálculo da condutividade hidráulica em função da umidade, quando se adota o uso de simplificações metodológicas como o gradiente de potencial hidráulico unitário. Neste caso, observou-se que os erros na condutividade hidráulica são crescentes com a diminuição da umidade e podem subestimá-la em valores compreendidos entre 12 até $73 \%$. Porém, de acordo com Libardi (1978), tendo em vista o fenômeno da variabilidade espacial, o uso de simplific ações para o cálculo da função $K(\theta)$, sob condições de campo, pode ser vantajoso, pois permite a substituição de métodos mais precisos por outros mais simples e que possibilitem a obtenção de um maior número de medidas.

Russo \& Bresler (1981) sugerem uma relação entre a condutividade hidráulica e o potencial total. Neste caso o coeficiente de variação da condutividade hidráulica do solo não saturado aumenta quando o valor do potencial total diminui.

Importante registrar também, que o método de determinação pode ser fator de variação da condutividade hidráulica para um mesmo solo, podendo 
tanto subestimar quanto superestimar os valores da função $\mathrm{K}(\theta)$ (Bacchi \& Reichardt, 1988; Comegna et al., 1996) mesmo quando a variabilidade é simplificada em função da aplicação de técnicas e conceitos como o "scaling" (Mallants et al. 1997).

Neste sentido Reynolds \& Zebchuk (1996) realizaram um experimento com os objetivos de: a) comparar um grande número de medidas de condutividade hidráulica calculada pelos métodos do permeâmetro de Guelph e furo de trado; b) caracterizar a distribuição das medidas de $\mathrm{K}_{\mathrm{o}}$ e sua relação com a variabilidade espacial da textura, umidade volumétrica antecedente, conteúdo de matéria orgânica e superfície topográfica de um solo de textura argilosa. Os métodos resultaram em estimativas equivalentes para $\mathrm{K}_{\mathrm{o}}$. Os resultados sugerem também que, o alcance, a magnitude e a estrutura da variabilidade da condutividade hidráulica do solo saturado foram controlados, primariamente, pelo grau de desenvolvimento e estabilidade da estrutura do solo no campo, em relação à textura, conteúdo de matéria orgânica e superfície topográfica.

Associados aos métodos, os diversos procedimentos de cálculo também devem ser registrados como importantes fontes de variação da condutividade hidráulica, como mostram os resultados de Calvache et al. (1995). Porém, deve-se ressaltar que esta não é uma regra geral, tendo em vista os resultados de Queiroz et al. (1997), que não encontraram diferenças significativas quanto ao procedimento de cálculo da condutividade hidráulica do solo saturado, medida pelo método do furo do trado.

O resultado da influência de todo este conjunto de fatores e suas relações é tornar a condutividade hidráulica do solo uma das suas propriedades com maior índice de variabilidade espacial e temporal. Comprovando esta realidade, Souza et al. (1997b) verificaram a influência conjunta da gradagem e 
matéria orgânica na distribuição de poros de um horizonte Ap para três diferentes solos e seus reflexos na condutividade hidráulica em relação aos horizontes mais profundos. Nos três casos analisados a condutividade hidráulica foi maior no horizonte Ap, logicamente em função da maior macroporosidade apresentada por este horizonte.

Warrick \& Nielsen (1980) apresentam uma tabela em que registram os níveis de variação de algumas propriedades físicas do solo. De acordo com estes autores a condutividade hidráulica é uma propriedade que apresenta alta variabilidade. Seus dados mostram que a condutividade hidráulica do solo saturado pode apresentar até $190 \%$ de variação, enquanto que para a condutividade hidráulica do solo não saturado são bem mais significativos, podendo alcançar valores até $420 \%$ de variação. Complementando, resultados experimentais publicadas por Anderson \& Cassel (1986) indicam que a condutividade hidráulica do solo pode variar de 130 até 3.300\%. Estes níveis de variação indicam que a utilização e extrapolação de valores médios, resultantes de observações experimentais de campo em estudos de dinâmica da água no solo, para este parâmetro hidráulico em suas aplicações agrícolas, geram erros cuja ordem de grandeza são significativamente elevadas, afirmam Nielsen et al. (1973) e Cadima et al. (1980).

Uma análise mais apurada permite identificar nos resultados de Cadima et al. (1980) outras informações interessantes sobre a variabilidade da condutividade hidráulica do solo não saturado. Estes autores analisaram, sob condições de campo, a variabilidade espacial da condutividade hidráulica de um Latossolo Vermelho-Amarelo (Latossolo Vermelho (EMBRAPA (1999)), textura média. Eles concluíram que a variabilidade é mais acentuada nas camadas superficiais, diminuindo significativamente em profundidade. Também 
constataram que a variabilidade temporal é muito significativa nas camadas superiores do perfil. Neste caso, os valores de condutividade hidráulica diminuíram bruscamente nas primeiras vinte e quatro horas após a interrupção da infiltração, atingindo valores extremamente baixos aos quarenta dias de experimento.

Calvache et al. (1995) compararam dois procedimentos para determinação das relações $\mathrm{K}(\boldsymbol{\theta})$. Utilizando o método do perfil instantâneo em cinco parcelas distribuídas em uma área de $10.000 \mathrm{~m}^{2}$ de um Typic Haplustoll eles concluíram que o ponto crítico das estimativas de $\mathrm{K}$ estão nos valores de $\mathrm{K}_{\mathrm{o}}$, cuja variação pode chegar a $150 \%$, resultando em valores de $\mathrm{K}(\theta)$ com até $100 \%$ de variabilidade.

Resultados de Jong van Lier \& Libardi (1999) também mostram que o valor da condutividade hidráulica do solo saturado, $\mathrm{K}_{\mathrm{o}}$, é a principal causa de variabilidade nas relações matemáticas entre $\mathrm{K}$ e $\theta$. Estes autores conduziram um experimento para medir a variabilidade dos parâmetros da equação exponencial que relaciona a condutividade hidráulica com a umidade do solo, utilizando o método do perfil instantâneo, em uma área de $1.000 \mathrm{~m}^{2}$, com doze pontos de observação, em nove profundidades, de uma Terra Roxa Estruturada Latossólica (Nitossolo (EMBRAPA (1999)). Neste experimento os valores de $\gamma$ (correspondente ao $\beta$ da eq. 8) e $K_{o}$ mostraramse muito variáveis. Para o $\gamma$, a variação foi da ordem de 200 a 6000 em uma mesma profundidade, enquanto o $\mathrm{K}_{\mathrm{o}}$ variou de $10^{-8} \mathrm{~m}^{2} \mathrm{~h}^{-1} \mathrm{kPa}^{-1}$ a $10^{2} \mathrm{~m}^{2} \mathrm{~h}^{-1} \mathrm{kPa}^{-1}$. Verificaram também uma variação muito maior dos valores de $\gamma$ nas camadas superficiais, evidenciando que os problemas na determinação da função $K(\theta)$ e suas aplicações em estudos hidrológicos devem considerar essa característica. 
Os mesmos autores, Jong van Lier \& Libardi (1999), afirmam que a relação $\mathrm{K}$ versus $\theta$, quando determinada pelo método do perfil instantâneo, principalmente para as camadas superficiais, não representa uma área muito maior do que àquela onde o método foi aplicado. Complementando esta última informação, Anderson \& Cassel (1986) indicam que somente existe autocorrelação para propriedades como a condutividade hidráulica em distâncias menores que 2,5 metros e, conseqüentemente, quando for necessária a obtenção de amostras independentes para investigar propriedades físicas do solo, como a condutividade hidráulica, o planejamento da amostragem deve considerar este fato.

Ao contrário de Jong van Lier \& Libardi (1999) e Anderson \& Cassel (1986), resultados de vários estudos apresentados por Iwata et al. (1994) indicam que a dependência espacial da função $K(\theta)$ pode alcançar valores acima de 30 metros.

De acordo com Berg \& Klamt (1997), o conhecimento da variabilidade espacial das características do solo tem importância significativa para o correto uso deste recurso natural, uma vez que ela afeta as amostragens para fins de avaliações químicas, físicas e biológicas, indicando o número mais representativo de amostras, para o levantamento e a classificação, o mapeamento e aplicação de técnicas para o manejo e a recuperação dos solos.

Por sua vez, Warrick \& Nielsen (1980) sugerem que os estudos e avaliações sobre a variabilidade dos solos devem contemplar os padrões e freqüências de distribuição e estrutura da variabilidade. Sugerem a comparação entre solos, locais e métodos de análise para todos os parâmetros possíveis, a partir de grupos multidisciplinares e com o uso da expressiva base de dados já existente. Finalizando, afirmam que "a variabilidade dos parâmetros físicos do 
solo pode ser integrada para responder as crescentes questões sobre problemas específicos que permitam escolher os melhores sistemas de manejo". Assim, pode-se alcançar a solução dos problemas contemporâneos, relativos à condutividade hidráulica, com equilíbrio entre o econômico e o técnico, gerando informações científicas mais claras e precisamente analisadas, cujos resultados poderão ser utilizados com grande confiança.

Como se trata de um meio naturalmente descontínuo, o conceito de homogeneidade para os solos e suas características tem uma aplicação relativa e depende, portanto, da escala de observação (Seyfried, 1998). Por isso, estabeleceu-se que a quantificação da variabilidade de um certo atributo medido neste corpo geológico deve ser feita por meio de técnicas estatísticas (Grossi Sad, 1986).

Miyazaki (1993) também considera que a heterogeneidade do solo é função de uma escala, visto que medidas de propriedades como densidade do solo, conteúdo de água, potencial mátrico, textura e temperatura, dependem do elemento de volume ou tamanho da amostra. Portanto, a definição de uniformidade e heterogeneidade do solo depende de um volume elementar representativo (VER), o qual deve apresentar um pequeno desvio padrão, retratar a estrutura da variabilidade espacial e ser adequado para a operacionalização do método de medida. Vários trabalhos foram realizados com o objetivo de determinar a VER para as diversas propriedades físicas do solo, dentre as quais a condutividade hidráulica (Cogels, 1983; Bouma et al., 1989; Lauren et al.,1988; Rice \& Bowman, 1988).

Em escala macro, as propriedades do solo na paisagem, variam em resposta a variações regionais de clima e material de origem, conferindo-lhes características diagnósticas que possibilitam a sua individualização como corpos 
naturais homogêneos ao nível de ordem. No campo, para efeito de classificação e mapeamento, tanto a variação em grande escala, quanto aquela que ocorre em pequenas distâncias têm sido extensivamente descritas e classificadas. Não raro, em muitos locais do planeta, como nos EUA, existem levantamentos de solos com escala suficiente para identificar até dez unidades de mapeamento por propriedade rural, tal o patamar de detalhamento alcançado. Ao nível de série, a variabilidade das propriedades do solo é causada por pequenas mudanças na topografia que, por sua vez, afetam o transporte e o armazenamento de água no perfil, influenciando significativamente o desenvolvimento do solo. Porém, mesmo os mapeamentos mais detalhados não são suficientes para expressar e descrever, em minúcias, os padrões de variação das propriedades do solo ao nível de parcela no campo (Mulla \& McBratney, 2000), sendo necessário, pois, a aplicação de técnicas mais refinadas para quantificar precisamente algumas de suas propriedades no campo.

A obtenção dos materiais de solo para quantificação da variabilidade pode ser feita utilizando amostras contínuas ou discretas. No processo de amostragem contínuo, a medida de uma determinada propriedade do solo é feita em toda abrangência da área de interesse no campo. Para tanto, usamse fotografias aéreas ou imagens de satélite, obtidas pelas técnicas de sensoriamento remoto. Como exemplo desta técnica, Mulla \& McBratney (2000) citam a determinação da condutividade elétrica do solo com o uso do sensor de indução eletromagnética “Geonics EM-38". Neste caso o procedimento de amostragem não precisa de planejamento prévio e elimina a interpolação entre as medidas. O processo de amostragem discreto requer a coleta de amostras em locais predeterminados e usa técnicas invasivas de obtenção. Desta maneira somente uma parte da população é observada e as suas características são inferidas por meio de técnicas estatísticas. 
As técnicas estatísticas aplicadas ao estudo da variabilidade dos solos podem ser divididas em duas categorias: a estatística clássica e a geoestatística.

A geoestatística é uma ferramenta de análise de amostragem regionalizada, que descreve a dependência e a variabilidade espacial de uma variável a partir de correlogramas e semivariogramas, que explicitam o nível de dependência espacial, bem como o alcance de cada amostragem. A variável regionalizada possui, pois, um valor considerado representativo para toda uma região no espaço, podendo ser representada por funções numéricas ordinárias que assumem um valor definido em cada ponto e descreve, matematicamente, um fenômeno natural qualquer. Este conceito possibilitou a interpretação precisa de resultados experimentais relativos a muitas propriedades químicas e físicas do solo (Cambardella et al., 1994; Gonçalves et al., 1996b; Couto \& Klamt, 1997; Rodrigues \& Zimback, 1997; Sousa et al., 1999; Mulla \& McBratney, 2000).

Detalhamentos dos princípios básicos, aspectos e requerimentos para o cálculo das diversas funções da geoestatística e suas aplicações no estudo da variabilidade das propriedades físicas do solo foram publicados por vários autores (Nielsen et al., 1973; Vieira et al., 1983; Trangmar et al., 1985; Vieira, 1997; Vieira, 2000; Wendroth et al., 1997).

Warrick \& Nielsen (1980) discutem a variabilidade espacial das propriedades físicas do solo no campo pela análise e detalhamento das funções estatísticas usadas para este tipo de estudo e, também, apresentam exemplos para ilustrar os conceitos teóricos.

Russo \& Bresler (1981) afirmam que as propriedades hídricas do solo não variam aleatoriamente no campo e que, portanto, sua descrição 
estatística deve considerar a estrutura da variabilidade espacial. Considerando que a estrutura da variabilidade espacial das propriedades hídricas do solo é caracterizada por uma escala integral, que representa a distância na qual determinado parâmetro está correlacionado com seu par e, conseqüentemente, o espaço para o qual cada valor é representativo, os autores relatam que cada parâmetro hídrico pode ser caracterizado estatisticamente por uma função de probabilidade independentemente da sua posição espacial e por uma função de autocorrelação que depende somente do valor da distância que separa dois pontos no campo.

Gajem et al., (1981) estudaram a dependência e a estrutura espacial para onze propriedades físicas de um Typic Torrifluvent no Arizona. Neste caso foi difícil realizar generalizações, muito embora a zona de influência das propriedades físicas tenha sido fortemente dependente da distância entre as amostras. Os resultados também indicam que é difícil atribuir uma escala mais precisa para estudos de variabilidade de parâmetros físicos do solo.

Reichardt et al. (1986) fizeram uma revisão consultando importantes trabalhos sobre o tema variabilidade espacial de solos e apresentam uma comparação entre a estatística clássica e a geoestatística. Os autores mostram que as técnicas são complementares e que a geoestatística possibilita a obtenção de respostas que os métodos clássicos não conseguem fornecer.

Libardi et al. (1986) aplicaram as funções da teoria das variáveis regionalizadas para avaliar a magnitude da variabilidade espacial da umidade, textura e densidade de uma Terra Roxa Estruturada (Nitossolo (EMBRAPA (1999)) e concluíram que, as funções, autocorrelação e semivariância mostraram potencialidade para uso neste tipo de estudo. 
Considerando que os métodos estatísticos diferem basicamente na forma de avaliar a variabilidade dos dados, Silva (1988) realizou um experimento com o objetivo de comparar a estatística clássica com a geoestatística em relação à quantificação da variabilidade dos atributos físicos do solo, textura, densidade dos sólidos, densidade do solo e curva de retenção de água em um Latossolo Roxo (Latossolo Vermelho (EMBRAPA (1999)). Como não conseguiu, nas condições de seu experimento, identificar a estrutura da variabilidade, este autor considera que a geoestatística não encerra todas as dificuldades para estudos de variabilidade espacial, muito embora seja uma importante ferramenta auxiliar. No entanto, Mata (1997), afirma que a geoestatística o permitiu chegar a conclusões que passariam despercebidas caso fosse utilizada somente as ferramentas "tradicionais" ou estatística clássica, confirmando as conclusões de Reichardt et al. (1986).

Mulla \& McBratney (2000) detalham os conceitos e interpretações para a variabilidade espacial pela estatística clássica e pela geoestatística, ilustrando sua discussão com modelos de semivariogramas, amostragens e interpolações. Também apresentam uma relação das propriedades físicas do solo e seus respectivos coeficientes de variação. Neste caso estão indicados quatro grupos de variabilidade: baixa magnitude de variação, baixa a média; média a alta e alta magnitude de variabilidade. A condutividade hidráulica saturada é classificada como de alta variabilidade, com percentuais variando de 48 a 352\%, segundo os autores.

A estatística não espacial, freqüentemente referida como estatística clássica, também é usada para examinar aspectos de variabilidade espacial dos parâmetros físicos do solo. Neste caso a amostragem é feita de forma inteiramente casualizada e sem considerar a posição relativa de cada variável no 
espaço. Também assume-se que as amostras são completamente independentes entre si. Estes métodos estatísticos foram desenvolvidos a partir do ano de 1919, quando Ronald A. Fischer assumiu a direção do Departamento de Estatística da Estação Experimental de Rothampstead em Londres e passou a buscar métodos matemáticos que lhe possibilitasse obter conclusões sobre vários fenômenos experimentais. A base teórica e detalhamento dos métodos estatísticos clássicos estão amplamente descritos em (Spiegel, 1968; Gomes 1987a; Gomes, 1987b; Banzato \& Kronka, 1995, Levine et al., 1998). Outros autores discutem diretamente a aplicação destes conhecimentos ao estudo da variabilidade dos solos (Warrick \& Nielsen, 1980; Reichardt et al., 1986; Souza, 1992; Miyazaki, 1993; Mulla \& McBratney, 2000).

Os parâmetros estatísticos considerados pela estatística clássica são a média, a moda, a mediana, o desvio padrão da média, a variância, a distribuição da freqüência dos dados, o coeficiente de variação, a assimetria, a curtose e os intervalos de confiança para as estimativas dos dados.

A média e seu correspondente desvio padrão são duas características chaves para a análise inicial da variabilidade de uma população. A média é considerada uma medida de posição ou medida de tendência central e sua estimativa é dada pela seguinte expressão matemática:

$$
\bar{X}=\frac{1}{N} \sum_{i=1}^{N} X_{i}
$$

sendo $\mathrm{N}$ o número de medidas consideradas e $\mathrm{X}$ o valor de cada medida em análise. A mediana é o valor do meio ou a média aritmética dos dois valores 
centrais, em uma seqüência ordenada de dados. A moda é o valor que ocorre com a maior freqüência.

A média fornece uma idéia do conjunto de dados porém não permite avaliar a sua dispersão. Para tanto, dentre outras, uma maneira sofisticada, mas de tratamento matemático muito simples e de propriedades sempre convincentes, é a estimativa do desvio padrão (s), que é a raiz quadrada da variância $\left(\mathrm{s}^{2}\right)$. O modelo matemático para calcular o desvio padrão é:

$$
s=\sqrt{\frac{1}{N-1} \sum_{i=1}^{N}\left(X_{i}-\bar{X}\right)^{2}}
$$

Na prática, a média representa apenas uma estimativa do valor correto da amostra. Tais estimativas são mais confiáveis à medida que se aumenta o número de observações. $\mathrm{O}$ desvio padrão indica a heterogeneidade do conjunto de dados em estudo. Desvios grandes indicam dados heterogêneos e com elevada dispersão de seus elementos. Ao contrário, desvios pequenos indicam mais homogeneidade dos dados e conseqüentemente pequena dispersão.

Segundo Libardi et al., (1996) o desvio padrão tem a vantagem de apresentar a variabilidade dos dados na unidade de medida original, sendo, desta forma, recomendável como estatística de avaliação da variabilidade. Porém a utilização do desvio padrão para comparação de duas variáveis diferentes é inadequada, visto que as unidades de medida também são diferentes. Neste caso torna-se necessário uma medida relativa da variabilidade, tal qual o coeficiente de variação. 
O coeficiente de variação é um número que representa o desvio padrão em percentagem da média. Para medidas de dispersão normalizadas em torno de uma média o CV é estimado pela expressão:

$$
C V=\frac{s}{\bar{X}} \times 100
$$

O CV é, pois, um número abstrato e relativo, que indica a precisão dos dados e possibilita a comparação racional entre valores diferentes. Propriedades do solo com CV elevado são mais variáveis que aquelas com baixo valor de CV. Neste caso, existe até proposições de uma classificação para identificar a extensão da variabilidade das propriedades do solo com base no seu coeficiente de variação.

Warrick \& Nielsen (1980) classificaram a variabilidade das propriedades do solo, expressa pelo coeficiente de variação, em três níveis: Baixa variação $(\mathrm{CV}<12 \%)$, média $(12 \%<\mathrm{CV}<80 \%)$ e alta $(\mathrm{CV}>80 \%)$. Por outro lado, Mulla \& McBratney (2000) citam outro esquema de classificação bem mais rigoroso, no qual valores de $0-15 \%, 16-35 \%$ e $>36 \%$, para o coeficiente de variação, indicam pequena, média e alta variabilidade, respectivamente.

Informações comp lementares aos momentos estatísticos já descritos podem ser obtidas pela caracterização da freqüência de distribuição dos parâmetros medidos, contribuindo para definir de maneira mais completa a sua variabilidade. 
A freqüência de distribuição corresponde a um arranjo tabular dos dados por classes, juntamente com as freqüências correspondentes. Esta função permite calcular médias, dispersões e a probabilidade de um dado valor ocorrer entre limites especificados. As curvas de freqüência aparecem, na prática, sob diversas formas características. Podem ter distribuição normal ou não, sendo simétrica ou assimétrica em relação à média. Quando a frequiência de distribuição é normal, a média, a mediana e a moda são iguais. Nos outros casos são diferentes. Uma distribuição assimétrica muito comum é a log-normal. Quando isto ocorre o valor da mediana é maior que a moda e menor que a média. Considerando que a distribuição normal é uma exigência básica para análise de dados pelos métodos da estatística clássica, as distribuições de frequiências assimétricas devem ser normalizadas. No caso da distribuição log-normal, isto é feito calculando-se o logaritmo natural do dado observado. Exemplos de aplicações em que o logaritmo é usado para normalizar a distribuição dos dados aparecem em estudos das propriedades hídricas do solo (Sisson \& Wierenga, 1981; Reynolds \& Zebchuk, 1996; Schaap \& Leij, 1998; Comegna et al., 2000).

A média (m) e a variância $\left(\mathrm{s}^{2}\right)$ da distribuição do logaritmo transformado podem ser usadas para estimar a média aritmética dos dados não transformados usando a seguinte expressão:

$$
\bar{X}=\exp \left(m+0,5 s^{2}\right)
$$

A dispersão de uma frequiência de distribuição normal em torno da média é uma importante medida da variabilidade da população amostrada. A curva de freqüência de distribuição para uma população com alta variabilidade 
apresenta-se relativamente larga e ampla, ao contrário, se a população varia pouco, a curva tem aspecto estreito e muitos dos seus valores estarão bem próximos da média e mediana.

Segundo Reichardt et al. (1986) foram Nielsen et al. (1973) provavelmente os primeiros autores a verificarem que as propriedades do solo obedecem a diferentes padrões de distribuição. De acordo com os autores muitas propriedades do solo, como teores de areia e argila, apresentam uma distribuição normal, enquanto outras, como a condutividade hidráulica, seguem distribuição assimétrica, geralmente log-normal. Estes padrões de distribuição também foram encontrados por vários pesquisadores; areia e argila (Vieira, 1997), condutividade hidráulica (Libardi et al., 1980; Banton, 1993; Logsdon \& Jaynes, 1996).

Existem diversos métodos para identificar qual o tipo de distribuição de um conjunto de dados. Jones (1969) propõe a utilização de tabelas relacionando os valores de assimetria e curtose para testar a normalidade de um conjunto de dados com base na teoria estatística dos testes de hipótese; Warrick \& Nielsen (1980) sugerem um método gráfico como sendo uma das maneiras mais fáceis; Guerra (1980) cita os testes não paramétricos de Kolmogorov-Smirnov e Chi-Quadrado; Moraes (1991) e Beiguelman (1994) detalham o método dos momentos estatísticos, informando que é um dos mais utilizados para este propósito e Libardi et al., (1996) demonstram a verificações da normalidade para os métodos do gráfico de Henry, "box-plot" e ramos e folhas.

Em estudos de variabilidade uma pergunta a ser respondida é: Quantas amostras devem ser obtidas para representar adequadamente uma 
propriedade ou característica do solo diante de sua inerente variabilidade espacial?

Os estudos disponíveis apresentam as mais diversas proposições, recomendando desde dezenas até milhares de amostras. Diante das questões econômicas, de tempo e praticidade, como realizar este processo?

Esta etapa do estudo da variabilidade deve começar a partir de um planejamento de amostragem capaz de fornecer as bases para uma precisa identificação dos padrões da variabilidade espacial da propriedade em estudo. $\mathrm{O}$ número ótimo de amostras a ser coletado depende da variabilidade da população, do nível de precisão desejado para estimar a média da população, do intervalo de confiança da média populacional, do custo das análises e disponibilidade dos equipamentos de laboratório. Em alguns casos, como para a condutividade hidráulica do solo saturado, esse número pode alcançar valores impraticáveis de até 26.000 amostras para estimativa da média com razoável precisão (Anderson e Cassel, 1986).

Para o caso de parâmetros cujas amostras são independentes e apresentam distribuição normal, a seguinte fórmula é muito utilizada para estimar o número $(\mathrm{N})$ de pontos amostrais necessários para calcular, com a precisão desejada, o valor da sua média.

$$
N=\frac{t^{2} x s^{2}}{d^{2}}
$$


em que t é o valor tabulado de Student para o nível de confiança estabelecido, s é uma estimativa preliminar do desvio padrão da população, d é o desvio padrão desejado da população em relação à média. $\mathrm{Na}$ teoria, desde que $\mathrm{N}$ não é conhecido o número de graus de liberdade necessários para a estimativa de $\mathrm{t}$ também não é. Existem na literatura proposições que permitem estimar o verdadeiro valor de $\mathrm{N}$ a partir do cálculo interativo de valores estimados do próprio $\mathrm{N}$ e seus correspondentes graus de liberdade para t. Na prática, sempre assume-se que o tamanho da amostra (N) é suficiente para tal objetivo (Mulla \& McBratney, 2000), o que nem sempre é correto.

Segundo Mulla \& McBratney (2000), o modelo matemático para calcular o número de amostras de populações para as quais a variabilidade espacial é considerada, difere da eq. (27). Neste caso, quando a correlação espacial existe, é necessário um grande número de amostras para estimar a média. Este incremento do número de amostras necessárias é estimado calculando-se o número de observações independentes para a população. Sendo assim, o verdadeiro número de amostras para estimar a média é dado pela relação $\mathrm{N}^{2} / \mathrm{N}^{*}$, na qual o denominador refere-se ao número equivalente de amostras independentes.

Normalmente o número de amostras que resulta da aplicação das metodologias tradicionais é muito grande, notadamente para os casos de propriedades do solo com grande variabilidade. Percebendo esta dificuldade prática para a obtenção de médias representativas, Vachaud et al. (1985) propuseram uma metodologia capaz de reduzir o número de observações requeridas para caracterizar uma propriedade física do solo. Com base em estudos de conteúdo de água no solo esses autores introduziram o conceito de estabilidade temporal. Tal conceito pode ser definido como resultante da 
associação invariável no tempo entre a localização espacial e as medidas estatísticas que caracterizam uma dada propriedade do solo, conforme bem explicitaram Wesenbeeck et al. (1988). Para a umidade no solo este conceito foi comprovado, na medida em que o teor de água em um local mais úmido no solo tende a se manter assim em qualquer tempo.

Gonçalves et al. (1999a) comprovaram o conceito de Vachaud et al. (1985) quando estudaram a estabilidade temporal da distribuição espacial da umidade no solo em uma área irrigada. Em seu trabalho os autores constataram a persistência das distribuições espaciais da umidade e a possibilidade de identificar locais de amostragem cujos valores permitam estimar a média geral da umidade em uma área, em qualquer tempo. Estas conclusões apresentam importantes conseqüências práticas relacionadas com o monitoramento da água e uso eficiente de sistemas de irrigação.

Para aplicação do conceito de estabilidade temporal a um conjunto de dados é necessário que duas condições sejam atendidas. A primeira condição requer, para um determinado tempo, um número suficiente de observações para obtenção de seus parâmetros estatísticos clássicos. Na segunda condição deve ser possível associar a cada posição ou local o seu valor estatístico de densidade de probabilidade de distribuição normal.

Para analisar a estabilidade temporal Vachaud et al. (1985) propõem duas técnicas.

A primeira, denominada de diferença relativa, faz uma análise dos desvios entre os valores observados individualmente e a média deles, medidos espacialmente. De acordo com Vachaud et al. (1985) igualdades ou pequenas 
variações da diferença relativa entre posições ao longo do tempo indica a estabilidade temporal.

A segunda técnica é o teste de correlação de Spearman (Campos, 1983), que é utilizado como uma ferramenta estatística para indicar o grau de concordância da variabilidade espacial obtida em diferentes tempos.

Kachanoski \& De Jong (1988) aplicaram o conceito de estabilidade temporal como definido por Vachaud et al. (1985). Concluíram que a armazenagem de água em um determinado local resulta da ocorrência de um conjunto de processos hidrológicos que operam em diferentes escalas espaciais e então, demonstraram que análises de coerência espacial poderiam ser usadas para examinar a estabilidade temporal como uma função da escala espacial de qualquer variável do solo. Suas conclusões significaram um avanço e ao mesmo tempo simplificaram a proposta de Vachaud et al. (1985).

Outras considerações adicionais ao número de amostras incluem a profundidade, o tempo, a composição e o volume da amostra. Por outro lado, a profundidade é dependente de muitos outros fatores como o tipo de propriedade a ser medida, o tipo de equipamento usado para coleta, tipo e profundidade de cultivo e principalmente das condições de solo (seco, úmido, compactado). $\mathrm{O}$ tempo ou período de amostragem é particularmente importante quando se mede variáveis temporais, como teor de água e condutividade hidráulica do solo. Resumindo, para evitar erros de amostragem é necessário um rigoroso planejamento estatístico juntamente com a aplicação de técnicas adequadas.

Várias estratégias para determinar a distribuição espacial dos pontos a serem amostrados foram desenvolvidas, entre as quais pode-se citar 
amostragem dirigida, ao acaso, estratificada ao acaso, sistemática, estratificada sistemática, em faixas e amostragem geoestatística (Mulla \& McBratney, 2000).

Uma das formas para se obter amostras representativas é a reamostragem aleatória, em que cada observação de uma população tem a mesma probabilidade de ser incluída na amostra. Este processo pode ser feito com ou sem reposição. No primeiro caso, uma observação pode ser escolhida mais de uma vez, enquanto que no método sem reposição a observação só pode ser escolhida uma vez em cada reamostragem. O método de reamostragem com reposição é mais vantajoso porque torna a população teoricamente infinita, na medida em que se pode obter um número muito grande de amostras. Sua desvantagem é ser um processo trabalhoso e complexo. Para superar esta limitação técnica, foram desenvolvidas poderosas metodologias de amostragem com base em programas de computador. A técnica "bootstrap" de estimação é uma delas.

O "bootstrap" é uma técnica computacional, recente, desenvolvida para realizar inferências estatísticas de uma amostra populacional. O uso do termo "bootstrap" tem origem na frase 'to pull oneself up by one’s bootstrap', atribuída ao Barão de Munchausen, no livro sobre suas aventuras, escrito por Rudolph Erich Raspe no século dezoito.

$\mathrm{Na}$ realidade o "bootstrap" é um procedimento computacional intensivo de reamostragem, baseado na técnica da substituição, que possibilita a estimação da distribuição amostral de estatísticas de interesse, tendo como base dados de uma amostra ou população. Utilizando-se esta técnica é possível realizar comparações estatísticas em áreas diversas do conhecimento científico, como economia, ecologia, genética, biologia e agronomia, incluindo física de solos 
(Efron \& Tibshirani, 1993; Chung et al., 1996; Venkovsky et al., 1997; Amador et al.; 2000; Jhun \& Jeong, 2000).

Aplicações da técnica "bootstrap" ao estudo da variabilidade de parâmetros hídricos do solo são encontradas nos trabalhos de Dane et al. (1986) e Hendrickx \& Wierenga (1990). Nestes trabalhos os autores utilizam o "bootstrap" para análise estatística e para o desenvolvimento de um método capaz de determinar o número mínimo de amostras necessárias para estimar a média de uma população a partir de um determinado grau de precisão.

Outro exemplo mais recente da aplicação da técnica "bootstrap" para estudo de propriedades hídricas do solo é o trabalho de Schaap \& Leij (1998). Estes pesquisadores utilizaram o "bootstrap" em associação com funções do tipo "neural networks" para desenvolver esquemas de modelagem para o cálculo e estimativas da curva de retenção e condutividade hidráulica em condições de saturação e não saturação. Segundo seus resultados, o "bootstrap" foi importante ferramenta de apoio para o desenvolvimento de um sistema de modelagem para calcular propriedades hídricas do solo.

Concluindo, pode-se afirmar que, associando-se os princípios da estatística clássica aos da geoestatística e aplicando-se as novas técnicas computacionais de reamostragem intensiva, como o "bootstrap", é possível definir, a partir do número de amostras necessário para se ter um coeficiente de variação aceitável e do conhecimento da dependência espacial do fator em estudo, padrões de análise para realizar um estudo confiável e preciso de determinada característica do solo. 


\section{MATERIAL E MÉTODOS}

\subsection{Localização da área experimental}

O experimento foi realizado no campus da Escola Superior de Agricultura Luiz de Queiroz - ESALQ/USP, localizado no município de Piracicaba (SP), cujas coordenadas geográficas são as seguintes: $22^{\circ} 42^{\prime} 30^{\prime \prime}$ de latitude Sul, $47^{\circ} 38^{\prime} 00^{\prime}$ de longitude Oeste e altitude de 580 metros. O relevo local é plano com declive na área experimental menor que $0,01 \mathrm{~m} \mathrm{~m}^{-1}$.

De acordo com os dados metereológicos coletados regularmente no posto metereológico da ESALQ, a precipitação média anual na área é de aproximadamente $1.250 \mathrm{~mm}$ por ano, concentrada no período de novembro a fevereiro; a temperatura média do ar é de $21,5^{\circ} \mathrm{C}$. O clima regional é classificado como tropical úmido, com chuvas de verão e seca de inverno, indicado como CWA pela classificação de Koëppen.

\subsection{Características do solo}


O solo é um Latossolo Vermelho Amarelo, álico, A moderado, textura média, (Typic Hapludox). Apresenta-se moderadamente a bem drenado e o uso atual é com pastagem de capim elefante. A descrição do perfil, os resultados da análise granulométrica e os dados para curva de retenção de água (Reichardt et al., 1979) referentes ao solo estudado estão registrados nos Apêndices 1, 2 e 3, respectivamente.

\subsection{Parcela Experimental}

A parcela experimental tinha um comprimento de $70 \mathrm{~m}$ e uma largura de $20 \mathrm{~m}$; na sua linha central ao longo do comprimento foram selecionados 50 pontos de observação, distanciados de $1 \mathrm{~m}$ entre si e, em cada um deles, instalados 5 tensiômetros, eqüidistantes, numa circunferência de raio de $0,10 \mathrm{~m}$, com suas cápsulas porosas localizadas às profundidades de 0,$15 ; 0,30$; 0,45; 0,60; 0,75 m (Figura 1). No centro da circunferência de cada conjunto dos 5 tensiômetros foi instalada uma sonda de TDR para medida da umidade nas mesmas cinco profundidades. Manômetros de mercúrio, localizados fora da área útil experimental, foram conectados aos tensiômetros, bem como os correspondentes cabos de TDR. Antes da instalação dos equipamentos a vegetação de capim elefante foi removida e queimada, assim como, foram realizadas uma aração e uma gradagem na camada $0-0,30 \mathrm{~m}$ para uniformizar a área experimental.

Os tensiômetros utilizados foram construídos com tubos de PVC rígido com diâmetro externo e interno medindo 0,021 $\mathrm{m}$ e 0,016 m, respectivamente, e comprimento correspondente à profundidade de instalação. 
Em um das extremidades foi acoplada e fixada, com cola, uma cápsula porosa e na outra uma tampa rosqueável. Uma tubulação de plástico, de "nylon", com diâmetro interno de 0,002 m, também colada ao tubo de PVC, foi utilizada para conectar cada um dos 5 tensiômetros de cada ponto à uma única cuba com mercúrio dos 5 manômetros de leitura do ponto. Os cabos dos TDRs e essa tubulação dos 5 tensiômetros foram embutidos em conduítes de plástico tipo “colpex", enterrados e conduzidos até o suporte dos manômetros de leitura de cada ponto.

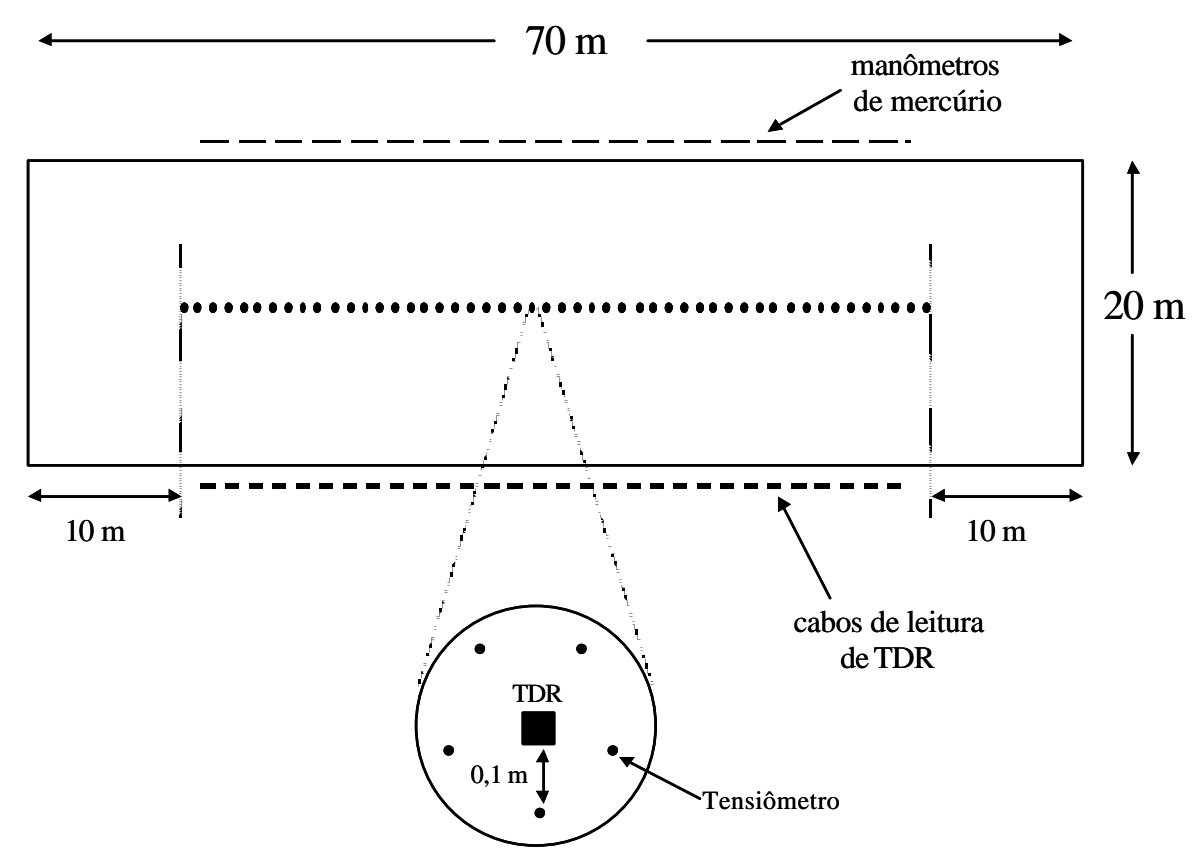

Figura 1- Parcela experimental com dimensões e localização dos 50 pontos de observação. $O$ detalhe mostra a configuração de um ponto de observação, no qual a distância horizontal entre os tensiômetros é de $0,13 \mathrm{~m}$ e a distância da sonda TDR à linha de tensiômetros $0,10 \mathrm{~m}$. 
As cápsulas porosas, de cerâmica, foram selecionadas e testadas antes e depois da confecção dos tensiômetros. O teste foi realizado para determinar a condutância hidráulica e a pressão de borbulhamento até 1,1 atmosfera, que é o valor acima do mínimo para o perfeito funcionamento do tensiômetro (Libardi, 1999) 1 .

As cubas do manômetro de mercúrio foram confeccionadas em acrílico, tinham forma cilíndrica e ficavam fixadas, por meio de um parafuso, ao suporte de madeira, no qual as leituras eram realizadas.

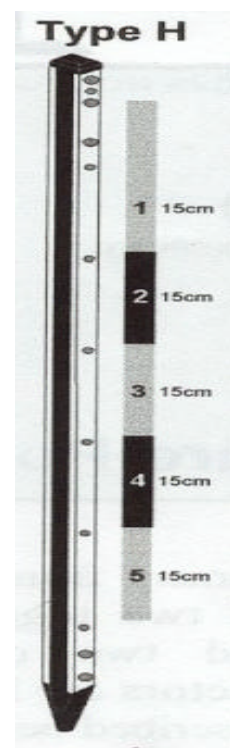

Figura 2 - Sonda do TDR Tipo 4 (PRB - H), modelo MP 917 da empresa E.S.I. Environmental Sensors Inc., mostrando os seguimentos e pontos de medida da umidade no solo

${ }^{1}$ LIBARDI, P.L. Condutância hidráulica de cápsulas porosas para tensiômetros. Piracicaba: ESALQ, Depto de Ciências Exatas, 1999. (Roteiro de aula prática) 
As sondas de TDR utilizadas foram do modelo "Type" 4 (PRB H), model MP 917 da empresa E.S.I. Environmental Sensors Inc., com cinco segmentos de 0,15 m para medida da umidade. As sondas, em forma de hastes, são construídas com partes de aço inoxidável, epóxi e plástico de alta densidade. Fisicamente é parecida com uma lança curta com laterais metálicas. Os segmentos de medida de cada haste são formados por componentes eletrônicos encapsulados nos intervalos definidos para leitura das umidades. A umidade medida em cada profundidade é uma média da umidade existente ao longo do segmento correspondente. O modelo possui também um código interno de identificação que é automaticamente reconhecido pelo software interno do modulo de leitura. A Figura 2 mostra o tipo de sonda que se utilizou no experimento.
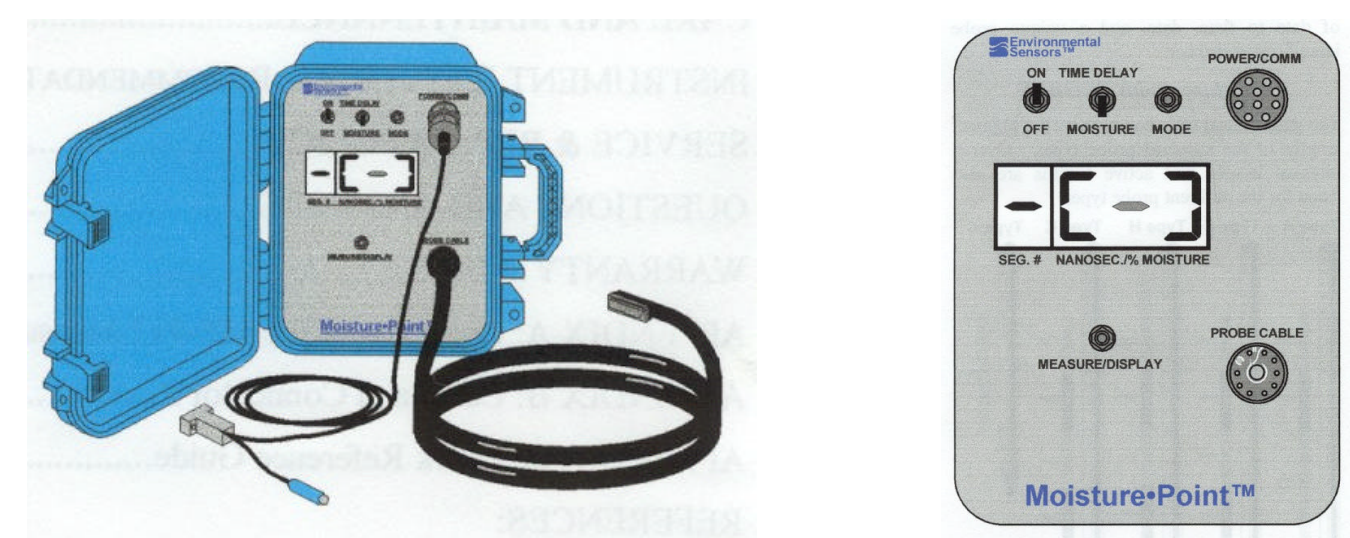

Figura 3 - Módulo de leitura e painel do aparelho TDR Moisture Point MP-917 da empresa E.S.I. Environmental Sensors Inc.

O Moisture Point MP-917 (Figura 3) apresenta em seu painel um "display" de quatro dígitos, dois interruptores simultâneos, dois botões de 
acionamento por pressão e dois conectores para cabos. Todos os botões são identificados por um rótulo indicando sua função. O "display", com os quatro dígitos, está dividido em duas partes. Na direita, indica o número do segmento da sonda. Na esquerda, dependendo da posição do interruptor, indica o "time delay" em nanossegundos (ns) ou a umidade em percentagem e a base de volume. Quando a leitura é feita em "time delay" o equipamento mostra o tempo de propagação do pulso eletromagnético para cada segmento da sonda.

Os tensiômetros e as hastes de TDR foram instalados no campo em furos previamente abertos com uma sonda de metal com diâmetro semelhante ao dos equipamentos correspondentes. Durante a instalação dos equipamentos tomou-se o cuidado de estabelecer um perfeito contato entre a cápsula porosa do tensiômetro e as sondas do TDR com o solo.

\subsection{Ensaio de perfil instantâneo}

A solo da parcela experimental foi umedecido aplicando-se água por meio de irrigação por aspersão, continuamente, durante 5 dias, até os tensiômetros indicarem leitura constante. Em seguida, a superfície do solo foi coberta com uma lona plástica, satisfazendo assim a primeira condição de contorno exigida pelo método do perfil instantâneo. A partir desse momento e durante o processo de redistribuição, a umidade no solo $(\theta)$ e o potencial mátrico $\left(\phi_{\mathrm{m}}\right)$ foram monitorados pelas leituras dos TDRs e dos tensiômetros. O intervalo entre duas leituras foi inicialmente de seis horas, aumentando gradativamente até 1, depois 2 dias até o fim do experimento, quando o processo de redistribuição já 
estava muito lento. O período de duração de coleta dos dados experimentais foi de 62 dias ou 1.370 horas, entre 19 de junho e 19 de agosto de 2000.

Devido à ocorrência de variações nas leituras iniciais dos tensiômetros, com muitos pontos apresentando potencial de pressão, a escolha do período de avaliação e determinação do tempo inicial representou uma dificuldade experimental. Assim, muito embora as leituras tenham se iniciado imediatamente após a cobertura da parcela com plástico, para a discussão dos resultados, escolheu-se 78 horas como tempo inicial, tendo em vista ter sido este o tempo a partir do qual todos os tensiômetros passaram a apresentar leituras indicando potencial mátrico muito próximo de zero. O tempo final (604 horas) foi escolhido por ter sido aquele que contemplou um conjunto completo de leituras de umidade no solo $(\theta)$ e de potencial mátrico $\left(\phi_{\mathrm{m}}\right)$ antes da ocorrência de uma chuva, da qual uma parte muito pequena infiltrou e poderia alterar as condições experimentais. A Figura 4 mostra alguns aspectos do experimento de perfil instantâneo. 


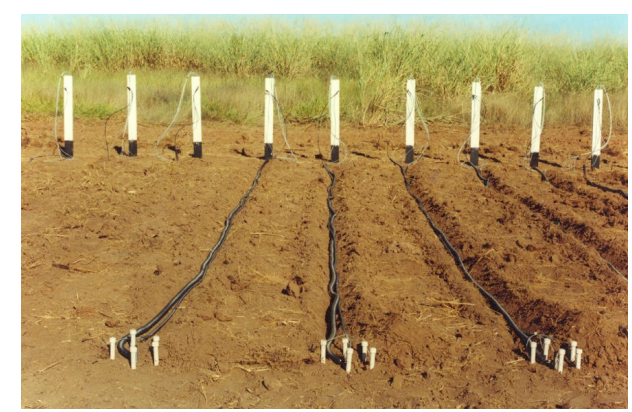

a

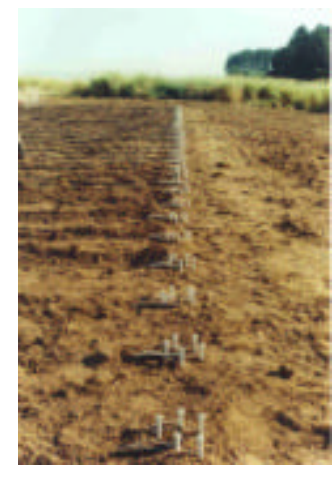

$\mathrm{c}$

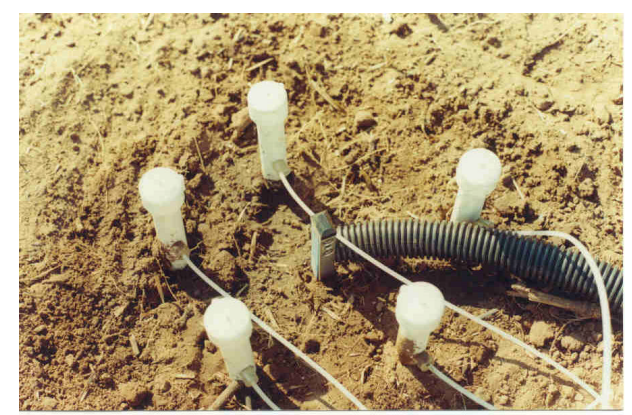

b

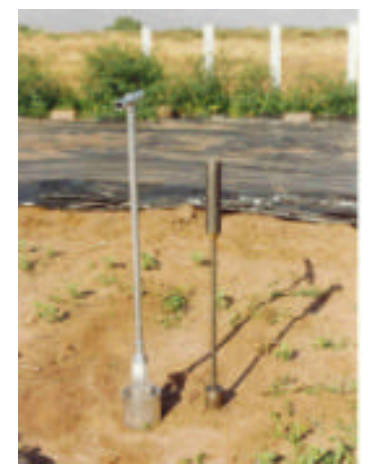

d

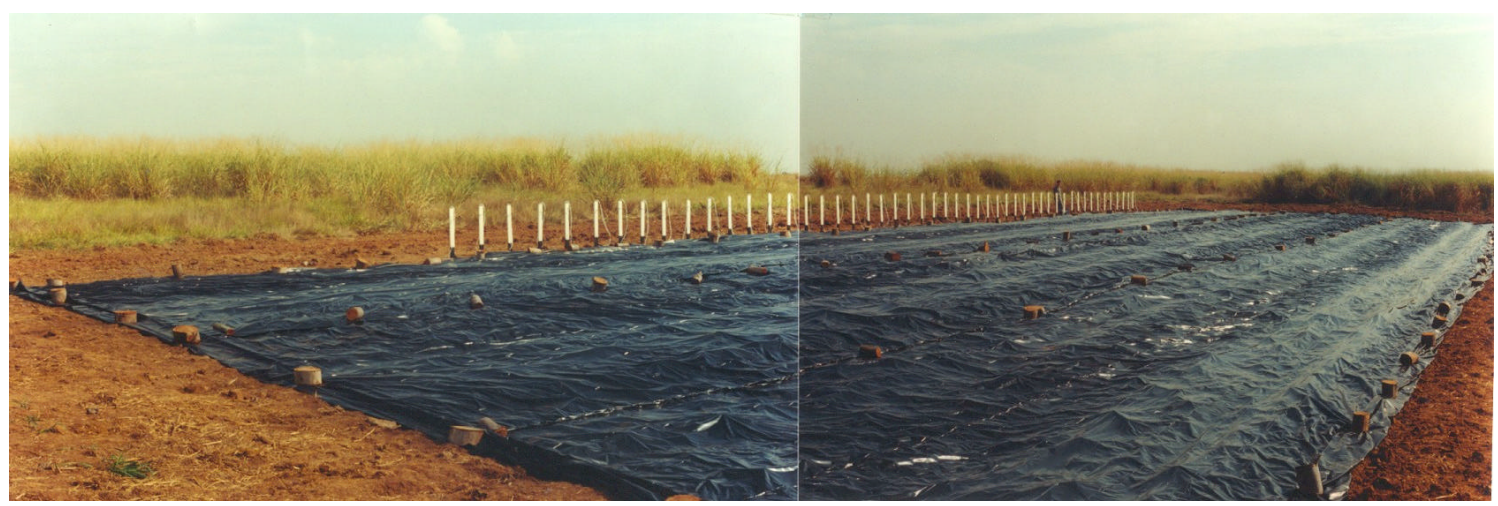

e

Figura 4 - Aspectos gerais do experimento de perfil instantâneo. a) ligação dos pontos de leitura aos manômetros, b) tensiômetros e TDR em um ponto de determinação, c) vista geral dos 50 pontos de determinação na linha central da parcela experimental, d) trados utilizados nas coletas, e) vista geral do experimento de perfil instantâneo 


\subsection{Calibração do TDR}

Terminado o ensaio de perfil instantâneo, a lona plástica foi retirada, permitindo a secagem e umedecimento do perfil do solo. Com o objetivo de estabelecer a relação entre a leitura do TDR e a correspondente umidade no solo, foram realizadas leituras de TDR e amostragem de solo por tradagem, em 14 pontos diferentes, nas mesmas profundidades das leituras dos TDRs. As amostras de solo foram utilizadas para a determinação da umidade por meio gravimétrico segundo a metodologia proposta por Kutilek \& Nielsen (1994). Foram retiradas 42 amostras por profundidade, totalizando 210 pares de leituras de TDR x umidade no solo $(\theta)$.

Para transformar a umidade gravimétrica em umidade volumétrica, também foram retiradas amostras indeformadas nas cinco profundidades. Estas amostras foram retiradas em orifícios feitos com o auxílio de um trado especialmente construído para este fim (Figura 4d). Tal equipamento possibilitou a abertura de orifícios com dimensões de $0,14 \mathrm{~m}$ de diâmetro, suficiente para a introdução de um amostrador de Uhland. Os cálculos seguiram o roteiro indicado por Hanks (1992) e Libardi (2000).

A partir do conjunto de dados de umidade volumétrica $(\theta)$ e leituras de TDR foram ajustadas equações de calibração para cada profundidade e cada ponto de observação.

\subsection{Análise computacional}


As leituras dos tensiômetros e das sondas de TDR foram processadas utilizando-se um programa de computador descrito por Jong van Lier \& Libardi (1999), cujo procedimento é apresentado a seguir:

Os valores de $\theta$ em função do tempo $(\mathrm{t}, \mathrm{h})$ são ajustados, para cada profundidade, à equação

$$
\boldsymbol{\theta}=n_{z} t^{m_{z}}
$$

em que $m_{z}$ e $n_{z}\left(h^{-m_{z}}\right)$ são os coeficientes de ajuste da eq. (28). Em função da eq. (28), tem-se que

$$
\left.\frac{\partial \Theta}{\partial t}\right|_{z}=n_{z} m_{z} t^{m_{z}-1}
$$

e, com base nessa equação, estima-se o termo $\partial h_{z} / \partial t$ da eq. (7) pela expressão

$$
\frac{\partial h_{z}}{\partial t}=\left.\sum_{i=1}^{z} z_{i} \frac{\partial \boldsymbol{\theta}}{\partial t}\right|_{i}=\sum_{i=1}^{z} z_{i} n_{i} m_{i} t^{m_{i}-1}
$$


sendo $\mathrm{z}_{\mathrm{i}}(\mathrm{m})$ a espessura da camada i. A partir da soma dos valores dos potenciais mátrico e gravitacional obtém-se o potencial total da água no solo $\left(\phi_{\mathrm{t}}, \mathrm{kPa}\right) \mathrm{em}$ cada tempo e profundidade, o qual é ajustado, para cada tempo, à equação

$$
\phi_{t}=p_{t}+q_{t} z+r_{t} z^{2}
$$

na qual $\mathrm{p}(\mathrm{kPa}), \mathrm{q}\left(\mathrm{kPa} \mathrm{m}^{-1}\right)$ e $\mathrm{r}_{\mathrm{t}}\left(\mathrm{kPa} \mathrm{m}^{-2}\right)$ são seus coeficientes de ajuste. Em função da eq. (31), tem-se que

$$
\left.\frac{\partial \phi_{t}}{\partial z}\right|_{t}=q_{t}+2 r_{t} z
$$

Por meio das equações (29) e (32) calculam-se, para cada t e z, os dois elementos do membro direito da eq. (7) obtendo o valor de $K(\theta)$ para a umidade correspondente. A partir do conjunto de pares de dados (K vs $\theta$ ) assim obtidos estimam-se os parâmetros $K_{0}$ e $\beta$ da eq. (13).

Dos cinqüenta pontos de medida instalados no campo cinco pontos foram eliminados devido à ocorrência de problemas e defeitos nas sondas de TDR e nos tensiômetros. 


\subsection{Análise estatística dos resultados}

Com o resultado da análise computacional descrita no item 3.6, gerou-se para cada profundidade, 45 valores de $\operatorname{lnK}_{\theta=0}$ e $\beta$ (eq. 8), os quais foram submetidos à análise estatística. Os valores de umidade $\theta\left(\mathrm{m}^{3} \mathrm{~m}^{-3}\right)$ resultaram das medidas indicadas pelas leituras do TDR calibradas pela correção com a umidade gravimétrica do solo. O potencial mátrico $\phi_{\mathrm{m}}(\mathrm{kPa})$ foi calculado com base na medição da altura da coluna de mercúrio para cada ponto e profundidade correspondentes, por meio da expressão (Libardi, 2000):

$$
\phi_{m}=-12,6 H+h_{c}+Z
$$

na qual, $\mathrm{H}$ é a leitura do tensiômetro, feita a partir da superfície do mercúrio na cuba; $h_{c}$ é a distância do nível de mercúrio na cuba à superfície do solo no momento da leitura e $\mathrm{Z}$ a profundidade de instalação da cápsula, todas em metros.

Para análise da variabilidade espacial dos dados de $\ln K_{\theta=0}, \beta, \theta$ e $\phi_{\mathrm{m}}$, utilizaram-se técnicas de estatística descritiva e estabilidade temporal.

As análises descritivas e exploratórias foram feitas com o objetivo de observar o comportamento geral dos dados obtidos e auxiliar no planejamento de outras análises estatísticas e seguiram as indicações de Libardi et al. (1996). Para tanto se utilizou o "software" Statistica for Windows (Stat Soft, 1993). As seguintes medidas estatísticas foram feitas: média, mediana, moda, desvio padrão, 
variância, coeficiente de variação, mínimo e máximo, amplitude total, primeiro quartil, terceiro quartil, amplitude interquartil, assimetria e curtose.

Considerando que os parâmetros que definem as principais características de um conjunto de dados também estão sujeitos a perturbações por valores atípicos, incluindo-se o estimador do método dos momentos para o semivariograma (Ribeiro Junior, 1995), Libardi et al., (1996) sugerem o uso de técnicas complementares para a verificação da adequação das medidas anteriores por meio da identificação de candidatos a "outliers" e descrição espacial do comportamento das variáveis que formam o conjunto de dados. Assim, de acordo com Libardi et al., (1996), o "limite crítico para "outliers" foi definido a partir da dispersão interquartil $(\Delta \mathrm{Q})$, segundo o qual, o limite superior é definido por $\mathrm{Q}_{3}+$ $1,5 \times \Delta \mathrm{Q}$ e o limite inferior por $\mathrm{Q}_{1}-1,5 \times \Delta \mathrm{Q}$. Depois da identificação dos "outiliers", verificou-se novamente a distribuição dos dados para confirmar se a observação discrepante realmente alterava, em algum sentido, o padrão de comportamento dos dados.

A verificação da distribuição dos dados quanto a sua normalidade foi feita com base nos coeficientes de assimetria e curtose, teste de KolmogorovSmirnov, análise visual da reta de Henry e "box-plot". Para complementar a verificação da hipótese da normalidade utilizou-se também a tabela apresentada por Jones (1969), a qual permite determinar os limites superiores e inferiores desses coeficientes, para verificação da normalidade. Neste caso o nível de significância foi de $5 \%$.

Tendo como base a equação utilizada por Santos \& Vasconcelos (1987) e Souza (1992), calculou-se o número mínimo de subamostras necessárias para estimar o valor médio representativo das propriedades avaliadas, para um nível de probabilidade de $5 \%$, nos seguintes valores de coeficiente de variação: 
5, 10, 20 e 30\% em torno da média. Segundo aqueles autores o número de amostras é dado por:

$$
n=\left(\frac{t_{\alpha} \cdot C V}{D}\right)^{2}
$$

sendo n o número mínimo de amostras para estimar o valor médio representativo de uma variável, $\mathrm{t}_{\alpha} \quad \mathrm{o}$ valor do teste $\mathrm{t}$ de Student para um determinado nível $\alpha$ de probabilidade, CV o coeficiente de variação e D a diferença desejada em torno da média, ambos expressos em percentagem.

Para os parâmetros $\beta$ e $\ln K_{\theta=0}$, a análise referente ao número de amostras foi também feita pela técnica "bootstrap" (Dane et al., 1986; Hendrickx \& Wierenga, 1990, Efron, 1992). A técnica "bootstrap" é amplamente descrita em Efron \& Tibshirani (1993) e consiste, basicamente, em um procedimento computacional intensivo de reamostragem, baseado na técnica da substituição, que possibilita estimar a distribuição amostral e estatísticas de interesse para calcular o número mínimo de amostras cuja mé dia represente uma população, sem necessidade de que o padrão de distribuição de freqüência dos dados seja normal e/ou determinado a priori. Utilizando uma rotina computacional, foram geradas, aleatoriamente e com reposição, 10.000 subamostras de tamanho $\mathrm{n}(5 \leq$ $\mathrm{n} \leq 45)$ para $\beta$ e $\operatorname{lnK}_{\theta=0}$ nas profundidades 0,$30 ; 0,45$ e $0,60 \mathrm{~m}$. Para cada subamostragem calcularam-se a média e a variância. Seguindo o procedimento sugerido por Dane et al. (1986) estimou-se o número de amostras (valores de $\beta$ e $\left.\ln K_{\theta=0}\right) \quad \operatorname{com} 5,10,20,30$ e $50 \%$ de variação em torno da média e, então o 
número mínimo de amostras para cada "n" correspondente à fração $F=0,9$ das 10.000 subamostragens (Hendrickx \& Wierenga, 1990).

Aplicou-se o procedimento sugerido por Vachaud et al. (1985), para identificar quais e quantos são os locais adequados para o monitoramento, com precisão aceitável e reduzido esforço amostral, da umidade e do potencial mátrico do solo. Para tanto, foram selecionados doze tempos de redistribuição, correspondentes ao período de avaliação experimental entre 78 e 604 horas no experimento de perfil instantâneo. Primeiramente calcularam-se os coeficientes de correlação de Spearman (SAS, 1991). O teste não paramétrico de Spearman é um procedimento eficiente que possibilita calcular o grau de dependência entre duas variáveis aleatórias. Um valor de $r$ igual à unidade corresponderá à igualdade de posição para qualquer local ou estabilidade perfeita entre duas datas ou tempos. Quanto mais próximo de 1 for o $\mathrm{r}$ mais estável será o processo (Campos, 1983; Vachaud et al., 1985). Na seqüência calcularam-se as diferenças relativas e seus desvios padrões. Os resultados foram analisados com base em um gráfico que possibilitou a identificação dos locais cujos valores sempre estiveram próximos da média de cada variável em qualquer tempo (Vachaud et al., 1985; Turatti \& Reichardt, 1991; Gonçalves et al., 1999). 


\section{RESULTADOS E DISCUSSÃO}

\subsection{Estatística descritiva e análise exploratória dos dados}

Informações de literatura (Hamlett et al., 1986; Libardi et al., 1996) indicam que um conjunto de dados deve ser avaliado por uma estatística descritiva, para se obter a primeira e fundamental idéia sobre o comportamento do fenômeno em estudo. Tal procedimento deve ser realizado tendo como base os princípios da estatística clássica, cujo resumo estatístico fornece as informações das medidas de posição, dispersão e forma da distribuição de frequiência para verificação da normalidade dos dados. Considerando que os parâmetros que definem as principais características de um conjunto de dados também estão sujeitos a perturbações por valores atípicos, Libardi et al., (1996) sugerem o uso de técnicas complementares para a verificação da adequação das medidas anteriores por meio da identificação de candidatos a "outliers" e descrição espacial do comportamento das variáveis que formam o conjunto de dados.

A identificação de dados extremos ou discordantes, também referidos como "outliers" é tão antiga quanto à aplicação dos conceitos da própria estatística. Seus efeitos para a análise de um conjunto de dados e os procedimentos para tratá-los de forma metodologicamente adequada foram 
relatados pela primeira vez no século dezenove. Realmente, recomenda-se a aplicação de procedimentos para identificar a existência de dados discrepantes antes de ser testada qualquer outra hipótese, pois a sua presença afetará os resultados de todos os testes estatísticos formais que utilizam resíduos, incluindo os de avaliação da variabilidade e normalidade (Ribeiro Junior, 1995). Muito embora na pesquisa cientifica não seja comum considerar a presença de "outliers", existem diversos métodos e critérios para sua detecção (Czermainski, 1986). Dentre estes, escolhemos aquele descrito por Libardi et al. (1996).

\subsubsection{Umidade do solo $(\theta)$}

Os resultados que constam da Tabela 1, mostram que as médias dos valores de umidade estiveram muito próximas durante o período do estudo para as três profundidades avaliadas, indicando que: a) o sistema de saturação inicial do solo foi eficiente e proporcionou uma adequada distribuição da água em todo o perfil da parcela experimental, garantindo as condições de homogeneidade desejadas para um experimento dessa natureza e b) o processo de redistribuição e secagem se deu de forma aproximadamente uniforme em todo o período de avaliação. Os maiores valores de umidade no início da avaliação foram 0,$27 ; 0,26$ e $0,27 \mathrm{~m} \mathrm{~m}^{3}$ para as profundidades 0,$30 ; 0,45$ e $0,60 \mathrm{~m}$, respectivamente. No final deste estudo (604 horas) esses valores alcançaram conteúdos mínimos de água no solo de 0,$19 ; 0,18$ e $0,18 \mathrm{~m}^{3} \mathrm{~m}^{-3}$ para as mesmas três profundidades. A Figura 5, representa graficamente a variação da umidade média $(\theta)$ em função do tempo para as três profundidades. A homogeneidade da umidade na área experimental é confirmada pelos baixos coeficientes de variação apresentados 
pelas três profundidades estudadas. Muito embora tenham sido baixos (4 a 6\%), os valores dos coeficientes de variação indicam uma tendência de aumento da variabilidade da umidade com o tempo para as profundidades $0,30 \mathrm{~m}$ e $0,45 \mathrm{~m}$, na qual este fenômeno se manifestou mais claramente, confirmando os resultados que indicam aumento da variabilidade dos teores de água no solo à medida que ocorre a secagem (Hendrickx \& Wierenga, 1990). Na profundidade 0,60 m não houve alteração da variabilidade com o tempo.

A proximidade entre os valores da média e mediana sinaliza que a umidade do solo apresenta distribuição aproximadamente simétrica para todas as profundidades. Mas, em se tratando de medidas de posição e de dispersão, é recomendado, para sua correta definição, que se observe mais de um parâmetro de estatística descritiva (Libardi et al., 1996). Assim, seguindo os critérios definidos por Jones (1969), ao nível de 5\% de probabilidade, os coeficientes de assimetria e curtose indicam que a umidade seguiu uma distribuição normal para os quatro tempos de avaliação nas três profundidades. Para complementar esta avaliação, observou-se o formato da distribuição dos dados por meio dos gráficos de dispersão e reta de Henry. Com o mesmo objetivo aplicou-se o teste de Kolmogorov-Smirnov (K-S). As Figuras 6 e 7, ilustram este procedimento para os valores de umidade nas três profundidades e nos tempos inicial e final. 
Tabela 1. Resumo estatístico para umidade do solo $\left(\mathrm{m}^{3} \mathrm{~m}^{-3}\right)$ em três profundidades e quatro tempos de amostragem, segundo uma transeção de 45 pontos espaçados de um metro.

\begin{tabular}{|c|c|c|c|c|c|c|c|c|}
\hline $\begin{array}{c}\text { Tempo } \\
\text { (h) }\end{array}$ & Média & Mediana & $\begin{array}{l}\text { Desvio } \\
\text { padrão }\end{array}$ & $\begin{array}{c}\text { C.V. } \\
\%\end{array}$ & Min & Max & Assi & Curt \\
\hline \multicolumn{9}{|c|}{$0,30 \mathrm{~m}$} \\
\hline 78 & 0,25 & 0,25 & 0,011 & 4,44 & 0,23 & 0,27 & $-0,30$ & $-0,78$ \\
\hline 220 & 0,23 & 0,24 & 0,012 & 5,22 & 0,20 & 0,25 & $-0,55$ & 0,11 \\
\hline 460 & 0,22 & 0,22 & 0,012 & 5,45 & 0,20 & 0,25 & 0,23 & $-0,51$ \\
\hline 604 & 0,21 & 0,22 & 0,010 & 4,76 & 0,19 & 0,24 & 0,32 & 0,07 \\
\hline \multicolumn{9}{|c|}{$0,45 \mathrm{~m}$} \\
\hline 78 & 0,24 & 0,24 & 0,009 & 3,75 & 0,21 & 0,26 & $-0,39$ & 0,45 \\
\hline 220 & 0,23 & 0,23 & 0,010 & 4,35 & 0,20 & 0,25 & $-0,47$ & 0,90 \\
\hline 460 & 0,21 & 0,21 & 0,009 & 4,29 & 0,19 & 0,23 & $-0,03$ & 0,06 \\
\hline 604 & 0,21 & 0,21 & 0,010 & 4,76 & 0,18 & 0,23 & $-0,07$ & 0,85 \\
\hline \multicolumn{9}{|c|}{$0,60 \mathrm{~m}$} \\
\hline 78 & 0,24 & 0,24 & 0,014 & 5,83 & 0,20 & 0,27 & $-0,11$ & 0,33 \\
\hline 220 & 0,23 & 0,23 & 0,014 & 6,09 & 0,19 & 0,26 & $-0,57$ & 1,05 \\
\hline 460 & 0,22 & 0,22 & 0,013 & 5,91 & 0,18 & 0,24 & $-0,76$ & 0,89 \\
\hline 604 & 0,21 & 0,22 & 0,013 & 6,19 & 0,18 & 0,25 & $-0,28$ & 0,65 \\
\hline
\end{tabular}



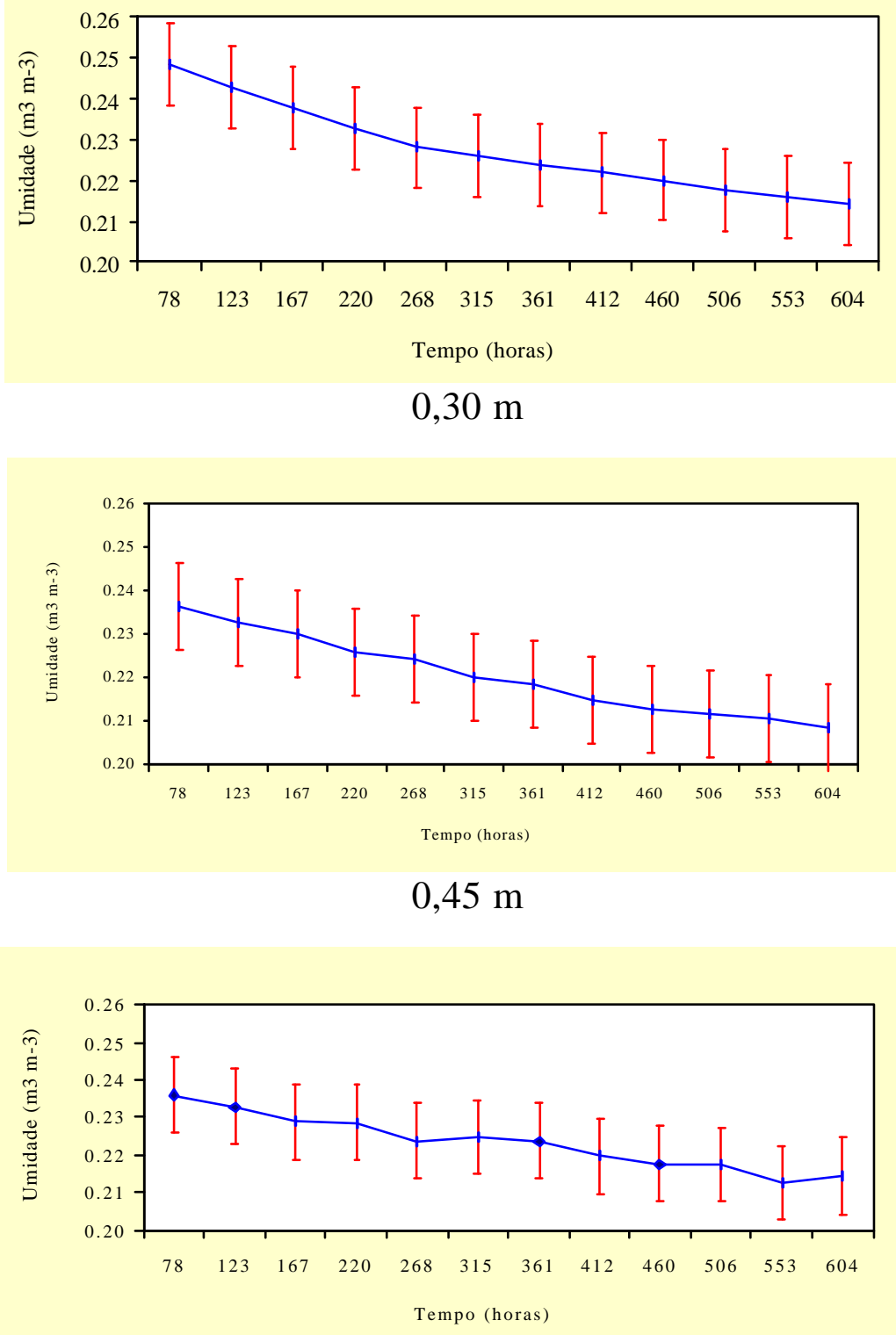

$0,60 \mathrm{~m}$

Figura 5 - Conteúdo médio de água $\left(\mathrm{m}^{3} \mathrm{~m}^{-3}\right)$ em função do tempo (horas) para três profundidades, durante $\mathrm{o}$ período de coleta de dados e redistribuição (78 a 604 horas). Barras verticais representam o desvio padrão médio para cada medida. 
O teste K-S indicou normalidade do conjunto de dados de umidade para todas as três profundidades nos quatro tempos de avaliação, fato confirmado pela distribuição equilibrada dos pontos em torno das retas normais, nas quais a presença de pontos mais afastados ocorreu apenas nas extremidades, sem contudo afetar a distribuição.

O gráfico "box-plot", que é definido pelo resumo dos cinco números, menor valor $\left(\mathrm{X}_{\text {menor }}\right)$, primeiro quartil $\left(\mathrm{Q}_{1}\right)$, mediana, terceiro quartil $\left(Q_{3}\right)$ e maior valor $\left(X_{\text {maior }}\right)$, oferece a representação gráfica do conjunto de dados, possibilitando a identificação visual da distribuição e os efeitos dos valores discrepantes na simetria da distribuição. Tal gráfico, para os dados de umidade para as três profundidades no tempo inicial e final, encontra-se ilustrado na Figura 8. Examinado-o percebe-se a simetria e o aumento da dispersão dos valores de umidades em profundidade, confirmando as indicações resultantes das técnicas anteriores utilizadas para a interpretação dos dados.

De acordo com os critérios definidos em Libardi et al. (1996) foram calculados os limites, inferior e superior, para identificação de "outliers", cujos resultados constam da Tabela 2. Para umidade do solo $\theta$ não foram identificados valores extremos. Este fato decorre, certamente, da uniformidade do processo de secagem durante o experimento, definindo uma tendência de continuidade espacial para esta variável, apesar do aumento da amplitude e do coeficiente de variação dos seus teores ao longo do tempo nas três profundidades. 

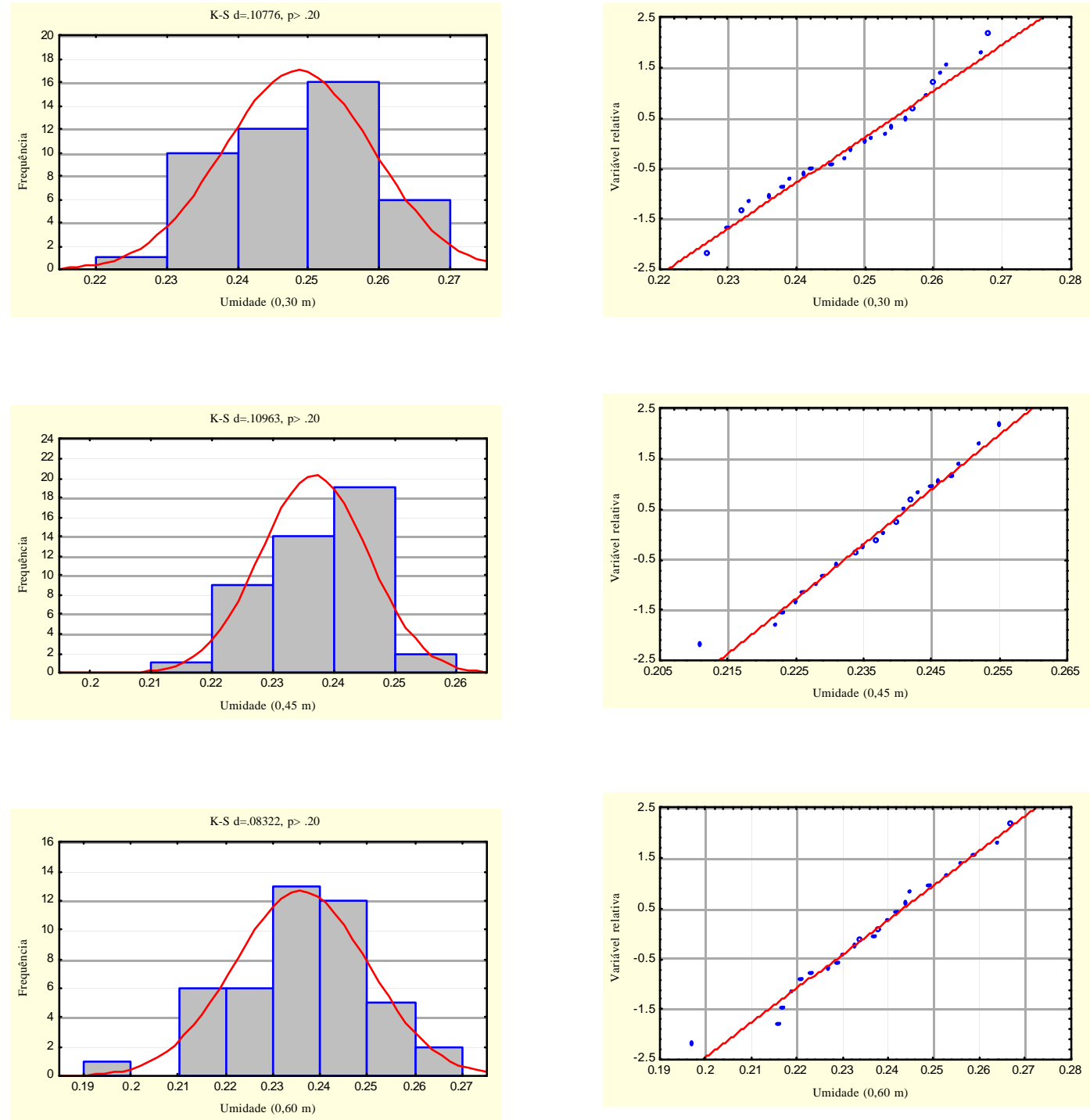

Figura 6 - Histogramas de freqüência, teste de Kolmogorov - Smirnov (K-S) e retas de probabilidade de Henry, para umidade $\theta\left(\mathrm{m}^{3} \mathrm{~m}^{-3}\right)$, para três profundidades e no tempo inicial (78 horas). 

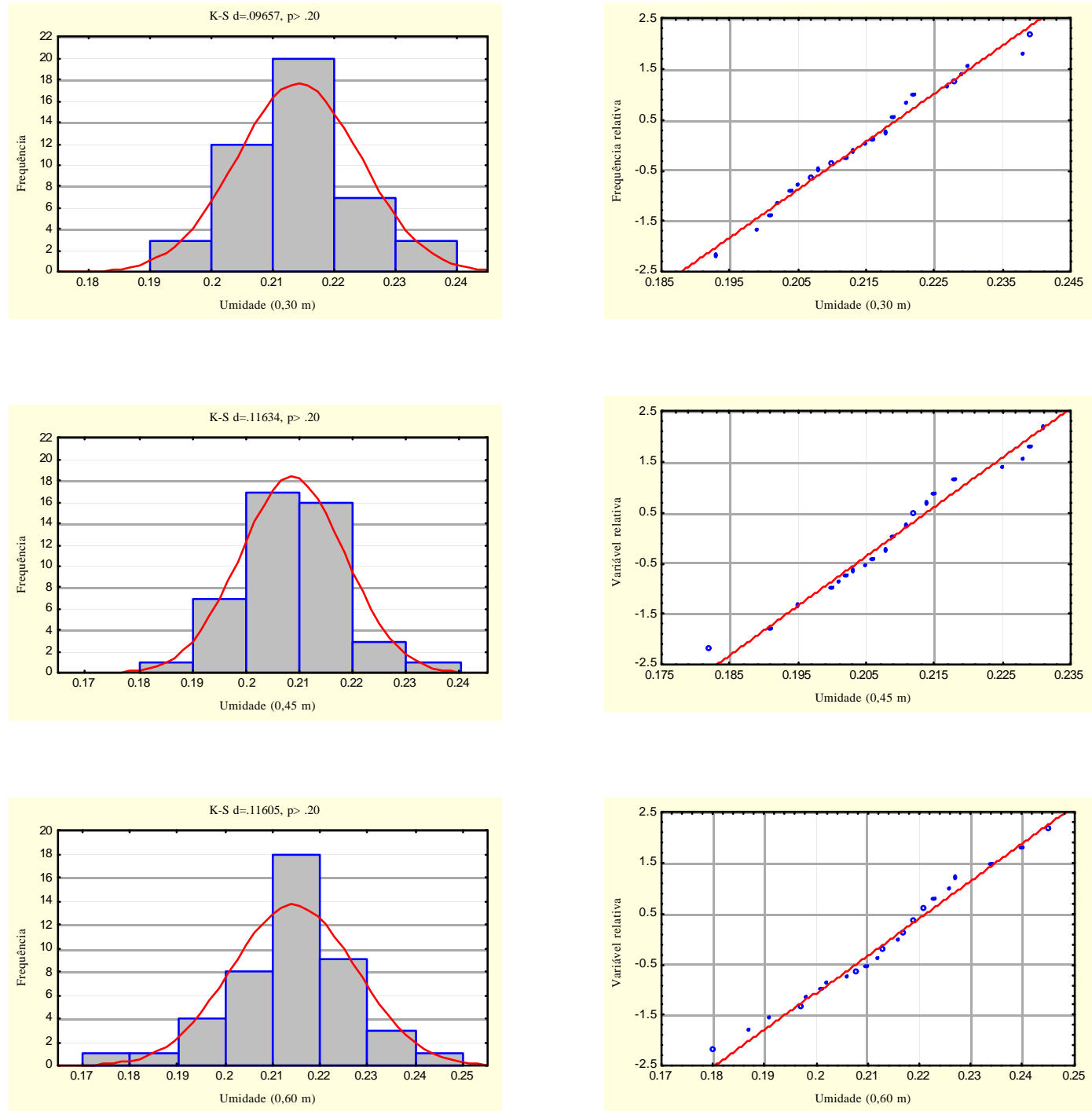

Figura 7 - Histogramas de frequiência, teste de Kolmogorov - Smirnov (K-S) e retas de probabilidade de Henry, para umidade $\theta\left(\mathrm{m}^{3} \mathrm{~m}^{-3}\right)$, para três profundidades e no tempo final (604 horas). 


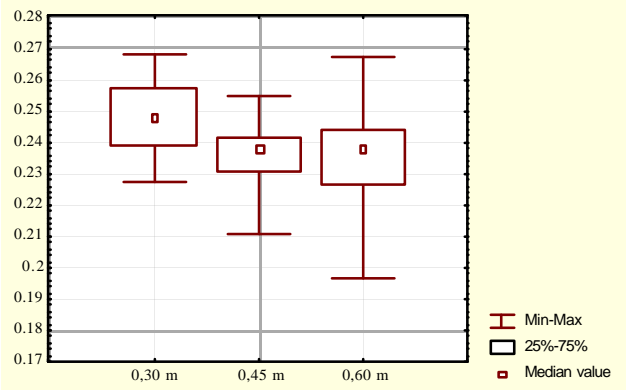

Tempo inicial

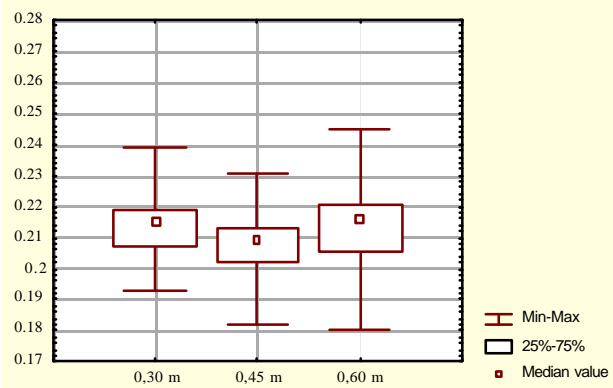

Tempo final

Figura 8 - Gráfico "box-plot" para umidade $\theta\left(\mathrm{m}^{3} \mathrm{~m}^{-3}\right)$, para três profundidades, no tempo inicial (78 horas) e final (604 horas). 
Tabela 2. Limite inferior e superior para identificação de valores candidatos a "outliers" para umidade do solo $\theta\left(\mathrm{m}^{3} \mathrm{~m}^{-3}\right)$ em três profundidades e quatro tempos de amostragem, segundo uma transeção de 45 pontos espaçados de um metro.

\begin{tabular}{cccccc}
\hline Tempo (h) & $1^{\circ}$ Quartil & $3^{\circ}$ Quartil & Limite inf. & Limite sup. “Outliers" \\
\hline 78 & 0,24 & 0,26 & 0,21 & 0,28 & Não \\
220 & 0,22 & 0,24 & 0,20 & 0,27 & Não \\
460 & 0,21 & 0,23 & 0,18 & 0,26 & Não \\
604 & 0,21 & 0,22 & 0,19 & 0,24 & Não \\
& & & $0,45 \mathrm{~m}$ & \\
78 & 0,23 & 0,24 & 0,22 & 0,26 & Não \\
220 & 0,22 & 0,23 & 0,21 & 0,25 & Não \\
460 & 0,21 & 0,22 & 0,19 & 0,24 & Não \\
604 & 0,20 & 0,21 & 0,19 & 0,23 & Não \\
& & & $0,60 \mathrm{~m}$ & & \\
78 & 0,23 & 0,24 & 0,20 & 0,27 & Não \\
220 & 0,22 & 0,24 & 0,20 & 0,25 & Não \\
460 & 0,21 & 0,23 & 0,18 & 0,26 & Não \\
604 & 0,21 & 0,22 & 0,18 & 0,24 & Não \\
\hline
\end{tabular}

Considerando a comprovação da normalidade e assumindo a independência dos dados, pode-se, pela eq. (34), calcular o número de amostras para representar adequadamente a umidade o solo. 
Tabela 3. Número de amostras necessárias para estimar o valor médio da umidade $\theta\left(\mathrm{m}^{3} \mathrm{~m}^{-3}\right)$ em três profundidades para quatro níveis de variação permitida, considerando $t_{10 \%}$.

\begin{tabular}{ccccc}
\hline & \multicolumn{4}{c}{ Variação permitida em torno da média } \\
\cline { 2 - 5 } Tempo (h) & $5 \%$ & $10 \%$ & $20 \%$ & $30 \%$ \\
\hline 78 & 2 & $0,30 \mathrm{~m}$ & 1 \\
220 & 3 & 1 & 1 & 1 \\
460 & 3 & 1 & 1 & 1 \\
604 & 3 & 1 & 1 & 1 \\
& & 1 & 1 & \\
78 & 2 & 1 & 1 & 1 \\
220 & 2 & 1 & 1 & 1 \\
460 & 2 & 1 & 1 & 1 \\
604 & 2 & 1 & 1 & 1 \\
& 4 & 1 & 1 & 1 \\
78 & 4 & 1 & 1 & 1 \\
220 & 4 & 1 & 1 & 1 \\
460 & 4 & & 1 & 1 \\
604 & & 1 & & 1 \\
\hline
\end{tabular}

Os resultados, que estão na Tabela 3, mostram que o número de amostras necessárias para estimar a umidade do solo é pequeno, sendo maior que a unidade apenas para o nível de variação permitida de 5\%. Neste nível percebese um incremento do número de amostras com a profundidade, logicamente como 
resultado do aumento do coeficiente de variação no mesmo sentido, tendo em vista a relação direta entre os parâmetros, número de amostras e coeficiente de variação.

\subsubsection{Potencial mátrico $\left(\phi_{\mathrm{m}}\right)$}

Em estudos de potencial mátrico da solução no solo existem muitas fontes de erros que contribuem para a variabilidade das leituras dos tensiômetros. São erros relacionados aos equipamentos, instalação no campo e coleta dos dados, cuja magnitude é bem reduzida, devido aos cuidados experimentais que são tomados nestes casos. Assim, a variância total das medidas de potencial mátrico é devida, quase que exclusivamente, à variabilidade das propriedades do solo (Souza et al, 1979; Villagra, 1988). Considerando que, neste experimento, todos os cuidados para uniformização das medidas e minimização dos erros experimentais foram tomados, estamos assumindo que a variabilidade apresentada pelo conjunto de dados relativos aos valores de potencial mátrico é decorrente apenas das características do solo.

Os valores de potencial mátrico, em $\mathrm{kPa}$, resultantes das medidas nos 45 pontos nas três profundidades estão sumarizados na Tabela 4. Analisandoa verifica-se que, em geral, os valores médios do potencial má trico para as três profundidades foram diferentes e tornaram-se mais negativos ao longo do tempo. Sabendo-se que são parâmetros hídricos diretamente relacionados (Libardi, 2000), espera-se que o padrão de comportamento do potencial mátrico siga o mesmo da umidade, ou seja, tanto menor ou mais negativo quanto mais seco estiver o solo. Esta tendência foi mantida. Porém, enquanto a amplitude de 
variação para a umidade foi muito uniforme ao longo do tempo e se manteve na faixa de 1,2 a 1,3 vezes, para o potencial mátrico a mesma relação foi muito irregular e variou de 2 até 26 vezes, indicando ser este um parâmetro com maior grau de dispersão que a umidade do solo.

Tabela 4. Resumo estatístico para valores de potencial mátrico $\phi_{\mathrm{m}}(\mathrm{kPa})$ em três profundidades e quatro tempos de amostragem, segundo uma transeção de 45 pontos espaçados de um metro.

\begin{tabular}{lcccccccc}
\hline $\begin{array}{c}\text { Tempo } \\
(\mathrm{h})\end{array}$ & Média & Mediana & $\begin{array}{c}\text { Desvio } \\
\text { padrão }\end{array}$ & $\begin{array}{c}\text { C.V. } \\
\%\end{array}$ & Min & Max & Assi & Curt \\
\hline \multicolumn{7}{c}{$0,30 \mathrm{~m}$} \\
78 & $-1,25$ & $-1,19$ & 0,46 & 37,80 & $-2,41$ & $-0,36$ & $-0,39$ & $-0,33$ \\
220 & $-2,39$ & $-2,44$ & 0,43 & 17,99 & $-3,41$ & $-1,65$ & $-0,12$ & $-0,72$ \\
460 & $-3,79$ & $-3,73$ & 0,47 & 12,40 & $-5,23$ & $-2,94$ & $-0,51$ & 0,78 \\
604 & $-4,31$ & $-4,36$ & 0,48 & 11,14 & $-5,16$ & $-2,52$ & 1,19 & 3,22 \\
& & & $0,45 \mathrm{~m}$ & & & & \\
78 & $-0,49$ & $-0,41$ & 0,39 & 79,59 & $-1,41$ & 0,00 & $-0,58$ & $-0,71$ \\
220 & $-1,68$ & $-1,66$ & 0,57 & 33,93 & $-2,66$ & 0,00 & 0,52 & 0,60 \\
460 & $-3,13$ & $-3,20$ & 0,80 & 25,56 & $-4,58$ & $-0,71$ & 0,84 & 1,23 \\
604 & $-3,62$ & $-3,70$ & 0,78 & 21,55 & $-4,87$ & $-1,45$ & 0,83 & 0,73 \\
& & & 0,60 & & & & & \\
78 & $-0,52$ & $-0,44$ & 0,49 & 94,23 & $-2,04$ & 0,00 & $-1,09$ & 0,98 \\
220 & $-1,24$ & $-1,30$ & 0,64 & 51,61 & $-2,55$ & 0,00 & 0,21 & $-0,71$ \\
460 & $-2,51$ & $-2,57$ & 0,72 & 28,69 & $-3,71$ & $-0,70$ & 0,33 & $-0,58$ \\
604 & $-3,08$ & $-3,09$ & 0,71 & 23,05 & $-4,33$ & $-1,80$ & 0,11 & $-0,98$ \\
\hline
\end{tabular}


O desvio padrão é uma medida que reflete o modo da dispersão de um conjunto de dados numéricos. Analisando-se os valores dos desvios padrão para o potencial mátrico, percebe-se dois tipos de comportamento. O primeiro tipo ocorre na profundidade $0,30 \mathrm{~m}$, na qual o grau de variabilidade das medidas manteve-se aproximadamente constante com o tempo. A explicação para este fato está na faixa de umidade que predominou no experimento (faixa úmida). Realmente o desvio padrão do potencial mátrico depende da umidade do solo no momento da medida. Quando o solo está secando ocorrem três zonas bem definidas de comportamento para a relação umidade versus potencial mátrico. Quando a medida é feita tanto na faixa mais úmida quanto na mais seca é muito comum ocorrer baixa variabilidade de potencial mátrico durante o processo. (Hendrickx et al., 1990). Pode ser também que, ao longo da transeção dos 45 pontos existam segmentos homogêneos, cuja identificação e comportamento não tenham sido revelados pela técnica estatística usada para analisar os dados. É possível que a utilização de outros procedimentos estatísticos, mais robustos, tipo janelas móveis (Hendrickx et al.,1990; 1986; Webster, 1978) permitam identificar essas zonas homogêneas ao longo da transeção, quantificando as características de suas propriedades, que podem ser significativamente diferentes entre si, tornando a técnica que os trata como iguais, ineficiente e deturpando os resultados.

O segundo tipo de comportamento ocorreu nas profundidades $0,45 \mathrm{e}$ 0,60 m, nas quais houve um aumento bem definido do desvio padrão dos valores de potencial mátrico à medida que o solo secou. Essa tendência também foi encontrada por Hendrickx et al.(1990) e Yeh (1985).

Considerando que a umidade do solo foi uniforme em todo o perfil, era de se esperar que as três camadas apresentassem o mesmo padrão de 
variabilidade quanto ao potencial mátrico, o que não ocorreu. Tais resultados indicam que a variabilidade das medidas de potencial mátrico resultou, principalmente, da heterogeneidade vertical do solo e que existe uma sensibilidade muito grande, definida por uma relação não linear, entre estes parâmetros hídricos, mesmo na faixa mais úmida de conteúdo de água no solo.

Para os resultados deste experimento, a utilização do coeficiente de variação como parâmetro descritivo da variabilidade do potencial mátrico precisa ser feita com muito critério. Diferentemente do desvio padrão, o coeficiente de variação indica uma redução da variabilidade com o tempo nas três profundidades. Certamente este é um comportamento não relacionado com o fenômeno e ocorreu devido ao aumento, em módulo, dos valores de potencial mátrico, o que é normal e experimentalmente correto. Desta forma, a relação matemática entre estes índices resultou na redução dos valores do coeficiente de variação. Neste caso, o desvio padrão é o parâmetro estatístico que melhor descreve o comportamento do potencial mátrico, enquanto que o coeficiente de variação deverá ser utilizado para caracterizá-lo de forma geral, apenas classificando-o quanto ao seu grau de variabilidade. Assim, de acordo com os critérios de Warrick \& Nielsen (1980), vê-se que os valores do coeficiente de variação do potencial mátrico atingiram todos os níveis de variação (baixo, médio e alto). No início do experimento o coeficiente de variação foi médio na profundidade $0,30 \mathrm{~m}$ e alto nas profundidades 0,45 e 0,60 m. Com o tempo evoluiu para médio e manteve-se assim nas três profundidades até o tempo final da análise (Tabela 4).

Comparando-se a variabilidade em profundidade, nota-se que o comportamento do potencial mátrico diferiu daqueles normalmente encontrados na literatura. Geralmente as maiores variabilidades são encontradas nas camadas 
mais superficiais (Hendrick et al., 1990; Babalola, 1978, Nielsen et al., 1973). Aqui, a variabilidade na profundidade mais externa $(0,30 \mathrm{~m})$ foi sempre menor em relação às mais internas $(0,45$ e $0,60 \mathrm{~m})$. A ocorrência destes resultados, longe de ser um problema experimental, indica a necessidade de estudos mais detalhados que possam melhorar o entendimento das causas de variação quantificando principalmente aquelas relativas ao solo.

Os valores da média e mediana (Tabela 4) apresentam-se um pouco diferentes, indicando um certo grau de assimetria na distribuição dos dados, contudo sem afetar a normalidade da distribuição, mesmo para os casos em que a média e a mediana estiveram afastadas. De acordo com os critérios definidos por Jones (1969), ao nível de 5\% de probabilidade, os coeficientes de assimetria e curtose indicam que a distribuição dos valores do potencial mátrico apresentou o seguinte comportamento: $\mathrm{Na}$ profundidade $0,30 \mathrm{~m}$ a distribuição foi normal no início do experimento, 78 horas, passando a não normal no tempo 604 horas. $\mathrm{Na}$ profundidade $0,45 \mathrm{~m}$ os valores tiveram o mesmo comportamento $\mathrm{e}$ apresentaram-se fora da normalidade nos tempos 460 e 604 horas. Na profundidade $0,60 \mathrm{~m}$ a verificação da normalidade, segundo Jones (1969), indicou que os dados do tempo 78 horas não foram normais. Analisando-se estes resultados com base nas Tabelas 4 e 5, percebe-se que a presença de "outliers" afetou, de alguma forma, a verificação da normalidade pelos índices de Jones (1969), tendo em vista a coincidência entre presença de valores extremos e não normalidade. Para comprovar tal conclusão aplicou-se o mesmo método para verificação da normalidade para os dados de potencial mátrico sem os "outliers", cujo resumo estatístico para este procedimento encontra-se na Tabela 6.

Os resultados da Tabela 6 , mostram que: na profundidade $0,30 \mathrm{~m} \mathrm{e}$ no tempo 460 horas a retirada do valor extremo praticamente não afetou a média 
e a mediana, reduziu o coeficiente de variação e tornou a distribuição perfeitamente assimétrica. No tempo 604 horas, com a retirada do valor extremo, a média e a mediana ficaram mais próximas, o coeficiente de variação foi reduzido e melhorou muito o índice de assimetria, tornando os dados normais. Para a profundidade $0,45 \mathrm{~m}$, a retirada dos valores extremos, apesar de ter reduzido tanto a média quanto à mediana, não aproximou o valor desses parâmetros. No entanto, o coeficiente de variação e a assimetria foram reduzidos, melhorando sua distribuição. Na profundidade $0,60 \mathrm{~m}$ houve uma significativa redução do valor da média e sua conseqüente aproximação da mediana. O coeficiente de variação e a assimetria também foram afetados. Em ambos os casos houve redução do seu valor, sendo bem acentuada para o coeficiente de assimetria, cujo valor passou de - 1,09 para - 0,82. 
Tabela 5. Limite inferior e superior para identificação de valores candidatos a "outliers" para potencial mátrico $(\mathrm{kPa})$ em três profundidades e quatro tempos de amostragem, segundo uma transeção de 45 pontos espaçados de um metro.

\begin{tabular}{lccccc}
\hline \multicolumn{1}{c}{$\begin{array}{c}\text { Tempo } \\
(\mathrm{h})\end{array}$} & $1^{\mathrm{o}}$ Quartil & $3^{\text {o }}$ Quartil & Limite inf. & Limite sup. & "Outliers" \\
\hline \multicolumn{5}{c}{$0,30 \mathrm{~m}$} \\
78 & $-1,66$ & $-0,92$ & $-2,77$ & 0,19 & Não \\
220 & $-2,78$ & $-2,08$ & $-3,83$ & $-1,03$ & Não \\
460 & $-4,11$ & $-3,48$ & $-5,06$ & $-2,54$ & Sim (1) \\
604 & $-4,66$ & $-4,16$ & $-5,42$ & $-3,40$ & Sim (1) \\
& & & $0,45 \mathrm{~m}$ & & \\
78 & -086 & $-1,95$ & $-1,86$ & 0,80 & Não \\
220 & $-2,21$ & $-1,40$ & $-3,43$ & $-0,17$ & Sim (1) \\
460 & $-3,78$ & $-2,79$ & $-5,27$ & $-1,29$ & Sim (2) \\
604 & $-4,35$ & $-3,23$ & $-6,03$ & $-1,55$ & Sim (1) \\
& & & $0,60 \mathrm{~m}$ & & \\
78 & $-0,86$ & $-0,09$ & $-2,02$ & 1,08 & Sim (1) \\
220 & $-1,78$ & $-0,85$ & $-3,18$ & 0,56 & Não \\
460 & $-3,19$ & $-1,97$ & $-5,03$ & $-0,13$ & Não \\
604 & $-3,63$ & $-2,62$ & $-5,15$ & $-1,11$ & Não \\
\hline
\end{tabular}

* Valores entre parênteses indicam o número de candidatos a "outliers".

Aplicando-se a metodologia de Jones (1969), para verificação da normalidade dos dados após a retirada dos valores extremos, nota-se que, com exceção do tempo 78 horas da profundidade $0,60 \mathrm{~m}$, todos os outros casos 
passaram a ter distribuição normal após a retirada dos valores extremos. Estes resultados confirmam a influência dos valores extremos na distribuição e a importância de sua eliminação para a análise de um conjunto de dados, tendo em vista que a retirada de apenas um valor extremo resultou na modificação da distribuição para a maioria dos casos estudados. Indica também a sensibilidade da metodologia proposta por Jones (1969) a presenças desses valores extremos.

Tabela 6. Resumo estatístico para valores de potencial mátrico $(\mathrm{kPa})$ apenas nas profundidades e nos tempos de amostragem em que foram identificados e após a retirada dos "outliers".

\begin{tabular}{|c|c|c|c|c|c|c|c|c|}
\hline $\begin{array}{c}\text { Tempo } \\
\text { (h) }\end{array}$ & Média & Mediana & $\begin{array}{l}\text { Desvio } \\
\text { padrão }\end{array}$ & $\begin{array}{c}\text { C.V. } \\
\%\end{array}$ & Min & Max & Assi & Curt \\
\hline \multicolumn{9}{|c|}{$0,30 \mathrm{~m}$} \\
\hline 460 & $-3,75$ & $-3,71$ & 0,42 & 11,20 & $-4,78$ & $-2,94$ & 0,00 & $-0,51$ \\
\hline 604 & $-4,35$ & $-4,36$ & 0,48 & 11,03 & $-5,16$ & $-3,44$ & 0,23 & $-0,23$ \\
\hline \multicolumn{9}{|c|}{$0,45 \mathrm{~m}$} \\
\hline 220 & $-1,72$ & $-1,68$ & 0,52 & 30,23 & $-2,66$ & $-0,48$ & 0,12 & $-0,36$ \\
\hline 460 & $-3,19$ & $-3,21$ & 0,72 & 22,57 & $-4,58$ & $-1,22$ & 0,49 & 0,48 \\
\hline 604 & $-3,67$ & $-3,73$ & 0,71 & 19,35 & $-4,87$ & $-1,85$ & 0,64 & 0,39 \\
\hline \multicolumn{9}{|c|}{$0,60 \mathrm{~m}$} \\
\hline 78 & $-0,48$ & $-0,43$ & 0,44 & 91,67 & $-1,59$ & 0,00 & $-0,82$ & 0,02 \\
\hline
\end{tabular}

Para complementar a avaliação dos padrões de distribuição, observou-se o formato da distribuição dos dados pelos dos gráficos de dispersão e reta de Henry. Com o mesmo objetivo aplicou-se o teste de Kolmogorov-Smirnov 
(K-S). Os gráficos que mostram a dispersão dos dados de potencial mátrico estão representados na Figura 9 para o tempo inicial e na Figura 10 para o tempo final.

O teste K-S indicou normalidade do conjunto de dados de potencial mátrico para todas as três profundidades nos dois tempos de avaliação, quais sejam 78 e 604 horas. Este resultado é confirmado pela distribuição equilibrada dos pontos em torno da reta normal, nas quais a presença de pontos mais afastados ocorre apenas nas extremidades das retas, indicando a possível presença de valores mais afastados da média, sem contudo afetar a distribuição. 

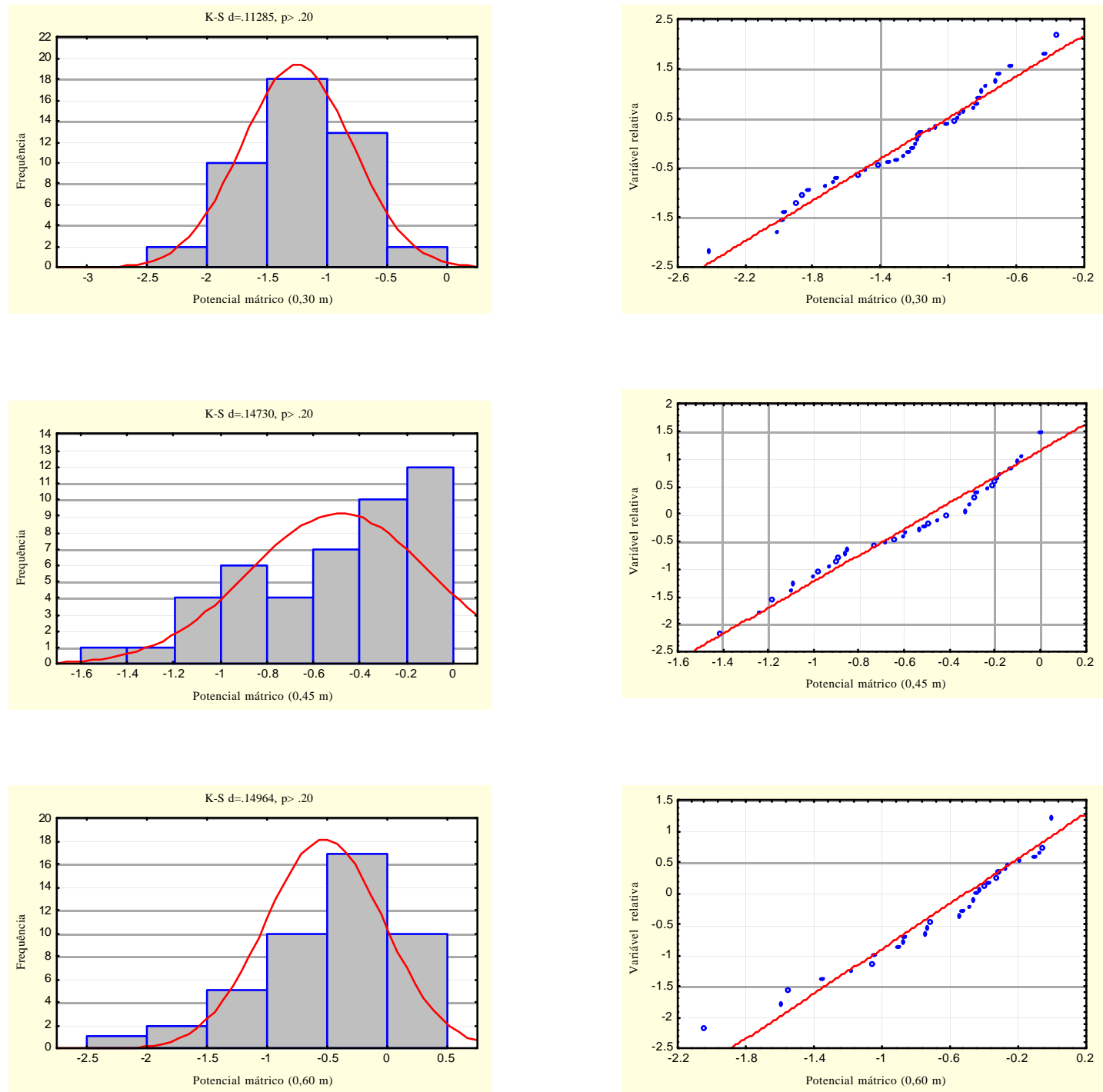

Figura 9 - Histogramas de freqüência, teste de Kolmogorov - Smirnov e retas de probabilidade de Henry, para potencial mátrico $\phi_{\mathrm{m}}(\mathrm{kPa})$ para três profundidades e no tempo inicial (78 horas). 

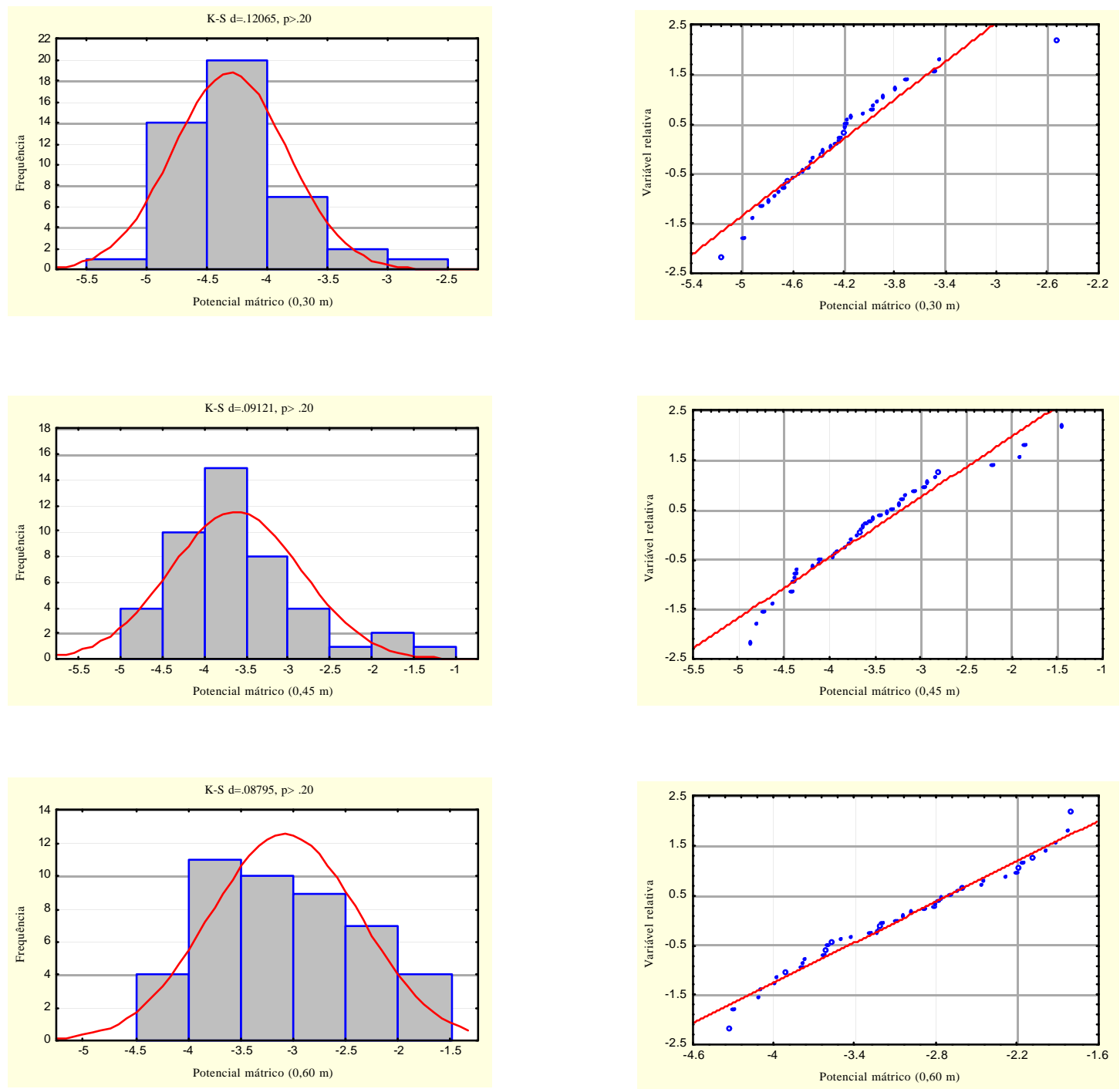

Figura 10 - Histogramas de frequiência, teste de Kolmogorov - Smirnov e retas de probabilidade de Henry, para potencial mátrico $\phi_{\mathrm{m}}(\mathrm{kPa})$ para três profundidades e no tempo final (604 horas).

O gráfico "box-plot" para os dados de potencial mátrico para as três profundidades no tempo inicial e final, encontra-se ilustrado na Figura 11. Examinado-a percebe-se que há uma diferença de padrão no comportamento das 
distribuições dos dados com o tempo. No início (78 h) houve um aumento da assimetria com a profundidade. Neste caso a assimetria é positiva. Ao contrário, no tempo 604 horas, a assimetria diminui em profundidade, passando a ser negativa e indicando a ocorrência de valores muito altos em relação ao conjunto de dados.
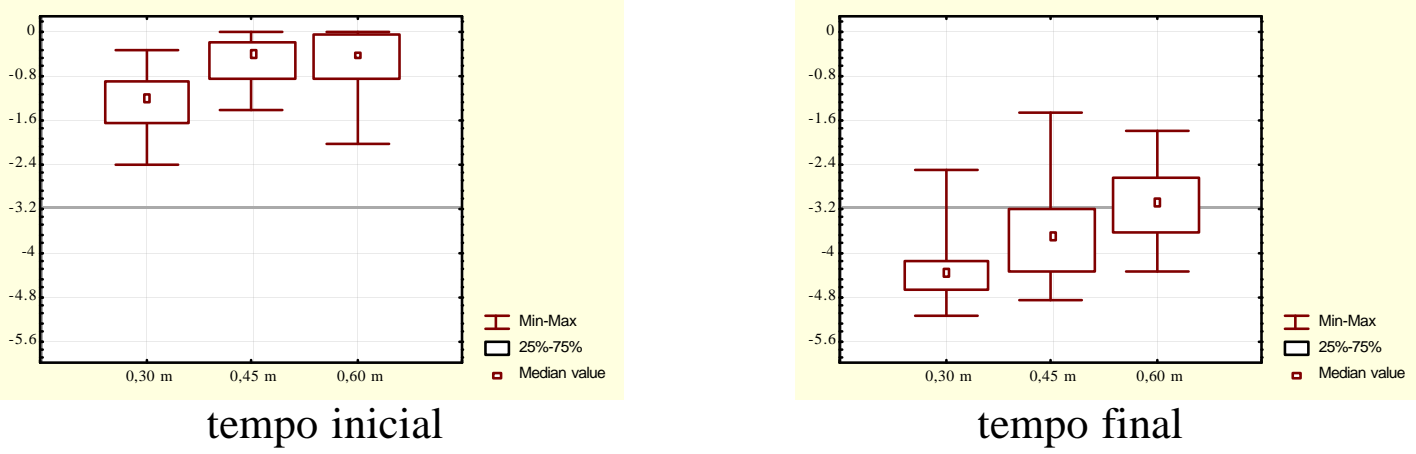

Figura 11 - Gráfico "box-plot" para potencial mátrico $\phi_{\mathrm{m}}(\mathrm{kPa})$ para três profundidades e nos tempos inicial (78 horas) e final (604 horas).
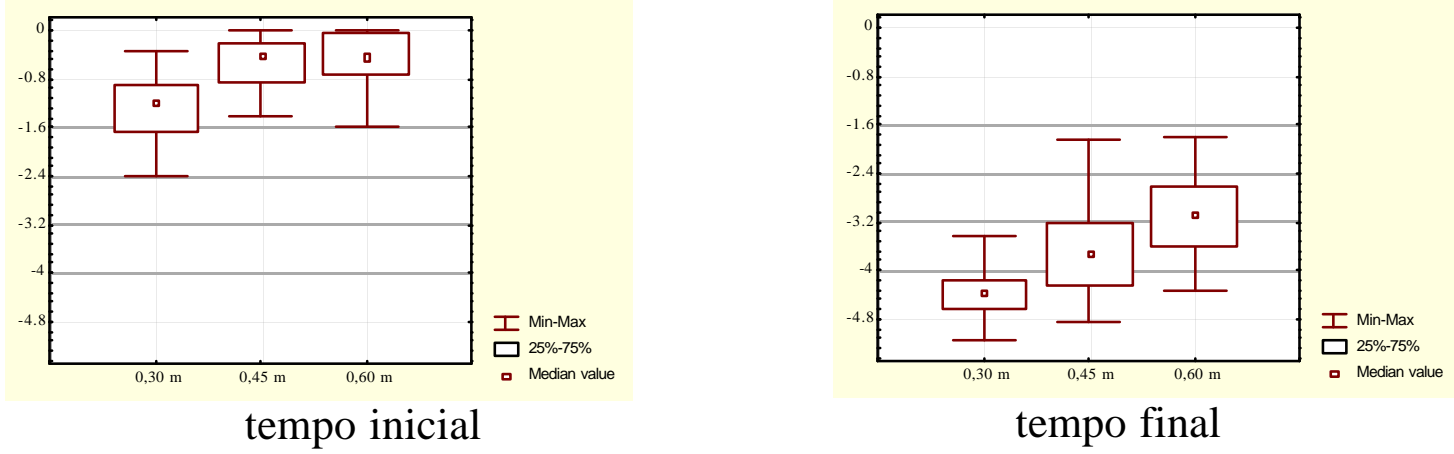

Figura 12 - Gráfico "box-plot" para potencial mátrico $\phi_{\mathrm{m}}(\mathrm{kPa})$, para três profundidades e nos tempos inicial (78 horas) e final (604 horas), após a remoção dos "outliers". 
A Figura 12 mostra os gráficos "box-plot" para o conjunto de dados após a eliminação dos valores extremos. Comparando as Figuras 11 e 12 percebe-se que a eliminação dos valores extremos não alterou a assimetria de forma significativa e manteve o mesmo padrão de comportamento dos dados. Este fato decorre do pequeno número de valores extremos que foram identificados, bem como da baixa magnitude de seus valores absolutos em relação ao conjunto de dados.

Considerando a comprovação da normalidade, assumindo-se a independência dos valores para o conjunto dados e após a eliminação dos valores considerados extremos, calculou-se, por meio da eq. (34), o número de amostras necessárias para representar adequadamente o potencial mátrico do solo. $\mathrm{Na}$ Tabela 7 consta o número de amostras necessárias para estimar o potencial mátrico tendo como base o conjunto de dados semeliminar os valores extremos. $\mathrm{Na}$ Tabela 8 estão os mesmos resultados, porém com a eliminação dos valores extremos. Analisando-se a Tabela 7 , nota-se que o número de amostras diminui com o tempo nas três profundidades e para as diversas variações permitidas em torno da média, logicamente, devido à redução do coeficiente de variação que se deu da mesma forma. A eliminação dos valores extremos, contribuiu para reduzir a dispersão dos dados e o número de amostras necessárias para estimativa dos valores de potencial mátrico com o tempo (Tabela 8). No geral os resultados mostram que no tempo inicial, quando a variabilidade das leituras é maior, o número de pontos a serem medidos para estimar a média com variações de 5 e $10 \%$ em torno da média, nas três profundidades, é muito alto, sendo até mesmo impraticável em condições de campo. À medida que o tempo passa e o solo vai secando esse número de pontos a serem medidos diminui consideravelmente, principalmente para variações de $10 \%$ em torno da média, considerada neste estudo como a ideal. 
Tabela 7. Número de amostras necessárias para estimar o valor médio do potencial mátrico $\phi_{\mathrm{m}}(\mathrm{kPa})$ em três profundidades para quatro níveis de variação permitida, considerando $t_{10 \%}$.

\begin{tabular}{lcccc}
\hline & \multicolumn{4}{c}{ Variação permitida em torno da média } \\
\cline { 2 - 5 } Tempo (h) & $5 \%$ & $10 \%$ & $20 \%$ & $30 \%$ \\
\hline 78 & 155 & $0,30 \mathrm{~m}$ & 4 \\
220 & 37 & 39 & 10 & 1 \\
460 & 18 & 9 & 2 & 1 \\
604 & 14 & 3 & 1 & 1 \\
& & 1 & \\
78 & 721 & 180 & 45 & 20 \\
220 & 130 & 33 & 8 & 4 \\
460 & 74 & 18 & 5 & 2 \\
604 & 52 & 13 & 3 & 1 \\
& & $0,60 \mathrm{~m}$ & & 28 \\
78 & 1025 & 256 & 64 & 8 \\
220 & 300 & 75 & 19 & 2 \\
460 & 94 & 23 & 6 & 4 \\
604 & 60 & 15 & & 3 \\
\hline
\end{tabular}

Os resultados da Tabela 7 também mostram que o número de tensiômetros necessários para estimar o potencial mátrico em uma determinada área, aumenta com a profundidade. Este incremento deve-se ao incremento da dispersão das leituras de potencial mátrico, expressa pelo desvio padrão, em 
profundidade. Estas conclusões são aplicáveis para a faixa de umidade e tensão da água no solo que predominaram neste experimento.

Tabela 8. Número de amostras necessárias para estimar o valor médio do potencial mátrico $\phi_{\mathrm{m}}(\mathrm{kPa})$, após a retirada dos “outliers", apenas nas profundidades e nos tempos de amostragem em que foram identificados, considerando $\mathrm{t}_{10 \%}$.

\begin{tabular}{lcccc}
\hline & \multicolumn{4}{c}{ Variação permitida em torno da média } \\
\cline { 2 - 5 } Tempo (h) & $5 \%$ & $10 \%$ & $20 \%$ & $30 \%$ \\
\hline & & $0,30 \mathrm{~m}$ & & \\
460 & 14 & 4 & 1 & 1 \\
604 & 14 & 3 & 1 & 1 \\
& & $0,45 \mathrm{~m}$ & & 3 \\
220 & 102 & 25 & 6 & 2 \\
660 & 57 & 14 & 4 & 1 \\
784 & 42 & 11 & 3 & 26 \\
\hline
\end{tabular}

\subsubsection{Coeficiente angular $(\beta)$ da relação $\ln K=\beta \theta+\ln K_{\theta=0}$}

A natureza porosa do solo determina uma forte sensibilidade na relação entre a condutividade hidráulica $(\mathrm{K})$ e a umidade do solo $(\theta)$, a qual é definida como sendo uma função exponencial, $K=K_{o} \exp \left[\beta\left(\theta-\theta_{0}\right)\right]$ (Warrick 
\& Nielsen, 1980; Libardi et al., 1980). Logaritimizando a equação exponencial que define a relação entre condutividade hidráulica, $K(\theta)$, e a umidade $(\theta)$ tem-se que $\operatorname{lnK}=\beta\left(\theta-\theta_{0}\right)+\ln K_{0}$, sendo $\beta$ o coeficiente angular da reta definida pela equação acima, $K_{o}$ e $\theta_{0}$, respectivamente, os valores da condutividade hidráulica e umidade no tempo zero de redistribuição. Registros de literatura (Falleiros et al., 1998; Jong van Lier \& Libardi, 1999) mostram que a variabilidade desses parâmetros é sempre muito alta. A equação acima também pode se escrita como $\operatorname{lnK}=\beta(\theta)+\ln K_{\theta=0}$, em que $\ln K_{\theta=0}$ é o valor de $\ln K$ para $\theta=0 . \quad O \ln K_{\theta=0}$ não é um valor físico, porém é importante para entender a variabilidade dos fatores da função $K(\theta)$.

A Tabela 9, apresenta o resumo estatístico para os valores de $\beta$ nas três profundidades consideradas neste estudo. Porém, para melhor compreender e avaliar estes resultados, deve-se considerar primeiramente a influência dos "outliers" sobre os parâmetros estatísticos que caracterizam o coeficiente angular $\beta$. De fato, constatou-se a presença de valores extremos nas três profundidades (Tabela 10). Os valores extremos afetaram a média, a mediana, o desvio padrão, o coeficiente de variação e os índices de assimetria e curtose, resultando em uma distribuição não normal para o conjunto de dados originais. A representação gráfica dos valores originais de $\beta$, pelos diagramas de dispersão, retas de Henry e "box-plot”, estão nas Figuras 13 e 15a. 
Tabela 9. Resumo estatístico dos dados originais para valores do coeficiente angular ( $\beta$ ) da relação $\operatorname{lnK}=\beta \theta+\ln K_{\theta=0}$, em três profundidades, segundo uma transeção de 45 pontos espaçados de um metro.

\begin{tabular}{ccccccccc}
\hline $\begin{array}{c}\text { Prof } \\
(\mathrm{m})\end{array}$ & Média & Mediana & $\begin{array}{c}\text { Desvio } \\
\text { padrão }\end{array}$ & $\begin{array}{c}\text { CV } \\
\%\end{array}$ & Min & Max & Assi & Curt \\
\hline 0,30 & 51,40 & 47,71 & 22,44 & 43,65 & 14,11 & 162,64 & 2,82 & 13,33 \\
0,45 & 53,59 & 44,50 & 32,96 & 61,50 & 20,70 & 223,12 & 3,68 & 16,40 \\
0,60 & 61,90 & 44,19 & 73,56 & 118,84 & 6,24 & 496,81 & 5,00 & 28,84 \\
\hline
\end{tabular}

Tabela 10. Limite inferior e superior para identificação de valores candidatos a "outliers" para o coeficiente angular $(\beta)$ da relação $\operatorname{lnK}=\beta \theta+$ $\ln K_{\theta=0}$, em três profundidades, segundo uma transeção de 45 pontos espaçados de um metro.

\begin{tabular}{cccccc}
\hline $\begin{array}{c}\text { Prof } \\
(\mathrm{m})\end{array}$ & $1^{\mathrm{o}}$ Quartil & $2^{\mathrm{o}}$ Quartil & Limite inf. & Limite sup. & “Outliers" \\
\hline 0,30 & 39,89 & 57,81 & 13,01 & 84,70 & $\operatorname{Sim}(2)$ \\
0,45 & 37,76 & 52,79 & 15,21 & 75,34 & $\operatorname{Sim}(6)$ \\
0,60 & 34,26 & 57,68 & $-0,87$ & 92,81 & $\operatorname{Sim}(5)$ \\
\hline
\end{tabular}

* Valores entre parênteses indicam a quantidade de "outliers" 

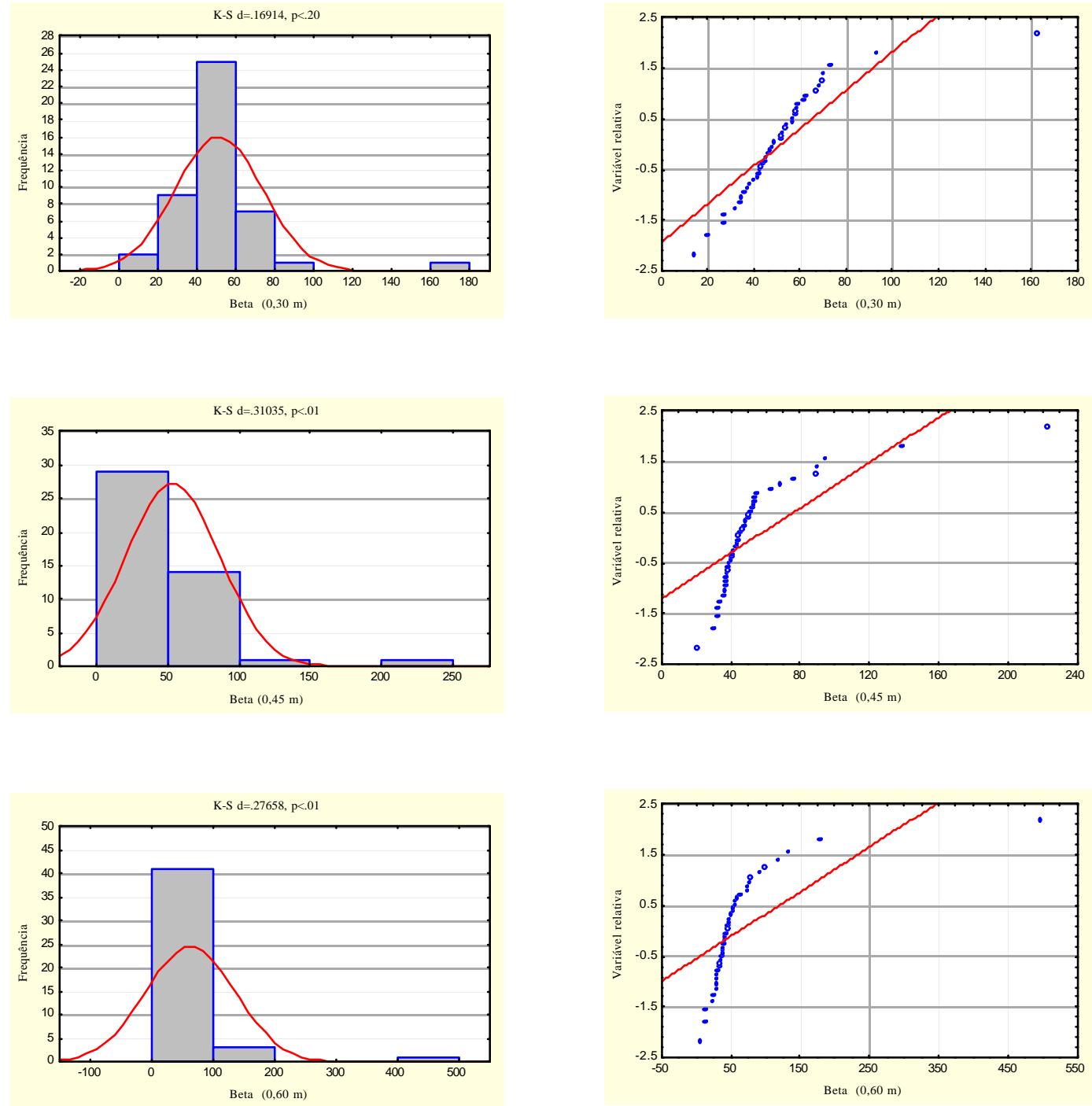

Figura 13 - Histogramas de freqüência, teste de Kolmogorov - Smirnov (K-S) e retas de probabilidade de Henry, dos valores originais, para o coeficiente angular $(\beta)$ da relação $\operatorname{lnK}=\beta \theta+\operatorname{lnK}_{\theta=0}$, em três profundidades, segundo uma transeção de 45 pontos espaçados de um metro. 
O resumo da análise estatística após a retirada dos valores extremos encontra-se na Tabela 11. Considerando que os resultados para $\beta$ são mais realistas e confiáveis depois da eliminação dos valores extremos determinados pelo procedimento da análise exploratória (Libardi et al. 1996), optourse pela análise da variabilidade deste parâmetro com base no novo resumo estatístico. Analisando a Tabela 11, percebe-se as significativas alterações resultantes da eliminação dos valores extremos. Primeiramente os valores da media e mediana se tornaram muito mais próximos, principalmente nas profundidades 0,30 e 0,45 $\mathrm{m}$. Na profundidade $0,60 \mathrm{~m}$ os valores da media e da mediana ainda mantiveram uma certa distância. Este fato deve-se à presenç a, no conjunto de dados de $\beta$ para esta profundidade $(0,60 \mathrm{~m})$, de um valor muito próximo, porém abaixo do limite superior para ser considerado "outlier" e que por isso não foi eliminado. Como resultado a média foi elevada em relação à mediana. No entanto, não houve alteração do padrão de distribuição dos dados, que continuaram sendo normais.

Observando-se a Tabela 11 nota-se que os valores médios de $\beta$ foram próximos nas três profundidades. Segundo Falleiros et al. (1998) os valores deste parâmetro variam de 50 - 200, podendo, em alguns casos, superar 500 (Jong van Lier \& Libardi, 1999). Neste estudo estiveram sempre abaixo de 50 e, portanto, mais próximos dos valores mais baixos encontrados por Libardi et al. (1980) e bastante inferiores ao registrados por Jong van Lier \& Libardi (1999).

Os valores do desvio padrão foram diferentes nas três profundidades. Apresentoutse próximo de 13,00 na profundidade 0,30 m, diminuiu para 9,00 em $0,45 \mathrm{~m}$ e aumentou para 18,00 na profundidade $0,60 \mathrm{~m}$, mostrando uma certa irregularidade. O mesmo comportamento é encontrado para o coeficiente de variação, cuja tendência foi diminuir da profundidade 0,30 para $0,45 \mathrm{~m}$ e voltar a aumentar desta para a profundidade $0,60 \mathrm{~m}$. Warrick e Nielsen 
(1980) não explicitam valores para o coeficiente $\beta$. No entanto, considerando as faixas de variabilidade definidas pelos autores, pode-se afirmar que o $\beta$ apresentou médio índice de variabilidade nas três profundidades. Estes resultados diferem daqueles normalmente encontrados para outros solos, cuja classificação indica tendência de alto índice de variabilidade para $\beta$ (Jong van Lier \& Libardi, 1999), porém foram próximos daqueles indicados por Falleiros et al. (1998).

No contexto deste estudo uma comparação muito interessante a ser feita é, entre os valores médios dos coeficientes de variação da umidade $\boldsymbol{\theta}$ ) (Tabela 1) e do coeficiente angular $(\beta$ ) (Tabela 11). Percebe-se que a umidade do solo apresentou pequenas diferenças de teor durante o tempo de secagem e redistribuição, mas que foram suficientes para causar variações significativas no valor do coeficiente angular $(\beta)$, indicando uma elevada sensibilidade das medidas de $\theta$ no cálculo das relações $K(\theta)$. Resultados semelhantes foram encontrados por Falleiros et al. (1998), levando-os a questionar os parâmetros até então utilizados para monitorar a dinâmica da água no solo.

Aplicando-se os critérios definidos por Jones (1969), ao nível de 5\% de probabilidade, para os dados após a eliminação dos valores extremos, encontra-se que, os valores de $\beta$ seguiram uma distribuição normal nas três profundidades. Fato confirmado pela observação dos padrões de distribuição dos gráficos de dispersão e reta de Henry e pelos resultados do teste de KolmogorovSmirnov (K-S) (Figura 14). 
Tabela 11. Resumo estatístico para valores do coeficiente angular $\beta$ ) da relação $\operatorname{lnK}=\beta \theta+\ln K_{\theta=0}$, após a retirada dos "outliers", em três profundidades, segundo uma transeção de 45 pontos espaçados de um metro.

\begin{tabular}{ccccccccc}
\hline $\begin{array}{c}\text { Prof } \\
(\mathrm{m})\end{array}$ & Média & Mediana & $\begin{array}{c}\text { Desvio } \\
\text { padrão }\end{array}$ & $\begin{array}{c}\text { CV } \\
\%\end{array}$ & Min & Max & Assi & Curt \\
\hline 0,30 & 47,84 & 47,58 & 13,33 & 27,87 & 14,11 & 72,80 & $-0,31$ & 0,04 \\
0,45 & 43,60 & 43,19 & 9,11 & 20,90 & 20,70 & 68,66 & 0,34 & 1,06 \\
0,60 & 44,02 & 41,47 & 18,25 & 41,46 & 6,24 & 92,29 & 0,51 & 0,55 \\
\hline
\end{tabular}



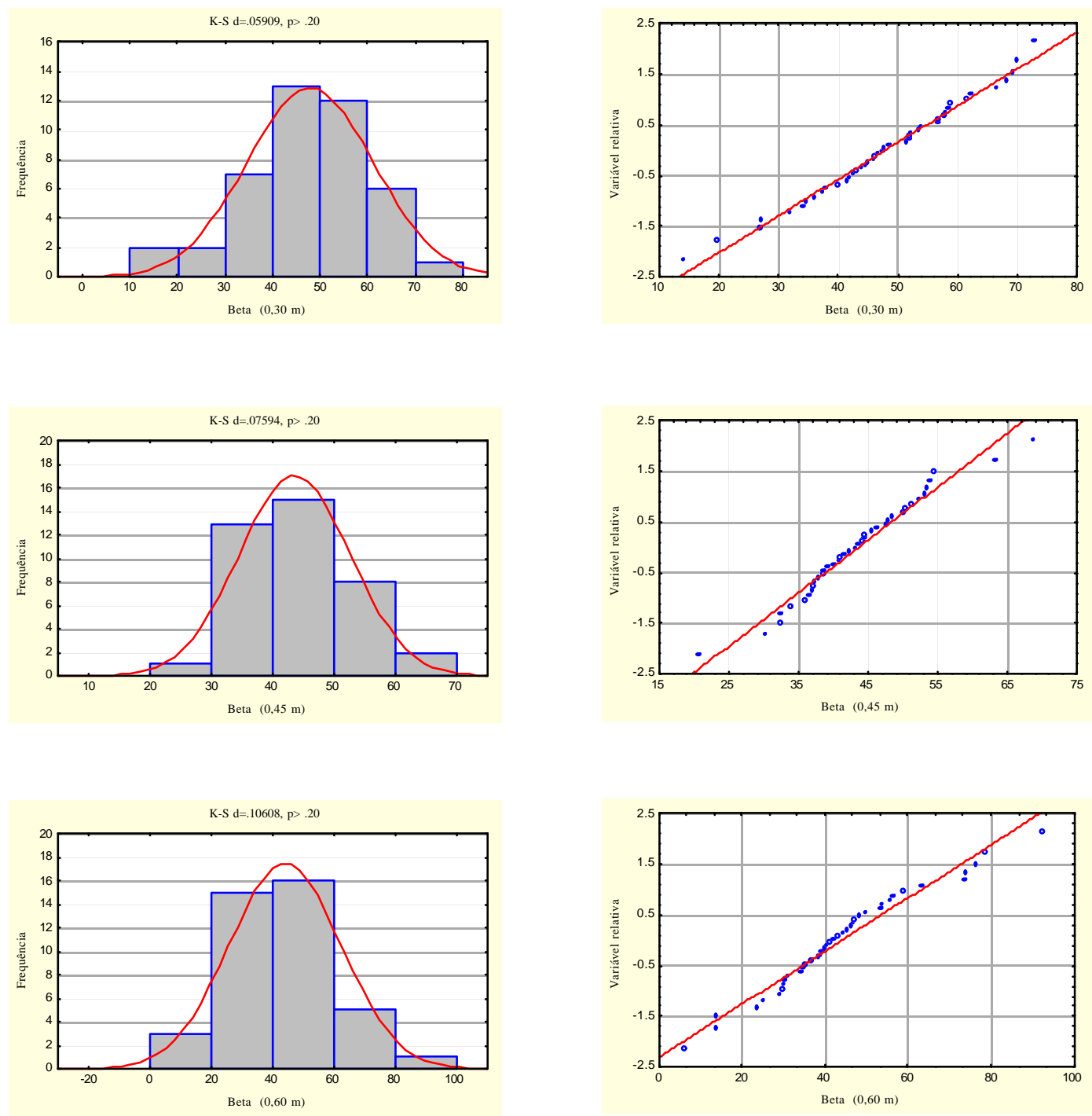

Figura 14 - Histogramas de freqüência, teste de Kolmogorov - Smirnov (K-S) e retas de probabilidade de Henry, para o coeficiente angular $(\beta)$ da relação $\operatorname{lnK}=\beta \theta+\ln K_{\theta=0}$, após a retirada dos "outliers", em três profundidades, segundo uma transeção de 45 pontos espaçados de um metro. 


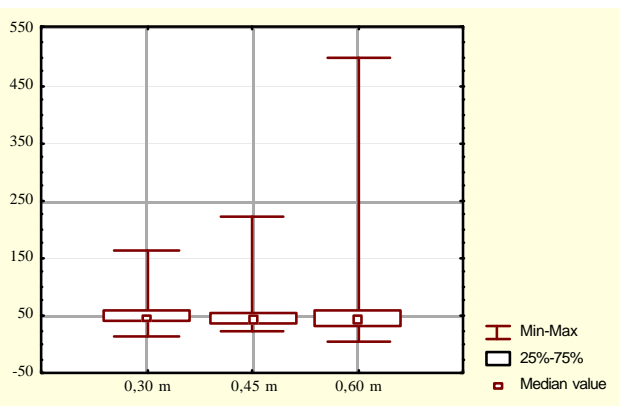

a

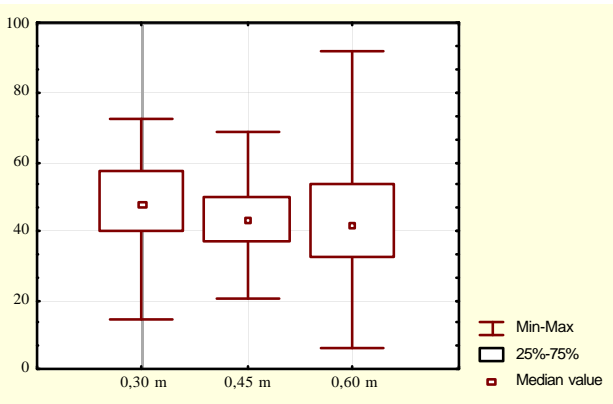

$\mathrm{b}$

Figura 15 - Gráfico "box-plot” para o coeficiente angular $(\beta)$, da relação $\operatorname{lnK}=$ $\beta \theta+\ln K_{\theta=0}$, em três profundidades, segundo uma transeção de 45 pontos espaçados de um metro: a) dados originais e b) após a retirada dos "outliers",

A Figura 15 ilustra muito bem o efeito dos valores extremos na distribuição e assimetria dos dados de $\beta$. A distribuição do conjunto de dados originais, para as três profundidades, mostra-se completamente assimétrica e positiva, indicando que a presença de poucos valores elevados contribuiu para distorcer a média dos dados, aumentando-a artificialmente (Figura 15a). Com a retirada dos valores extremos, nota-se que distribuição de $\beta$ passou a ter uma assimetria mais equilibrada, resultando em uma distribuição aproximadamente normal, na qual não existem valores elevados em uma direção específica, de modo que os valores altos e baixos se equilibram entre si (Figura 15b), resultando em valores médios mais próximos da realidade. Esse efeito dos valores extremos no valor das médias de $\beta$ para as três profundidades pode ser confirmado pela comparação entre as Tabelas 9 e 11.

Comprovada a hipótese da normalidade e assumindo a independência dos dados, calculou-se o número de amostras necessárias para 
estimar o valor de $\beta$ para a relação $\operatorname{lnK}=\beta \theta+\ln K_{\theta=0}$. Os resultados estão na Tabela 12. Nota-se uma tendência geral de reduzir o número de amostras com o aumento da variação permitida em torno da média nas três profundidades. Para uma variação de $10 \%$ em torno da média, referida como ideal neste estudo, a profundidade $0,45 \mathrm{~m}$ foi a que apresentou o menor número de medidas para estimativa de $\beta$, exigindo para tanto, 12 medidas. Nas outras profundidades os valores foram bem maiores, sendo necessárias 22 amostras na profundidade 0,30 m e 49 na profundidade $0,60 \mathrm{~m}$. Em comparação com os mesmos resultados para umidade e potencial mátrico no tempo final, qual seja 604 horas, esses valores apresentam-se bem diferentes, não sendo possível estabelecer qualquer relação de comportamento entre esses parâmetros h́dricos quanto ao número de amostras necessárias para sua estimativa.

Tabela 12. Número de amostras necessárias para estimar o valor médio para o coeficiente angular $(\beta)$ da relação $\ln K=\beta \theta+\ln K_{\theta=0}$, em três profundidades para quatro níveis de variação permitida, considerando $\mathrm{t}_{10 \%}$.

\begin{tabular}{ccccc}
\hline & \multicolumn{5}{c}{ Variação permitida em torno da média } \\
\cline { 2 - 5 } Prof $(\mathrm{m})$ & $5 \%$ & $10 \%$ & $20 \%$ & $30 \%$ \\
\hline 0,30 & 88 & 22 & 5 & 2 \\
0,45 & 49 & 12 & 3 & 1 \\
0,60 & 194 & 49 & 12 & 5 \\
\hline
\end{tabular}




\subsubsection{Coeficiente linear $\left(\ln K_{\theta}\right)$ da relação $\ln K=\beta \theta+\ln K_{\theta}$}

$\mathrm{O} \ln K_{\theta=0}$ representa o coeficiente linear da função $\operatorname{lnK}=\beta \theta+$ $\ln K_{\theta=0}$, que define a relação entre a condutividade hidráulica $(K(\theta))$ e a umidade $(\theta)$. Seu valor corresponde ao logaritmo natural da condutividade hidráulica para $\theta$ igual a zero. Sabendo-se que a condutividade hidráulica do solo apresenta distribuição log-normal e que a sua transformação para $\operatorname{lnK}$ resulta em um conjunto de dados com distribuição normal (Libardi et al. 1980; Logsdon \& Jaynes, 1996; Nielsen et al., 1973; Schaap \& Leij, 1998; Sisson \& Wierenga, 1981), esperava-se que a distribuição do conjunto de dados originais de $\ln K_{\theta=0}$ fosse aproximadamente normal, o que não ocorreu. Tal fato, deve-se a existência dos "outliers", cuja presença no conjunto de dados foi responsável por alterar a distribuição dos valores da condutividade hidráulica, mesmo depois da aplicação da transformação adequada, evidenciando, mais uma vez, a importância da realização da análise exploratória, como procedimento padrão para avaliação estatística de um conjunto de dados.

A Tabela 13 mostra o resumo estatístico para o conjunto original de dados de $\ln K_{\theta=0}$. Neste caso, nota-se que, a presença de valores extremos alterou a distribuição dos dados, afastando a média da mediana e tornando-os não normais. A representação gráfica desta situação, pelos diagramas de dispersão, retas de Henry e "box-plot", está nas Figuras 16 e 18a.

Pelas mesmas razões e seguindo o mesmo procedimento adotado para o conjunto de dados de $\beta$, optou-se por eliminar os "outliers" antes da realização de qualquer inferência sobre o $\operatorname{lnK}_{\theta=0}$. Assim, de acordo com os critérios propostos por Libardi et al. (1996), foram identificados e eliminados três 
valores extremos na profundidade $0,30 \mathrm{~m}$ e seis nas profundidades 0,45 e 0,60 m (Tabela 14).

Tabela 13. Resumo estatístico para valores originais de $\ln K_{\theta=0}$ da relação $\operatorname{lnK}=$ $\beta \theta+\ln K_{\theta=0}$, em três profundidades, segundo uma transeção de 45 pontos espaçados de um metro.

\begin{tabular}{ccccccccc}
\hline $\begin{array}{c}\text { Prof } \\
(\mathrm{m})\end{array}$ & Média & Mediana & $\begin{array}{c}\text { Desvio } \\
\text { padrão }\end{array}$ & $\begin{array}{c}\text { CV } \\
\%\end{array}$ & Min & Max & Assi & Curt \\
\hline 0,30 & $-17,08$ & $-16,37$ & 5,59 & 32,69 & $-41,81$ & $-3,75$ & $-1,77$ & 8,38 \\
0,45 & $-17,22$ & $-15,40$ & 7,46 & 43,31 & $-55,12$ & $-4,14$ & $-3,36$ & 15,42 \\
0,60 & $-18,57$ & $-15,00$ & 16,46 & 88,65 & $-116,09$ & $-1,64$ & $-5,00$ & 29,11 \\
\hline
\end{tabular}

Tabela 14. Limite inferior e superior para identificação de valores candidatos a "outliers" para valores de $\ln \mathrm{K}_{\theta=0}$ da relação $\ln \mathrm{K}=\beta \theta+\ln \mathrm{K}_{\theta=0}$, em três profundidades, segundo uma transeção de 45 pontos espaçados de um metro.

\begin{tabular}{cccccc}
\hline $\begin{array}{c}\text { Prof } \\
(\mathrm{m})\end{array}$ & $1^{\mathrm{o}}$ Quartil & $2^{\mathrm{o}}$ Quartil & Limite inf. & Limite sup. & “Outliers" \\
\hline 0,30 & $-19,25$ & $-14,38$ & $-26,56$ & $-7,08$ & $\operatorname{Sim}(3)$ \\
0,45 & $-17,72$ & $-14,11$ & $-23,13$ & $-8,69$ & $\operatorname{Sim}(6)$ \\
0,60 & $-18,39$ & $-12,96$ & $-26,53$ & $-4,82$ & $\operatorname{Sim}(6)$
\end{tabular}

* Valores entre parênteses indicam a quantidade de "outliers" 

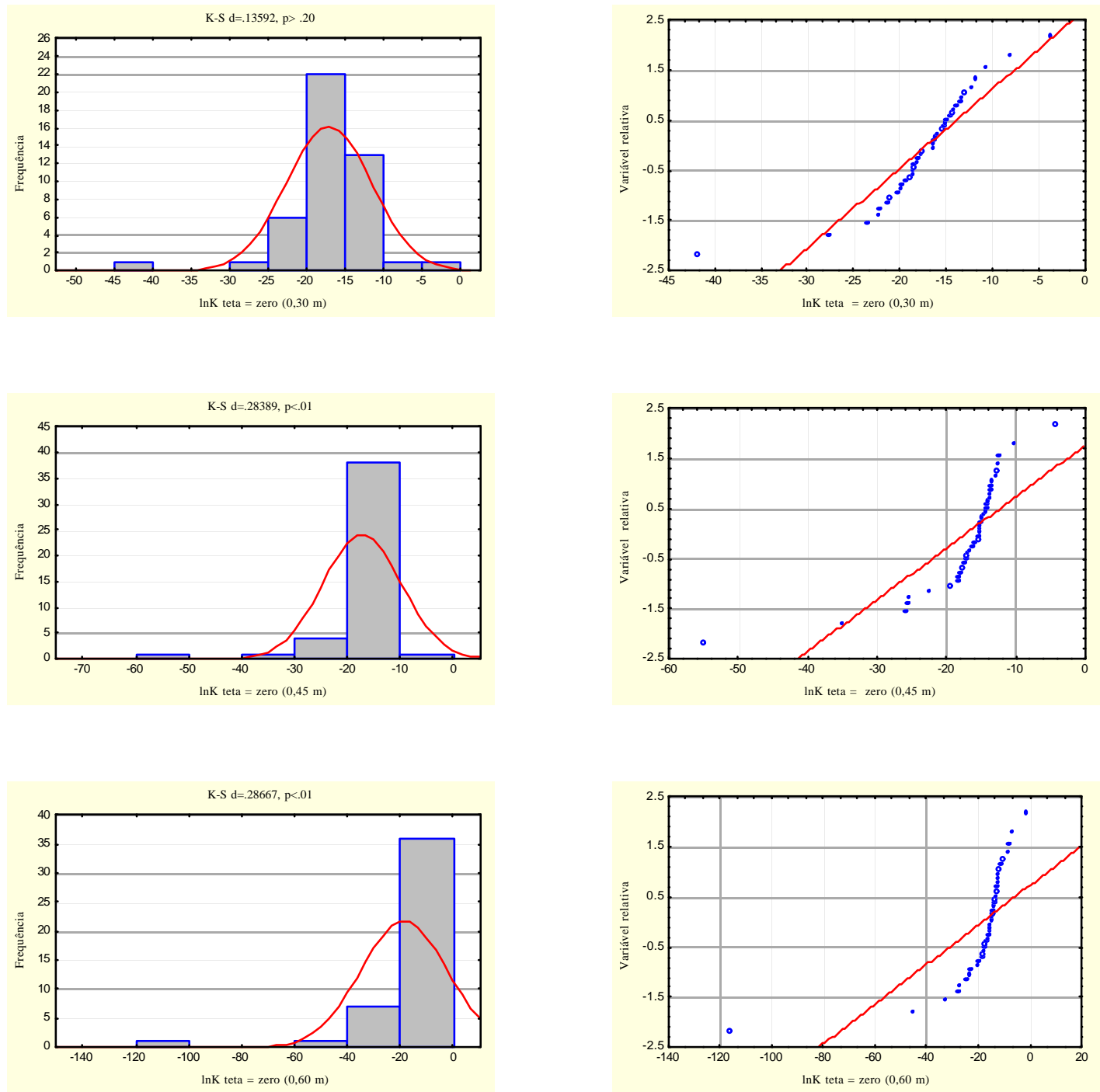

Figura 16 - Histogramas de freqüência, teste de Kolmogorov - Smirnov (K-S) e retas de probabilidade de Henry, para valores originais de $\ln _{\theta=0}$ da relação $\operatorname{lnK}=\beta \theta+\ln K_{\theta=0}$, em três profundidades, segundo um transecto de 45 pontos espaçados de um metro.

O resumo estatístico dos valores de $\ln \mathrm{K}_{\theta=0}$, após a eliminação dos "outliers", encontra-se na Tabela 15. Analisando-a percebe-se as significativas 
alterações resultantes da eliminação dos valores extremos. Primeiramente, os valores da media e da mediana ficaram muito mais próximos, principalmente nas profundidades 0,30 e $0,45 \mathrm{~m}$. A semelhança do que ocorreu com o $\beta$, também na profundidade $0,60 \mathrm{~m}$ os valores da media e da mediana ainda mantiveram uma certa distância, cuja razão não ficou tão evidente quanto no caso anterior, muito embora tenham se mantido com distribuição normal e com baixo índice de assimetria (Figura 17 e Figura 18b). Os valores médios de $\ln \mathrm{K}_{\theta=0}$ aumentaram em profundidade, passando de $-16,56$ em 0,30 $\mathrm{m}$ para $-15,48$ em $0,45 \mathrm{~m}$ e atingindo $-15,00$ na profundidade de $0,60 \mathrm{~m}$. Este comportamento revela-se diferente daquele apresentado pelo coeficiente $\beta$, cujas médias decresceram em profundidade (Tabela 11)

Tabela 15. Resumo estatístico para valores de $\ln K_{\theta=0}$ da relação $\ln K=\beta \theta+$ $\ln K_{\theta=0}$, após a retirada dos "outliers", em três profundidades, segundo uma transeção de 45 pontos espaçados de um metro.

\begin{tabular}{ccccccccc}
\hline $\begin{array}{c}\text { Prof } \\
(\mathrm{m})\end{array}$ & Média & Mediana & $\begin{array}{c}\text { Desvio } \\
\text { padrão }\end{array}$ & $\begin{array}{c}\text { CV } \\
\%\end{array}$ & Min & Max & Assi & Curt \\
\hline 0,30 & $-16,56$ & $-16,33$ & 3,35 & 20,21 & $-23,41$ & $-8,09$ & 0,17 & $-0,10$ \\
0,45 & $-15,48$ & $-15,24$ & 2,28 & 14,71 & $-22,58$ & $-10,15$ & $-0,58$ & 1,51 \\
0,60 & $-15,00$ & $-14,58$ & 3,84 & 25,59 & $-24,36$ & $-6,80$ & $-0,38$ & 0,60 \\
\hline
\end{tabular}



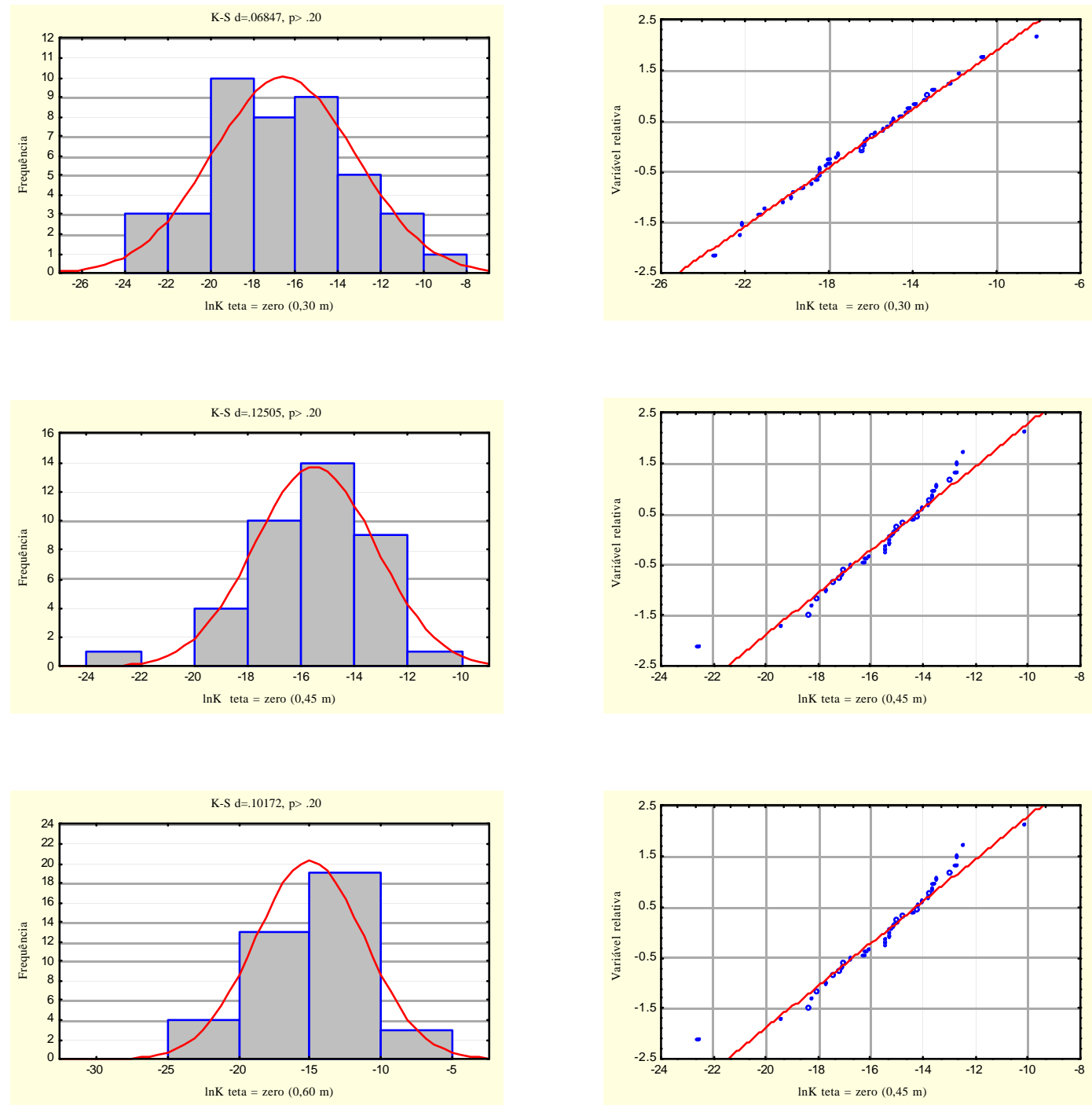

Figura 17 - Histogramas de freqüência, teste de Kolmogorov - Smirnov (K-S) e retas de probabilidade de Henry, para valores de $\ln K_{\theta=0}$ da relação $\operatorname{lnK}=\beta \theta+\ln K_{\theta=0}$, após a retirada dos "outliers", em três profundidades, segundo um transecto de 45 pontos espaçados de um metro. 
Os valores do desvio padrão foram semelhantes para as profundidades 0,30 e $0,60 \mathrm{~m}$ e bem menor na profundidade de $0,45 \mathrm{~m}$. Os coeficientes de variação para as três profundidades indicam um índice de variabilidade médio (Warrick e Nielsen, 1980), cujos valores foram 20\% na camada $0,30 \mathrm{~m}$, diminuindo para $14,7 \%$ na camada $0,45 \mathrm{~m}$ e aumentando para $25,6 \%$ na camada $0,60 \mathrm{~m}$. Outro aspecto importante relativo ao $\ln _{\theta=0}$ é que sua variabilidade, medida pelo índice de coeficiente de variação, foi sempre menor que os mesmos índices para $\beta$, indicando que a sensibilidade das medidas de umidade em relação a estes dois parâmetros da função $K(\theta)$ é diferente e mais sensível para o $\ln \mathrm{K}_{\theta=0}$.

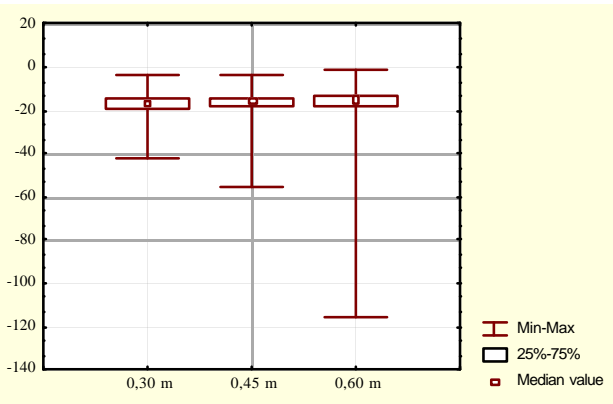

a

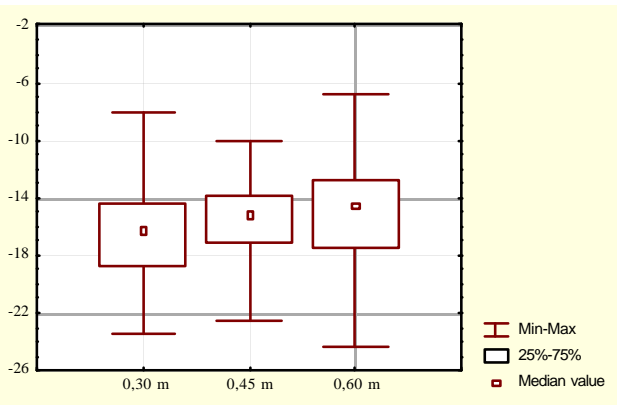

b

Figura 18 - Gráfico "box-plot" para valores de $\ln K_{\theta=0}$ da relação $\ln K=\beta \theta+$ $\ln K_{\theta=0}$, em três profundidades, segundo uma transeção de 45 pontos espaçados de um metro: a) com candidatos a "outliers" e b) após a retirada dos "outliers".

De acordo com os critérios definidos por Jones (1969), ao nível de $5 \%$ de probabilidade, os valores de $\ln K_{\theta=0}$, depois da eliminação dos "outliers", seguiram uma distribuição normal nas três profundidades. Fato confirmado pela 
observação dos padrões de distribuição dos gráficos de dispersão e reta de Henry e pelos resultados do teste de Kolmogorov-Smirnov (K-S), conforme a Figura 17.

Comprovada a hipótese da normalidade e assumindo a independência dos dados, calculou-se o número de amostras necessárias para estimar o valor de $\ln K_{\theta=0}$. Os resultados estão na Tabela 16. Para enriquecer a discussão, elaborou-se uma Tabela 17, com o número de amostras que seriam necessárias para estimar o valor de $\ln \mathrm{K}_{\theta=0}$ caso não houvesse a retirada de valores extremos. Esta comparação permite identificar mais um importante efeito da presença de valores extremos em um conjunto de dados.

Comparando a Tabela 16 com a Tabela 17, nota-se que, a presença de "outliers" aumenta significativamente o número de amostras necessárias para se estimar o valor de um parâmetro, tendo como base o seu coeficiente de variação. Os números sugerem, muitas vezes, valores impraticáveis, como verificado para a profundidade $0,60 \mathrm{~m}$, nos níveis de variação permitida de 5 e 10\%, em que seriam necessárias 887 e 222 amostras, respectivamente. Com a eliminação dos "outliers" houve uma tendência geral de reduzir o número de amostras nas três profundidades (Tabela 16). Nesta condição e para uma variação de $10 \%$ em torno da média, a profundidade $0,45 \mathrm{~m}$ foi a que apresentou o menor número de medidas necessárias para estimativa de $\ln K_{\theta=0}$, exigindo, para tanto, apenas 6 amostras. Nas outras profundidades, os valores foram maiores, sendo necessárias 12 amostras na profundidade $0,30 \mathrm{~m}$ e 18 na profundidade $0,60 \mathrm{~m}$. Em comparação com os mesmos resultados para o coeficiente $\beta$, o número de amostras necessárias para estimativa de um valor médio representativo foi bem menor nas três profundidades, refletindo, logicamente, os menores coeficientes de variação apresentados pelo $\ln \mathrm{K}_{\theta=0}$ em relação ao coeficiente angular $\beta$. 
Tabela 16. Número de amostras necessárias para estimar o valor médio de $\ln \mathrm{K}_{\theta=0}$ da relação $\operatorname{lnK}=\beta \theta+\ln K_{\theta=0}$, após a retirada dos "outliers", em três profundidades, para quatro níveis de variação permitida, considerando $\mathrm{t}_{10 \%}$.

\begin{tabular}{ccccc}
\hline & \multicolumn{4}{c}{ Variação permitida em torno da média } \\
\cline { 2 - 5 } Prof (m) & $5 \%$ & $10 \%$ & $20 \%$ & $30 \%$ \\
\hline 0,30 & 46 & 12 & 3 & 1 \\
0,45 & 24 & 6 & 2 & 1 \\
0,60 & 74 & 18 & 5 & 2 \\
\hline
\end{tabular}

Tabela 17. Número de amostras necessárias para estimar o valor médio de $\ln K_{\theta=0}$ da relação $\operatorname{lnK}=\beta \theta+\ln K_{\theta=0}$, com os valores originais, em três profundidades, para quatro níveis de variação permitida, considerando $\mathrm{t}_{10 \%}$.

\begin{tabular}{ccccc}
\hline & \multicolumn{4}{c}{ Variação permitida em torno da média } \\
\cline { 2 - 5 } Prof (m) & $5 \%$ & $10 \%$ & $20 \%$ & $30 \%$ \\
\hline 0,30 & 121 & 30 & 8 & 3 \\
0,45 & 212 & 53 & 13 & 6 \\
0,60 & 887 & 222 & 55 & 25 \\
\hline
\end{tabular}




\subsubsection{Análise "bootstrap" para $\beta$ e $\ln K_{\theta=0}$}

Quando um conjunto de variáveis apresenta distribuição normal é relativamente fácil calcular o número mínimo de amostras necessárias para estimar a média da população (Warrick \& Nielsen, 1980; Souza, 1992; Mulla \& Mcbratney, 2000). Porém, os métodos utilizados não se aplicam para os casos em que a distribuição das amostras não é normal ou é desconhecida. Torna-se necessário, então, a utilização de técnicas alternativas para avaliar tais casos. A técnica "bootstrap" de estimação é uma delas.

A técnica "bootstrap" é um procedimento computacional intensivo de reamostragem, baseado na técnica da substituição, que possibilita estimar a distribuição amostral de estatísticas de interesse e calcular o número mínimo de amostras, cuja média represente uma população, sem necessidade de que o padrão de distribuição de freqüência dos dados seja normal e/ou determinado a priori.

Os resultados da aplicação da técnica "bootstrap" para cálculo do número mínimo de amostras necessárias para estimar $\beta$ e $\operatorname{lnK}_{\theta=0}$ estão ilustrados nas Figuras 19 e 20, respectivamente. Os gráficos relacionam as frações (F) das 10.000 repetições "bootstrap" com variabilidade de $\pm 5,10,20,30$ e $50 \%$ em torno da média. Em ambos os casos, $\beta$ e $\ln K_{\theta=0}$, os resultados mostram que, para todos os níveis de variação em torno da média, ocorre um aumento das frações $\mathrm{F}$ a medida em que se eleva o número de amostras "bootstrap", até um patamar em que esse incremento torna-se tão pequeno que pode ser considerado estável. 

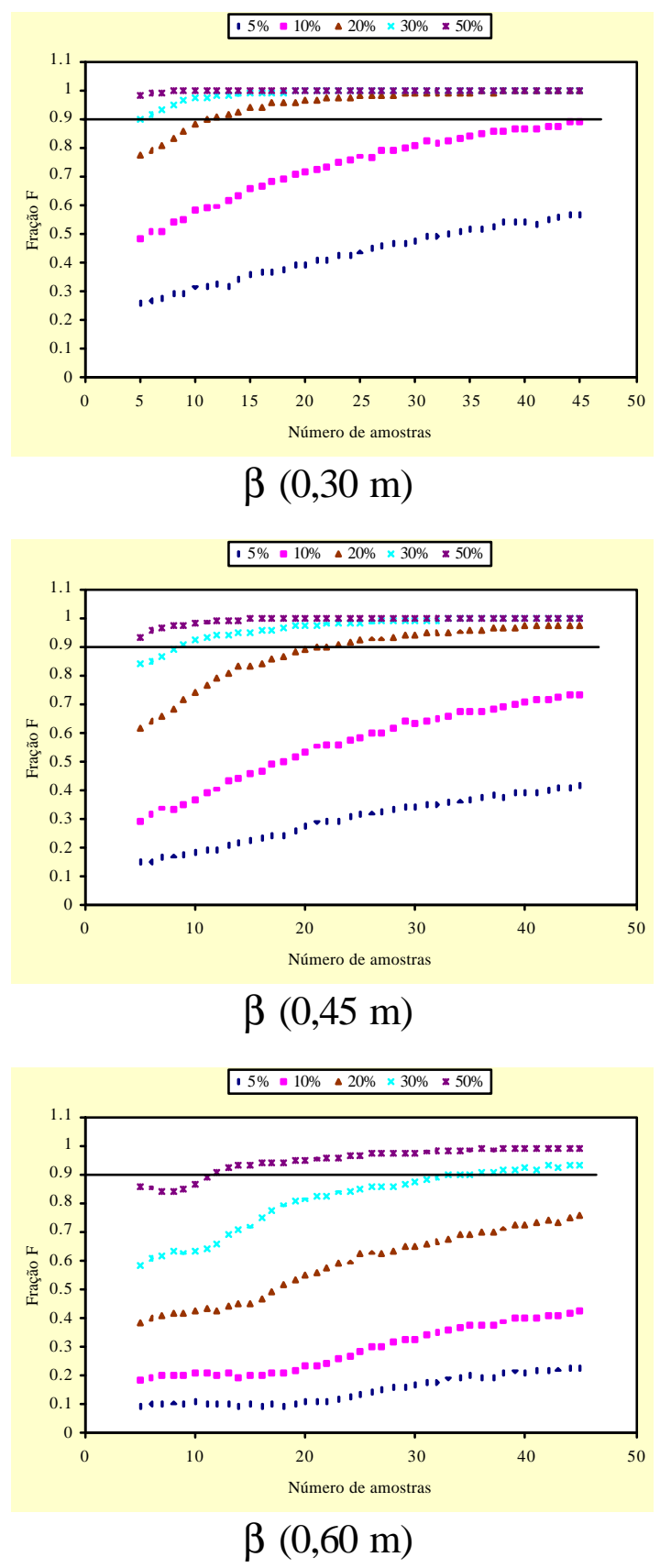

Figura 19 - Fração da amostra "bootstrap" para $\beta$, considerando 5, 10, 20, 30 e $50 \%$ de variação em torno da média, em função do tamanho da amostra 


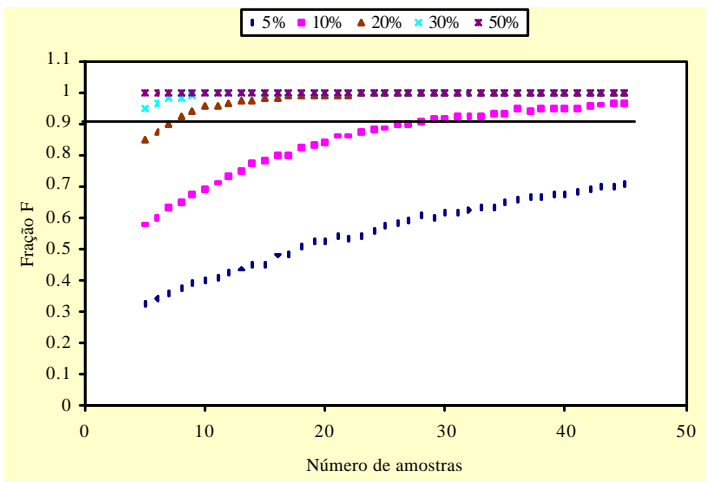

$\ln \mathrm{K}_{\theta=0}(0,30 \mathrm{~m})$

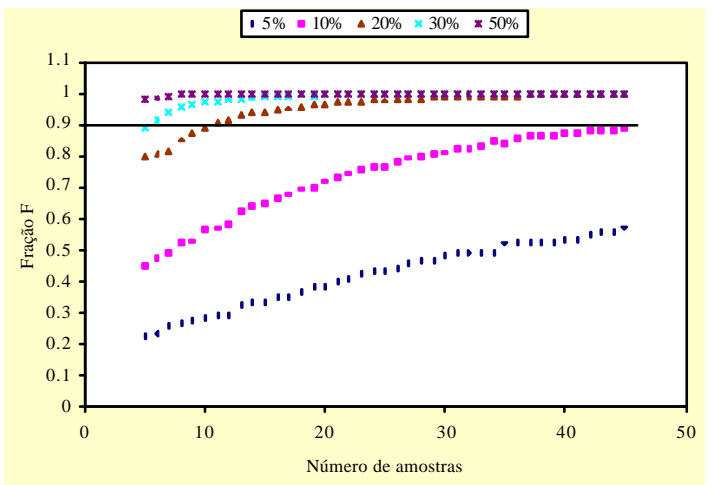

$\ln K_{\theta=0}(0,45 \mathrm{~m})$

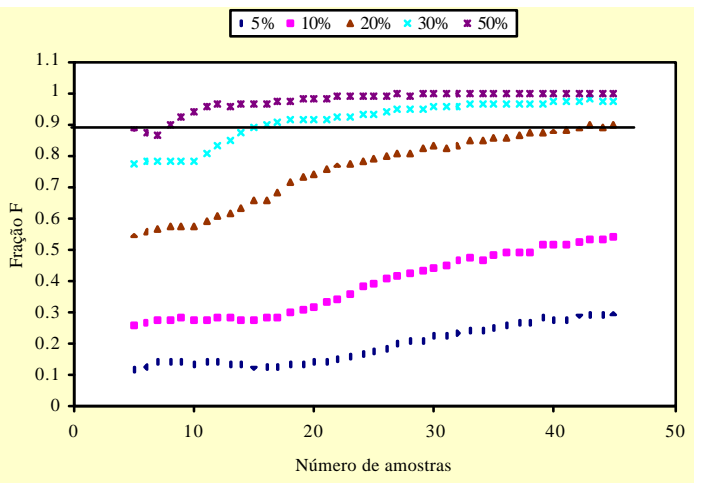

$\ln \mathrm{K}_{\theta=0}(0,60 \mathrm{~m})$

Figura 20 - Fração da amostra "bootstrap" para $\ln \mathrm{K}_{\theta=0}$, considerando 5, 10, 20, 30 e $50 \%$ de variação em torno da média, em função do tamanho da amostra 
Considerando um erro de $\pm 10 \%$, que é aceitável para amostragem em agricultura (Hendrickx \& Wierenga, 1990) as Figuras 19 e 20, também indicam que o número de observações necessárias para estimar o valor médio representativo de $\beta$ e $\ln K_{\theta=0}$, pode alcançar valores muito mais elevados que 45 amostras, como nos casos de $\beta$ nas profundidades 0,45 e $0,60 \mathrm{~m}$ e $\ln K_{\theta=0}$ na profundidade $0,60 \mathrm{~m}$, o que tornaria impraticável a utilização desse nível de precisão (90\%) para amostragem da função condutividade hidráulica. Assim, para o $\beta$, na profundidade $0,45 \mathrm{~m}$, o nível de erro aceitável para obtenção de um número factível de amostras seria $20 \%$, enquanto que na profundidade 0,45 terse-ia que admitir um erro de $30 \%$ para alcançar o mesmo objetivo. Quanto ao $\ln \mathrm{K}_{\theta=0}$ o erro aceitável deve ser de no mínimo $20 \%$.

Tabela 18. Número de amostras (n) necessárias para determinar a média de $\beta \mathrm{e}$ de $\operatorname{lnK}_{\theta=0}$ para variações em torno da média de 5, 10, 20 e 30\%, em três profundidades, após aplicação da técnica "bootstrap".

\begin{tabular}{lcccc}
\hline & \multicolumn{5}{c}{ Coeficiente de variação } \\
\cline { 2 - 5 } Prof $(\mathrm{m})$ & $5 \%$ & $10 \%$ & $20 \%$ & $30 \%$ \\
\hline \multirow{2}{*}{0,30} & $>45$ & $>45$ & 12 & 5 \\
0,45 & $>45$ & $>45$ & 23 & 9 \\
0,60 & $>45$ & $>45$ & $>45$ & 34 \\
& & & $\operatorname{lnK}_{\theta=0}$ & \\
0,30 & $>45$ & 24 & 7 & 5 \\
0,45 & $>45$ & 45 & 11 & 6 \\
0,60 & $>45$ & $>45$ & 45 & 16 \\
\hline
\end{tabular}


A Tabela 18, resultante da interpretação das Figuras 19 e 20, mostra os valores correspondentes de $\mathrm{n}$ obtidos pelo critério definido por Hendrickx \& Wierenga (1990), em que o número mínimo de amostras é determinado pelo valor correspondente ao menor valor de $\mathrm{n}$ que excede a fração $\mathrm{F}$ $=0,9$. Percebe-se que, tanto para $\beta$ quanto para $\operatorname{lnK}_{\theta=0}$, nas três profundidades, $\mathrm{o}$ número de amostras (n) diminui com o aumento da variação permitida em torno da média, o que é coerente.

Para $\beta$, o número de amostras aumenta com a profundidade. Para estimar a média, com $10 \%$ de variação permitida, é necessário um número de amostras superior a 45 nas três profundidades. No mesmo nível de erro, 10\%, e nas mesmas profundidades, para o $\ln K_{\theta=0} \mathrm{o}$ número de amostras também aumenta em profundidade e seriam necessárias 24, 45 e > 45 amostras. Considerando as características experimentais do método do perfil instantâneo pode-se afirmar que com esses números torna-se difícil a condução do método em condições de campo, em que os valores de $\mathrm{n}$ são elevados e impraticáveis tanto para $\beta$ quanto para $\ln \mathrm{K}_{\theta=0}$. Isto também indica que os resultados de experimentos desta natureza, com poucas ou apenas uma repetição, devem ser considerados com bastante ressalva e utilizados com muito critério, na medida em que são comprovadamente pontuais, confirmando as conclusões de Jong van Lier \& Libardi (1999) também para as camadas mais internas do solo.

Tendo em vista o elevado grau de variabilidade da condutividade hidráulica não saturada (Warrick \& Nielsen, 1980), variações em torno de $30 \%$ podem ser admitidas como perfeitamente aceitáveis, o que nos permite indicar o número mínimo de 34 amostras para estimativa dos parâmetros da função $K(\theta)$, tendo em vista ser este o maior valor encontrado para $\beta$ e $\ln K_{\theta=0}$, considerando 
coeficiente de variação de $30 \%$, nas três profundidades estudadas neste experimento (Tabela 18).

Tabela 19. Número de amostras para estimar a média de $\beta$ e $\operatorname{lnK}_{\theta=0}$ considerando dois métodos para determinação, tradicional e "bootstrap".

\begin{tabular}{|c|c|c|c|c|c|c|c|c|}
\hline \multirow[b]{2}{*}{ Prof (m) } & \multicolumn{4}{|c|}{ Tradicional } & \multicolumn{4}{|c|}{ "Bootstrap" } \\
\hline & $5 \%$ & $10 \%$ & $20 \%$ & $30 \%$ & $5 \%$ & $10 \%$ & $20 \%$ & $30 \%$ \\
\hline \multicolumn{9}{|c|}{$\beta$} \\
\hline 0,30 & 88 & 22 & 5 & 2 & $>45$ & $>45$ & 12 & 5 \\
\hline 0,45 & 49 & 12 & 3 & 1 & $>45$ & $>45$ & 23 & 9 \\
\hline 0,60 & 194 & 49 & 12 & 5 & $>45$ & $>45$ & $>45$ & 34 \\
\hline \multicolumn{9}{|c|}{$\ln K_{\theta=0}$} \\
\hline 0,30 & 46 & 12 & 3 & 1 & $>45$ & 24 & 7 & 5 \\
\hline 0,45 & 24 & 6 & 2 & 1 & $>45$ & 45 & 11 & 6 \\
\hline 0,60 & 74 & 18 & 5 & 2 & $>45$ & $>45$ & 45 & 16 \\
\hline
\end{tabular}

Outra comparação muito oportuna deve ser feita entre os valores de n calculados pelo método tradicional, eq. (34), e pelo "bootstrap. Os resultados deste exercício estão na Tabela 19. Nos dois casos, considerando variação igual ou maior que $10 \%$, o número de amostras estimadas pelo "bootstrap" foi sempre 
mais elevado. Não obstante, os dois métodos também mostraram semelhanças quanto a tendência de alguns resultados. Em ambos os casos o número mínimo de amostras necessárias para estimar a média foi maior para o $\beta$. Por outro lado, a grande diferença entre os valores estimados sugere que a aplicação desses métodos de estimativa para médias de um conjunto de amostras relativas a propriedades como a condutividade hidráulica deve ser feita com certa prudência.

Como método de estimativa, o "bootstrap", pela sua própria concepção, isto é independe do tipo de distribuição dos dados, é mais realístico, muito embora os custos e a complexidade para obtenção dos números de amostras por ele indicado sejam uma importante limitação a ser considerada. Por exemplo, números de amostras superiores a 45 ou mesmo 34 são impraticáveis, mas certamente já permitem reconhecer na técnica uma importante ferramenta para auxiliar na solução deste problema, principalmente se aplicada em condições experimentais mais uniformes, como comprovam os resultados de Hendrickx \& Wierenga (1990).

\subsubsection{Análise da estabilidade temporal para umidade e potencial mátrico}

A análise estatística exploratória para umidade do solo $\theta\left(\mathrm{m}^{3} \mathrm{~m}^{-3}\right)$ e potencial mátrico $\phi_{\mathrm{m}}(\mathrm{kPa})$, conforme descrita nos itens 4.1.1 e 4.1.2, Tabelas $1 \mathrm{e}$ 2 e Tabelas 4, 5 e 6, respectivamente, revela que os dados apresentam distribuição normal para os quatro tempos analisados, permitindo que se possa assumir, para os outros tempos intermediários, que o padrão de distribuição também seja normal. Desta forma, os dados se enquadram nas condições definidas por Vachaud et al. (1985), para que um conjunto de dados experimentais possa ter a sua estabilidade temporal avaliada. 
As Figuras 21 e 22 mostram a heterogeneidade espacial, ao longo da transeção, dos valores de umidade e potencial mátrico nas profundidades de $0,30,0,45$ e $0,60 \mathrm{~m}$. As ilustrações mostram quatro tempos, com destaque para os tempos inicial e final.

Detalhando-se a análise das Figuras 21 e 22, percebe-se que, tanto para umidade quanto para o potencial mátrico, os padrões de variabilidade das medidas são diferentes entre as três profundidades. Não obstante, quando se compara individualmente cada profundidade, nota-se, tanto para a umidade quanto para o potencial mátrico, que existe uma similaridade no comportamento das medidas durante o processo de redistribuição. Fica bem claro que a maioria dos pontos mantêm sempre a mesma posição em relação ao conjunto de medidas. Este comportamento é bem mais definido para a umidade do solo do que para o potencial mátrico. A maior uniformidade na distribuição das medidas de umidade em relação ao potencial mátrico resulta dos coeficientes de variação apresentados por esses parâmetros. Para umidade no solo, os coeficientes de variação foram mais baixos e semelhantes durante a redistribuição (Tabela 1). Já para o potencial mátrico os valores dos coeficientes de variação foram maiores e bem diferentes ao longo do tempo (Tabela 4). Daí, a diferença de comportamento entre esses parâmetros.

As mesmas ilustrações (Figuras 21 e 22) também mostram que as medidas de umidade e potencial mátrico se distribuem ao longo da transeção com uma estacionaridade que revela a ausência de qualquer tendência para concentração de valores em determinada direção. Tal fato permite assumir que a estacionaridade definida pela hipótese intrínseca também pode ser aplicada a este conjunto de dados. 
A Tabela 20 mostra os coeficientes de correlação de Spearman para a umidade e potencial mátrico do solo. Nota-se que existe uma similaridade das medidas feitas entre o tempo inicial ( 78 horas) e os onze tempos de redistribuição, incluindo o tempo final da avaliação (604 horas). Embora alguns valores de $r$ tenham sido baixos, todos os resultados apresentaram correlação significativa ao nível de significância de 0,01 (SAS, 1991), indicando a existência de estabilidade temporal forte nas posições locais com r próximo a 1. De outra forma, aplicandose os limites unilaterais de r para o teste de correlação de Spearman (Campos, 1983), a interpretação seria mais seletiva, tendo em vista o limite crítico de 0,671 para significância de 0,01. Então, teríamos uma redução significativa entre as correlações temporais, principalmente para as medidas de potencial mátrico. Neste caso, para a umidade no solo, na profundidade $0,30 \mathrm{~m}$, todos os tempos apresentaram uma correlação significativa; na profundidade $0,45 \mathrm{~m}$ a correlação existiria até o tempo 268 horas e na profundidade $0,60 \mathrm{~m}$ até 460 horas. Para o potencial mátrico a correlação não se apresenta linear. Alguns tempos intermediários apresentaram correlação significativa enquanto outros não. Tal fato pode resultar de diferenças nas relações determinísticas entre essas propriedades e as características do solo, como a textura e a estrutura, cuja comprovação poderá ser feita por meio de análises e avaliações posteriores e que não foram previstas para este estudo. 

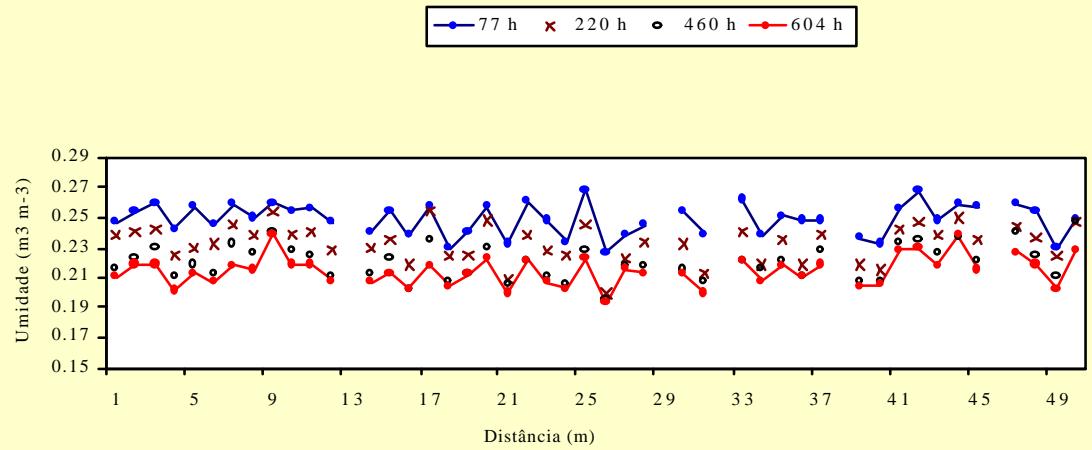

\section{$0,30 \mathrm{~m}$}

$\rightarrow-77 \mathrm{~h} \times 220 \mathrm{~h} \quad \bullet \quad 460 \mathrm{~h} \rightarrow 604 \mathrm{~h}$

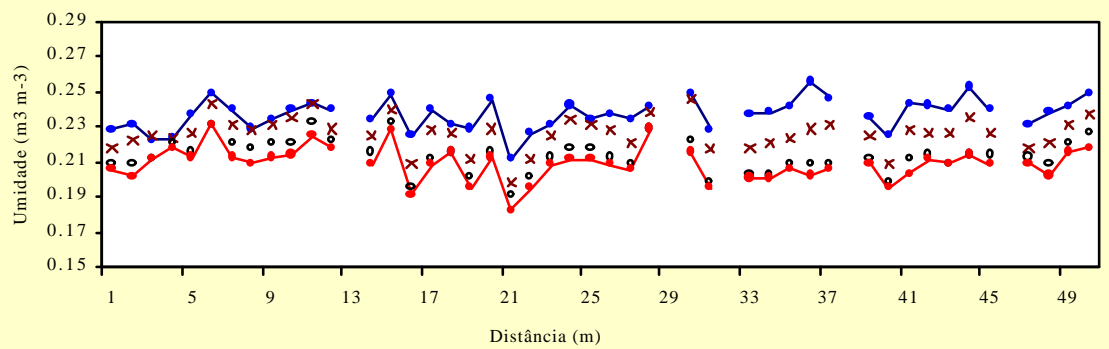

$0,45 \mathrm{~m}$

$\multimap-77$ h $\times 220$ h $\odot 460$ h $\rightarrow 604$ h

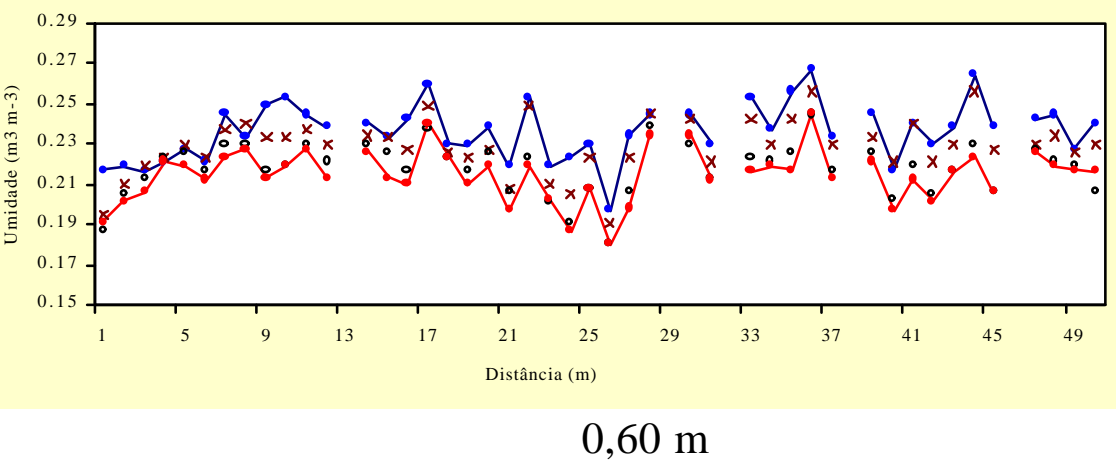

Figura 21 - Variabilidade da umidade do solo $\left(\mathrm{m}^{3} \mathrm{~m}^{-3}\right)$ segundo uma transeção de 45 pontos espaçados de um metro, em três profundidades e quatro tempos de amostragem. A linha interrompida indica os cinco pontos de medida que foram eliminados 

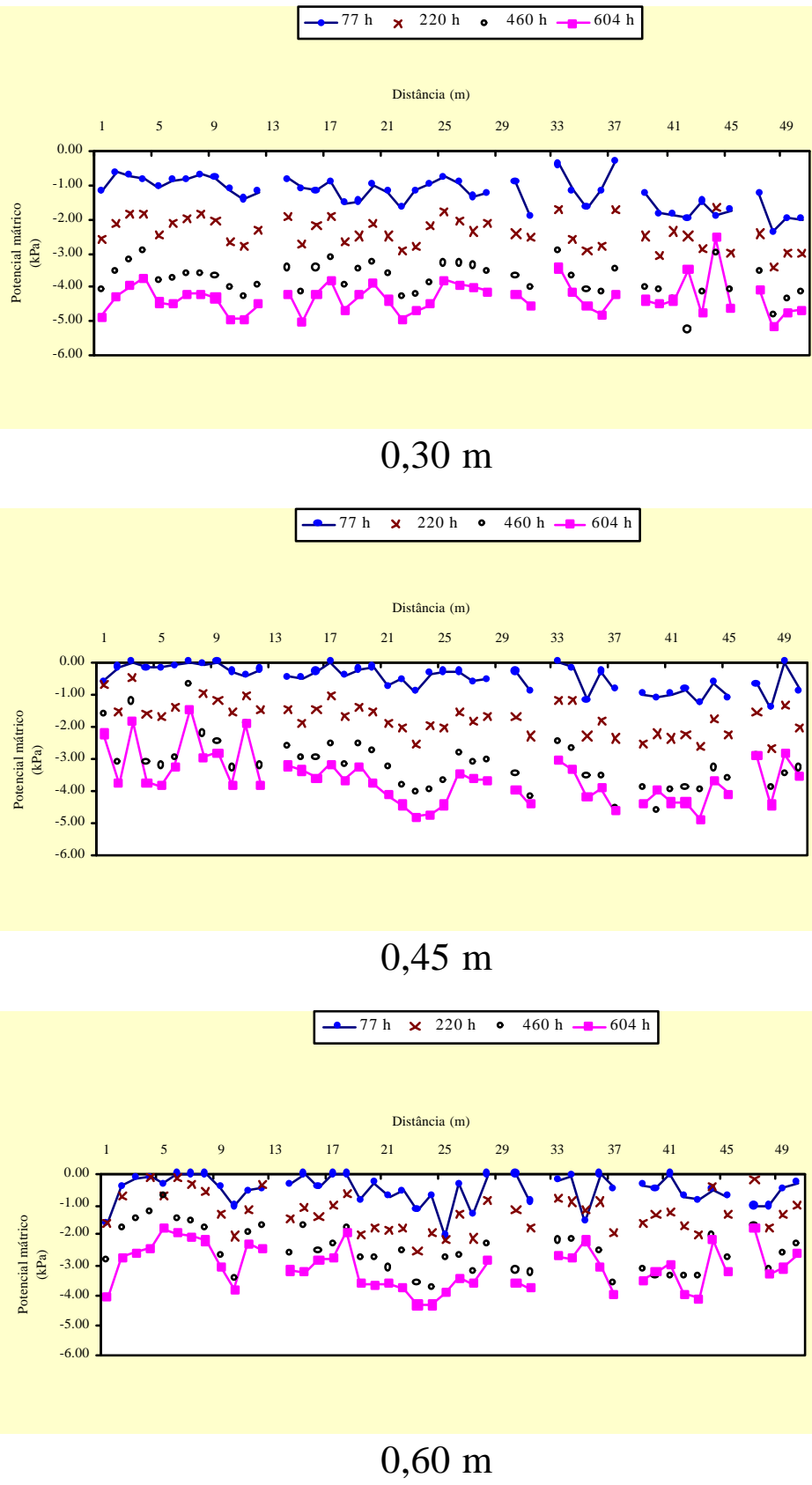

Figura 22 - Variabilidade do potencial mátrico $(\mathrm{kPa})$ segundo uma transeção de 45 pontos espaçados de um metro, em três profundidades e quatro tempos de amostragem. A linha interrompida indica os cinco pontos de medida que foram eliminados 
Tabela 20. Coeficientes de correlação entre o tempo inicial (78 horas) e os tempos de redistribuição durante o experimento de perfil instantâneo para umidade do solo $\left(\mathrm{m}^{3} \mathrm{~m}^{-3}\right)$ e potencial mátrico $(\mathrm{kPa})$ em três profundidades em uma transeção de 45 pontos espaçados de um metro.

\begin{tabular}{|c|c|c|c|c|c|c|}
\hline \multirow[b]{2}{*}{ Tempo (h) } & \multicolumn{3}{|c|}{ Umidade do solo } & \multicolumn{3}{|c|}{ Potencial mátrico } \\
\hline & $\begin{array}{c}0,30 \mathrm{~m} \\
78 \mathrm{~h}\end{array}$ & $\begin{array}{c}0,45 \mathrm{~m} \\
78 \mathrm{~h}\end{array}$ & $\begin{array}{c}0,60 \mathrm{~m} \\
78 \mathrm{~h}\end{array}$ & $\begin{array}{c}0,30 \mathrm{~m} \\
78 \mathrm{~h}\end{array}$ & $\begin{array}{c}0,45 \mathrm{~m} \\
78 \mathrm{~h}\end{array}$ & $\begin{array}{c}0,60 \mathrm{~m} \\
78 \mathrm{~h}\end{array}$ \\
\hline 78 & 1 & 1 & 1 & 1 & 1 & 1 \\
\hline 123 & 0,922 & 0,918 & 0,874 & 0,851 & 0,755 & 0,763 \\
\hline 167 & 0,870 & 0,854 & 0,844 & 0,682 & 0,691 & 0,697 \\
\hline 220 & 0,842 & 0,782 & 0,902 & 0,714 & 0,826 & 0,653 \\
\hline 268 & 0,733 & 0,683 & 0,787 & 0,717 & 0,652 & 0,725 \\
\hline 315 & 0,867 & 0,563 & 0,858 & 0,527 & 0,714 & 0,550 \\
\hline 361 & 0,819 & 0,600 & 0,727 & 0,606 & 0,673 & 0,641 \\
\hline 412 & 0,832 & 0,509 & 0,696 & 0,437 & 0,659 & 0,496 \\
\hline 460 & 0,806 & 0,488 & 0,718 & 0,628 & 0,674 & 0,497 \\
\hline 506 & 0,819 & 0,496 & 0,670 & 0,454 & 0,592 & 0,488 \\
\hline 553 & 0,778 & 0,501 & 0,565 & 0,483 & 0,530 & 0,558 \\
\hline 604 & 0,845 & 0,494 & 0,686 & 0,387 & 0,625 & 0,506 \\
\hline
\end{tabular}




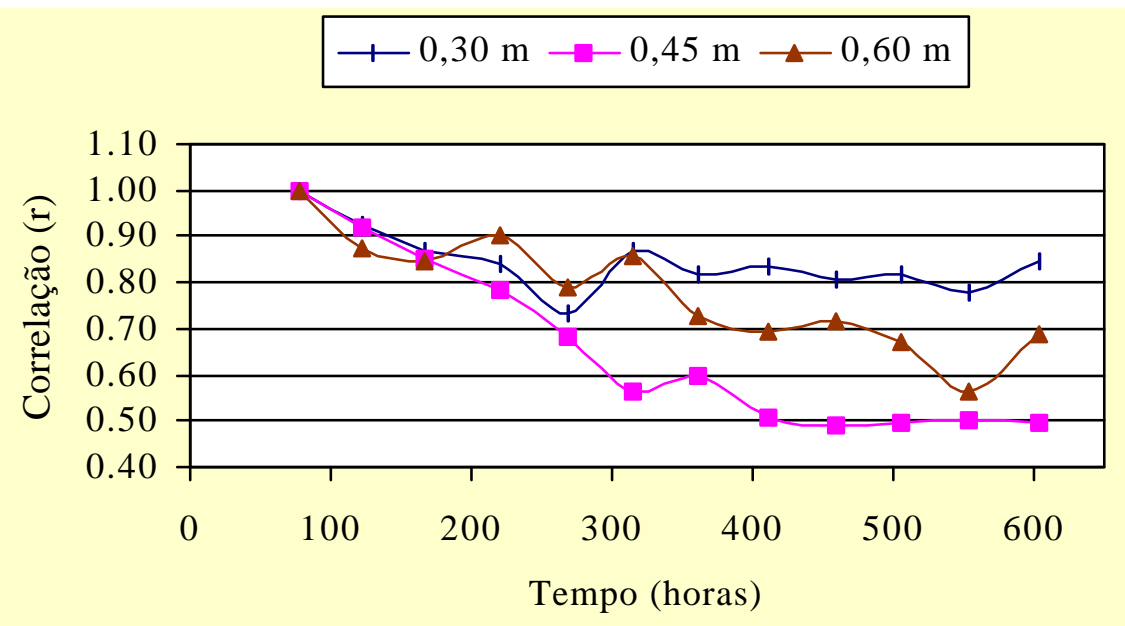

Umidade do solo

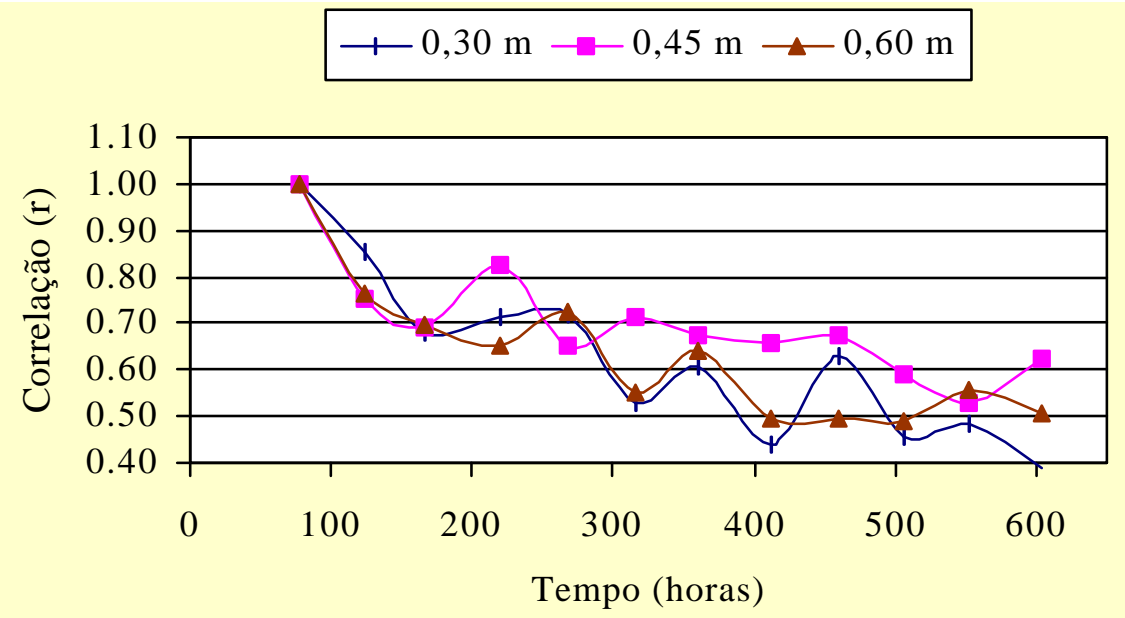

Potencial mátrico

Figura 23 - Coeficientes de correlação de Spearman entre o tempo inicial (78 horas) e onze tempos de redistribuição para umidade do solo e potencial mátrico em um experimento de perfil instantâneo.

A Figura 23 mostra os coeficientes de correlação de Spearman entre o tempo inicial e os onze tempos de redistribuição durante o período de avaliação experimental. De maneira geral, tanto para a umidade quanto para o potencial mátrico, os índices de correlação diminuíram com tempo nas três profundidades. Dentre estes, a umidade na profundidade $0,30 \mathrm{~m}$ apresentou a maior estabilidade 
temporal, tendo em vista que os valores de $\mathrm{r}$ mantiveram-se elevados e semelhantes durante todo o tempo de redistribuição.

O coeficiente de correlação de Spearman (r) possibilita verificar a existência da estabilidade temporal, mas não identifica os locais em que as medidas possam ser feitas para representar a média da variável em estudo para qualquer tempo e valor. Para tanto, Vachaud et al. (1985) sugerem o cálculo das diferenças relativas e seus respectivos desvios padrões. As diferenças relativas, quando ordenadas e plotadas em um gráfico, possibilitam identificar os pontos cujos valores sempre estejam próximos da média e possam ser utilizados como referência amostral.

Com os valores de umidade e potencial mátrico estimados para cada tempo, procedeu-se o cálculo das diferenças relativas (Vachaud et al., 1985), conforme as seguintes equações: Eq. (37) para umidade no solo e Eq. (38) para potencial mátrico.

$$
\begin{aligned}
& D R(\%)=\frac{\theta_{i j}-\bar{\theta}}{\bar{\theta}} \times 100 \\
& D R(\%)=\frac{\phi_{m(i j)}-\overline{\phi_{m}}}{\overline{\phi_{m}}} \times 100
\end{aligned}
$$

sendo: DR (\%) é a diferença relativa entre uma determinação individual para um local e tempo e a estimativa da média; $\theta_{\mathrm{ij}}$ a umidade no local i no tempo $\mathrm{j} ; \quad \overline{\boldsymbol{\theta}}$ a 
umidade média para todas as posições, no momento $\mathrm{j} ; \phi_{\mathrm{m}}$ o potencial mátrico no local i no tempo $\mathrm{j} ; \quad \overline{\phi_{m}}$ o potencial mátrico médio para todas as posições, no momento j. Com os resultados foram calculadas as diferenças relativas médias para todas as posições na transeção de 45 pontos. Com objetivo de indicar o grau de confiabilidade da medida também foram determinados os respectivos desvios padrões relacionados com as variações espaciais. Os resultados estão ilustrados na Figura 24 para a umidade e Figura 25 para o potencial mátrico. Analisando-as observa-se que alguns locais, sistematicamente, ou superestimam (DR $>0$ ) ou subestimam (DR < 0$)$ as medidas médias de umidade e potencial mátrico obtidas no campo, independentemente do tempo de observação. Segundo Gonçalves et al. (1999), o local a ser escolhido para a coleta de amostras, cujos valores sejam confiáveis e representativos, deve apresentar uma diferença relativa média igual ou muito próxima de zero e estar associada ao menor desvio padrão.

Adotando-se o critério de Gonçalves et al. (1999), foram identificados os pontos mais indicados para amostragem da umidade e do potencial mátrico nas três profundidades, 0,$30 ; 0,45$ e $0,60 \mathrm{~m}$.

Para a umidade do solo (Figura 24) os locais que mais se aproximaram do valor médio na transeção foram os seguintes: os pontos 5 e 14 na profundidade $0,30 \mathrm{~m} ; 16,34,8$ e 37 na profundidade $0,45 \mathrm{~m}$ e $12,44,5,9$ na profundidade $0,60 \mathrm{~m}$. Nota-se que praticamente não houve coincidência de pontos para estimativa das médias. Apenas o local de amostragem representado pelo TDR número 5 aparece como representativo para as profundidades 0,30 e 0,60 m.

Para o potencial mátrico (Figura 25) também não houve coincidência de locais representativos de amostragem nas três profundidades. Neste caso foram identificados os pontos 18, 20 e 31 na profundidade 0,30 m; 
28 e 14 na profundidade $0,45 \mathrm{~m}$ e, finalmente, os pontos 9 e 44 na profundidade $0,60 \mathrm{~m}$.
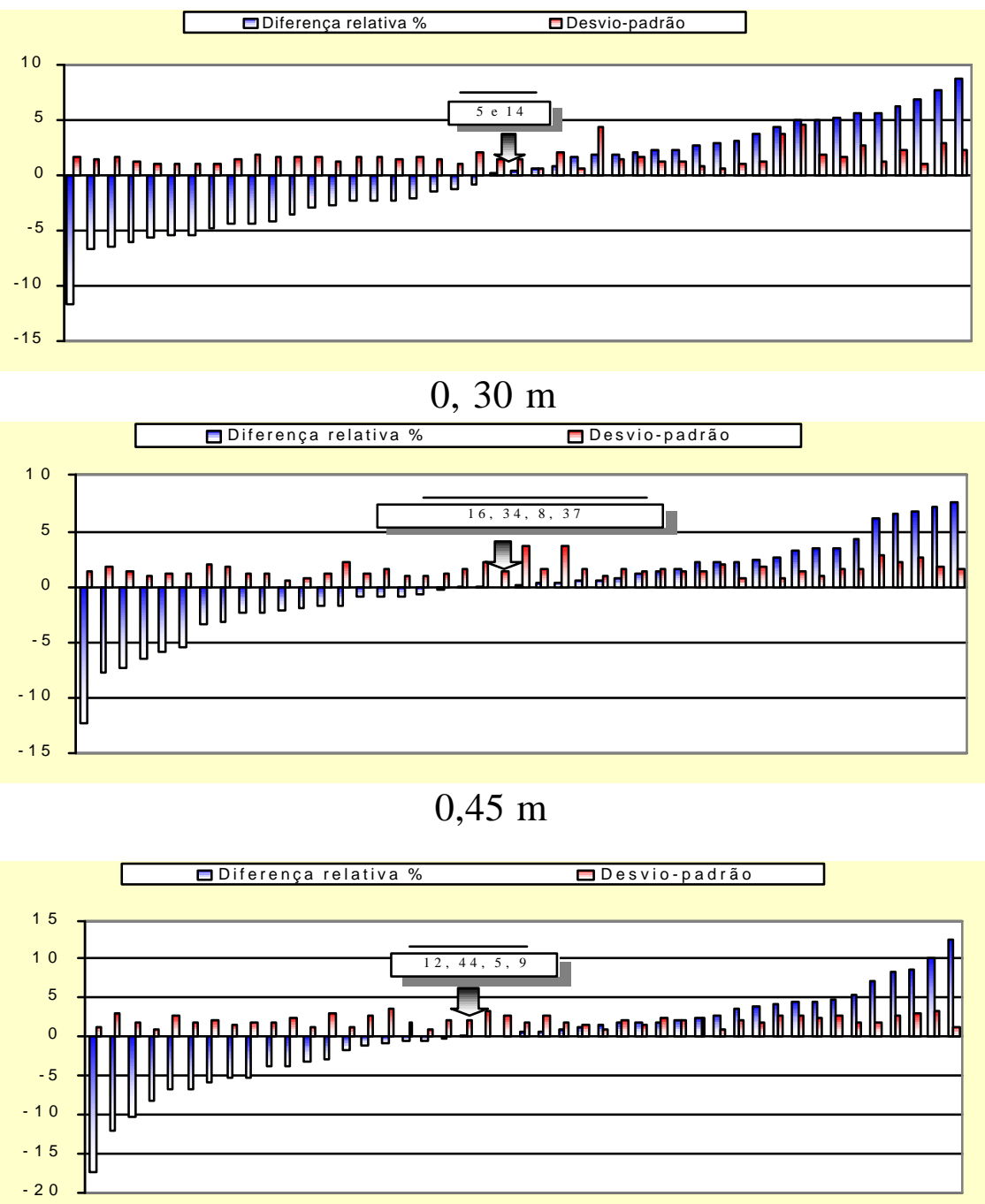

$0,60 \mathrm{~m}$

Figura 24 - Diferença relativa média intertemporal e desvio padrão para umidade do solo em três profundidades, segundo uma transeção de 45 pontos espaçados de um metro. Valores em destaque indicam os pontos que devem ser adotados para medidas representativas da média de umidade no solo. 

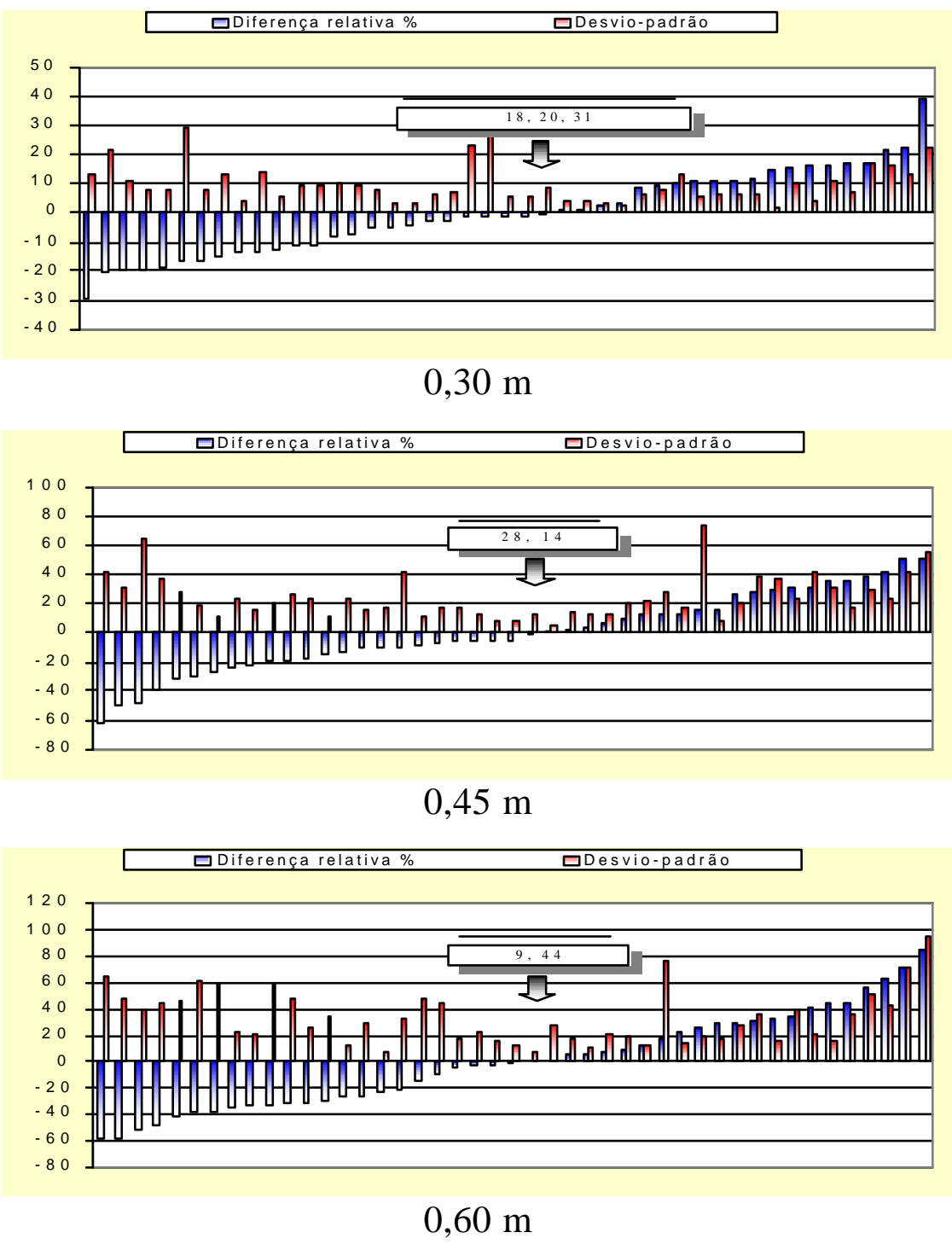

Figura 25 - Diferença relativa média intertemporal e desvio padrão para potencial mátrico em três profundidades, segundo uma transeção de 45 pontos espaçados de um metro. Valores em destaque indicam os pontos que devem ser adotados para medidas representativas da média de potencial mátrico do solo.

Para ambos os casos, neste solo e localização, qualquer um dos pontos identificados como estáveis no tempo poderiam ser escolhidos para o 
monitoramento e coleta de amostras médias representativas das variáveis, umidade e potencial mátrico. A existência de mais de um ponto com esta característica, bem como as diferenças entre as profundidades, devem ser atribuídas à variabilidade espacial da textura do solo, cuja influência nas medidas de umidade e potencial mátrico é bastante significativa (Vachaud et al., 1985).

Em relação às outras metodologias, tradicionalmente utilizadas para quantificar o número mínimo de amostras para estimar a média de uma determinada variável, o método da estabilidade temporal apresenta alguns resultados importantes do ponto de vista econômico e de execução. Permite identificar com precisão os locais mais adequados para as amostragens, possibilitando a redução do número de amostras necessárias e do custo de execução do esforço amostral para o planejamento de sistemas de uso e manejo de água e obtenção de conclusões em resultados experimentais de campo. 


\section{CONCLUSÕES}

O resultados experimentais nas três profundidades para os 45 pontos de observação permitem concluir que os parâmetros umidade do solo $(\theta)$, potencial mátrico $\left(\phi_{\mathrm{m}}\right)$, coeficiente angular $\beta$ e coeficiente linear $\ln \mathrm{K}_{\theta=0}$ da relação entre a condutividade hidráulica e a umidade, apresentaram distribuição normal, sendo a mesma fortemente afetada pela presença de valores extremos, notadamente no caso do $\beta$ em que a presença dos "outliers" foi responsável por alterações significativas nos índices e gráficos de probabilidade de distribuição.

As maiores variabilidades, determinadas pelos coeficientes de variação, foram para o coeficiente angular $\beta$ em relação ao coeficiente linear $\ln K_{\theta=0}$. Em ambos os casos, houve uma sensibilidade muita elevada das medidas de umidade no cálculo da função $K(\theta)$, tendo em vista que, pequenas variações no teor de água foram suficientes para causar variações significativas no $\beta$ e no $\ln \mathrm{K}_{\theta=0}$.

A variabilidade dos parâmetros hídricos estudados $\left(\theta, \phi_{\mathrm{m}}, \beta \mathrm{e}\right.$ $\left.\ln K_{\theta=0}\right)$ aumentou em profundidade, diferindo daqueles normalmente encontrados na literatura e indicando a necessidade de realização de estudos mais detalhados que possam melhorar o entendimento das causas de variação principalmente aquelas relativas ao solo. 
A variabilidade da umidade $(\theta)$ foi baixa $(<12 \%)$ e aumentou com o tempo de redistribuição, enquanto que o potencial mátrico $\left(\phi_{\mathrm{m}}\right)$, apresentou comportamento oposto, qual seja variabilidade alta (> 60\%) no início da redistribuição diminuindo para média (12 a 60\%) no final da avaliação

Não houve relação entre os parâmetros $\left(\theta, \phi_{\mathrm{m}}, \beta\right.$ e $\left.\operatorname{lnK_{\theta =0}}\right)$ quanto ao número de amostras necessárias para estimar a média. Com exceção da umidade $(\theta)$, nos outros casos esses valores apresentaram-se bem diferentes e em alguns bem elevados e impraticáveis. Este fato sinaliza que os resultados de experimentos de perfil instantâneo devem ser considerados com ressalva e utilizados com bastante critério tendo em vista serem comprovadamente pontuais.

A comparação entre o método tradicional e o "bootstrap", para calcular o número de amostras (n) de $\beta$ e $\operatorname{lnK}_{\theta=0}$, mostrou que as estimativas dos valores de $\mathrm{n}$ podem ser bastante diferentes e que a técnica "bootstrap" é mais realística, sendo por isso mais indicada, para determinar o número de amostras necessárias para estimar a média de $\beta$ e $\ln \mathrm{K}_{\theta=0}$ para um determinado nível de confiança e grau de precisão, podendo ser aplicado para estudos relativos a outras propriedades do solo.

A existência da estabilidade temporal para umidade e potencial mátrico do solo possibilita identificar, no campo, pontos que representam a médias dessas variáveis. Este método representa um avanço em relação as outras metodologias tradicionais, na medida em que possibilita a redução do número de amostras necessárias para estimar uma média representativa com elevada precisão e reduzido esforço amostral.

$\mathrm{Na}$ prática, a estratégia para estudos relativos aos parâmetros do solo com elevado grau de variabilidade deve contemplar, primeiramente, a 
identificação de zonas com estabilidade temporal, nas quais os experimentos devem ser realizados, o que levaria à obtenção de resultados mais precisos e representativos, com menor número de repetições. No caso específico da função $K(\theta)$ a sugere-se a verificação e identificação de locais com estabilidade temporal para os parâmetros $\theta$ e $\phi_{\mathrm{m}}$ ao longo do perfil do solo, em trabalhos experimentais de perfil instantâneo com mais de uma repetição. 


\section{REFERÊNCIAS BIBLIOGRÁFICAS}

ALVARENGA, M.I.N.; DAVIDE, A.C. Características físicas e químicas de um latossolo vermelho-escuro e a sustentabilidade de agroecossistemas. Revista Brasileira de Ciência do Solo, v.23, n.4, p.933-942, 1999.

ALVARENGA, M.I.N.; SOUSA, J.A. Atributos do solo e o impacto ambiental. Lavras: ESAL; FAEAP, 1995. 140p.

AMADOR, J.A.; WANG, Y.; SAVIN, M.C.; GÖRRES, JH. Fine-scale spatial variability of physical and biological soil properties in Kingston, Rhode Island. Geoderma, v.98, p.83-94, 2000.

AMOOZEGAR, A.; WARRICK, A.W. Hydraulic conductivity of saturated soils: Field methods. In: KLUTE, A. (Ed.) Methods of soil analysis. Madison: SSSA, 1986. Pt. 1: Physical and mineralogical methods, cap.29, p. 735-770.

ANDERSON, S.H.; CASSEL, D.K. Statistical and autoregressive analysis of physical properties of Portsmouth sandy loam. Soil Science Society of America Journal, v.50, p.1096-1104, 1986.

BABALOLA, O. Spatial variability of soil water properties in tropical soils of Nigeria. Soil Science, v.126, p.269-279, 1978. 
BACCHI, O.O.S.; REICHARDT, K. Escalonamento de propriedades hídricas na avaliação de métodos de determinação da condutividade hidráulica de solos. Revista Brasileira de Ciência do Solo, v.12, p.217-223, 1988.

BANTON, O. Field and laboratory determined hydraulic conductivities considering anisotropy and core surface area. Soil Science Society of America Journal, v.57, p.10-15, 1993.

BANZATTO, D.A.; KRONKA, S.N. Experimentação agrícola. 3.ed. Jaboticabal: FUNEP, 1995. 247p.

BAKER, J.M.; LASCANO, R.J. The spatial sensitivity of time-domain reflectometry. Soil Science, v.147, n.5, p.379-384, 1989.

BEIGUElman, B. Curso prático de bioestatística. 3.ed. Ribeirão Preto: Sociedade Brasileira de Genética, 1994. 244p.

BERG, M. van den; KLAMT, E. Variabilidade espacial de características de solos na região do planalto médio, RS. II. Análise da semivariância e da variância. Revista Brasileira de Ciência do Solo, v.21, n.3, p.401-408, 1997.

BORGES, A.L.; KIEHL, J.C.; SOUZA, L.S. Alteração de propriedades físicas e atividade microbiana de um latossolo amarelo álico após o cultivo com fruteiras perenes e mandioca. Revista Brasileira de Ciência do Solo, v.23, n.4, p.1019-1025, 1999. 
BOUMA, J. JONGMANS, A.G.; STEIN, A.; PEEK, G. Characterizing spatial variable hydraulic properties of a boulder clay deposit in the Netherlands. Geoderma, v.45, p.19-29, 1989.

BUCKINGHAM, E. Studies on the movement of soil moisture. Washington: USDA, Bureau of Soils, 1907. 61p. (Bulletin, 38).

CADIMA Z., A.; LIBARDI, P.L. REICHARDT, K. Variabilidade espacial da condutividade hidráulica em um latossolo vermelho-amarelo textura média, no campo. Revista Brasileira de Ciência do Solo, v.4, n.2, p.63-66, 1980.

CALVACHE, M.; PORTEZAN FILHO, O.; SILVA, J.C.A.; REICHARDT, K. Condutividade hidráulica de um solo Typic Haplustoll em condições de campo. In: CONGRESSO BRASILEIRO DE CIÊNCIA DO SOLO, 25., Viçosa, 1995. Resumos expandidos. Viçosa: SBCS; UFV, 1995. p.63.

CAMBARDELLA, C.A.; MOORMAN, T.B.; NOVAK, J.M.; PARKIN, T.B.; KARLEN, D.L.; TURCO, R.F.; KONOPKA, A.E. Field-scale variability of soil properties in Central Iowa soils. Soil Science Society of America Journal, v.58, p.1501-1511, 1994.

CAMPOS, H. Estatística experimental não-paramétrica. 4.ed. Piracicaba: ESALQ/FEALQ, 1983. 349p.

CARVALHO, L.G.; SAMPAIO, S.C.; SILVA, A.M. Determinação da condutividade hidráulica "in situ" de um latossolo roxo distrófico. In: CONGRESSO BRASILEIRO DE CIÊNCIA DO SOLO, 25., Viçosa, 1995. Resumos expandidos. Viçosa: SBCS; UFV, 1995. p.35. 
CENTURION, J.F.; DEMATTÊ, J.L.I. Efeitos de sistemas de preparo nas propriedades físicas de um solo sob cerrado cultivado com soja. Revista Brasileira de Ciência do Solo, v.9, p.263-266, 1985.

CHILDS, E.C. An introduction to the physical basis of soil water phenomena. London: A Wiley-Interscience; John Wiley, 1969. 493p.

CHUNG, H; LEE, K; KOO, J. A note on bootstrap model selection criterion. Statistics \& Probability Letters, v.26, p.35-41, 1996.

COGELS, O.G. Heterogeneity and representativity of sampling in the study of soil microstructure by the mercury intrusion method. Agricultural and Water Management, v.6, p.203-211, 1983.

COMEGNA, V.; DAMIANI, P.; SOMMELLA, A. Scaling the saturated hydraulic conductivity of a vertic ustorthens soil under conventional and minimum tillage. Soil \& Tillage Research, v.54, p.1-9, 2000.

COMEGnA, V.; DAMiAni, P.; D’ANNA, F.; RUGGIERO, C. Comparison of different field methods for determining the hydraulic conductivity curve of a volcanic vesuvian soil. Geoderma, v.73, p.231-244, 1996.

CORREAA, J.C. Efeito de métodos de cultivo em algumas propriedades físicas de um latossolo amarelo muito argiloso do estado do Amazonas. Pesquisa Agropecuária Brasileira, v.20, n.11, p.1317-1322, 1985. 
COUTO, E.G.; KLAMT, E. Variabilidade especial de propriedades químicas do solo afetadas pelo uso agrícola em solo sob pivô central no sul do Estado de Mato Grosso (compact disc). In: CONGRESSO BRASILEIRO DE CIÊNCIA DO SOLO, 26., Rio de Janeiro, 1997. Anais. Rio de Janeiro: SBCS; CNPS, 1997.

CZERMAINSKI, A.B. C. Análise exploratória de dados: identificação de um único "outlier" em dados de experimentos delineados em blocos casualizados. Piracicaba, 1986. 134p. Dissertação (Mestrado) - Escola Superior de Agricultura “Luiz de Queiroz”, Universidade de São Paulo.

DALTON, F.N. Development of time-domain reflectometry for measuring soil water content and bulk soil electrical conductivity. In: ADVANCES IN MEASUREMENT OF SOIL PHYSICAL PROPERTIES: BRINGING THEORY IN PRATICE, San Antonio, 1990. Proceedings. Madison: SSSA, 1992. p.143-167. (Especial Publication, 30)

DECHEN, S.C.F.; VIEIRA, S.R. Impacto de erosão induzida pela remoção da camada superficial, em atributos físicos e químicos do solo (compact disc). In: CONGRESSO BRASILEIRO DE CIÊNCIA DO SOLO, 26., Rio de Janeiro, 1997. Anais. Rio de Janeiro: SBCS; CNPS, 1997.

DANE, J.H.; REED, R.B.; HOPMANS, J.W. Estimating soil parameters and sample size by bootstapping. Soil Science Society of America Journal, v.50, p.283-287, 1986.

EFRON, B. Jacknife-after-Bootstrap standard errors and influence functions.

Journal of the Royal Statistical Society, v.54, p.83-127, 1992. 
EFRON, B.; TIBSHIRANI, R.J. An introduction to the bootstrap. London: Chapman and Hall, 1993. 436p.

EMPRESA BRASILEIRA DE PESQUISA AGROPECUÁRIA. Centro Nacional de Pesquisa de Solos. Sistema brasileiro de classificação de solos. Brasília, 1999. 412p.

FALLEIROS, M.C.; PORTEZAN, O.; OLIVEIRA, J.C.M.; BACCHI, O.O.S.; REICHARDT, K. Spatial and temporal variability of soil hydraulic conductivity in relation to soil water distribution, using an exponential model. Soil Technology, v.45, p.279-285, 1998.

FILIZOLA, H.F.; SANS, L.M.A.; FERRACINI, V.L. Parâmetros hídricos do solo como auxiliares na avaliação da poluição da água superficial e subsuperficial (compact disc). In: CONGRESSO BRASILEIRO DE CIÊNCIA DO SOLO, 26., Rio de Janeiro, 1997. Anais. Rio de Janeiro: SBCS; CNPS, 1997.

FLÜHLER, H.; ARDAKANI, M.S.; STOLZY, L.H. Error propagation in determining hydraulic conductivities from successive water content and pressure head profiles. Soil Science Society of America Journal, v.40, p.830-836, 1976.

FREEZE, R.A. Henry Darcy and the fountains of Dijon. Ground Water, v.32, n.1, p.23-30, 1994.

FRUEH, W.T.; HOPMANS, J.W. Soil moisture calibration of a TDR multilevel probe in gravely soils. Soil Science, v.162, n.8, p.554-565, 1997. 
GAJEM, Y.M.; WARRICK, A.W.; MYERS, D.E. Spatial dependence of physical properties of a typic torrifluvent soil. Soil Science Society of America Journal, v.45, p.709-715, 1981.

GARDNER. W.R. Calculation of capillary conductivity from pressure plate outflow data. Soil Science Society of America Proceedings, v.20, p.317$320,1956$.

GARDNER, W. R. Some steady-state solutions of the unsaturated moisture flow equation with apllication to evaporation from a water table. Soil Science, v.85, p.228-232, 1958.

GARDNER, W. R.; MIKLICH, F.J. Unsaturated conductivity and diffusivity measurements by a constant flux method. Soil Science, v.93, n.1, p.271-275, 1962.

GEE, G.W.; WARD, A.L. Innovations in two-phase measurements of soil hydraulic properties. In: WORKSHOP INTERNACIONAL EM AVANÇOS EM CIÊNCIA DO SOLO: A FÍSICA DO SOLO NA PRODUÇÃO AGRÍCOLA E QUALIDADE AMBIENTAL, Piracicaba: ESALQ, 1999. $\underline{\text { www.esalq.usp.br }}(14.10 .1999)$

GOMES, F.P. Curso de estatística experimental. 3.ed. Piracicaba: POTAFOS, 1987a. 162p.

GOMES, F.P. A estatística moderna na pesquisa agropecuária 12.ed. Piracicaba: Nobel, 1987b. 467p. 
GONÇALVES, A.C.A.; FOLEGATTI, M.A.; SILVA, A.P. Estabilidade temporal da distribuição espacial da umidade do solo em área irrigada por pivô central. Revista Brasileira de Ciência do Solo, v.23, p.155-164, 1999a.

GONÇALVES, A.C.A.; FOLEGATTI, M.A.; SILVA, A.P. Retenção de água no solo em área irrigada por pivô-central (compact disc). In: CONGRESSO LATINO-AMERICANO DE CIÊNCIA DO SOLO, 13., Águas de Lindóia, 1996. Solo-suelo 96: trabalhos. Piracicaba: SBCS; SLCS, 1996b.

GUERRA, P.A.G. Geoestatística operacional. Brasília: Ministério das Minas e Energia, 1988. 145p.

GUIMARÃES, E.C. Variabilidade da umidade e densidade do solo em um Latossolo Roxo. Campinas, 1993. 138p. Dissertação (Mestrado) - Faculdade de Engenharia Agrícola, Universidade Estadual de Campinas.

GREACEN, E.L. Soil water assessment by neutron method. Victoria: CSIRO, 1981. 140p.

GREEN, R.E.; AHUJA, L.R.; CHONG, S.K. Hydraulic conductivity, diffusivity and sorptivity of unsaturated soils: field methods. In: KLUTE, A. (Ed.) Methods of soil analysis. Madison: Soil Science Society of America, 1986. Pt. 1: Physical and mineralogical methods, cap.30, p. 771-798.

GROSSI SAD, J.H. Fundamentos sobre a variabilidade dos depósitos minerais. Rio de Janeiro: DNPM; CPRM; GEOSOL, 1986. 141p. 
HAMLETT, J.M.; HORTON, R.; CRESSIE, N.A.C. Resistant and exploratory techniques for use in semivariogram analyses. Soil Science Society of America Journal, v.50, p.868-875, 1986.

HANKS, R.J. Applied soil physics. 2. ed. New York: Springer-Verlag, 1992. 176p.

HENDRICKX, J.M.H.; WIERENGA, P.J. Variability of soil water tension in a trickle irrigated Chile pepper field. Irrigation Science, v.11, p.23-30, 1990a.

HENDRICKX, J.M.H.; WIERENGA, P.J.; NASH, M.S. Variability of soil water tension and soil water content. Agricultural and Water Management, v.18, p.135-148, 1990b.

HENDRICKX, J.M.H.; WIERENGA, P.J.; NASH, M.S.; NIELSEN, D.R. Boundary location from texture, soil moisture, and infiltration data. Soil Science Society of America Journal, v.50, p.1515- 1520, 1986.

HILLEL, D.; KRENTOS, V.D.; STYLIANOU, Y. Procedure and test of an internal drainage method for measuring soil hydraulic characteristics in situ. Soil Science, v.114, p.395-400, 1972.

HOOK, W.R.; LIVINGSTON, N.J. Propagation velocity errors in time reflectometry measurements of soil water. Soil Science Society of America Journal, v.59, p.92-96, 1995.

HOOK, W.R.; LIVINGSTON, N.J. Errors in converting time domain reflectometry measurements of propagation velocity to estimates of soil water content. Soil Science Society of America Journal, v.60, p.35-41, 1996. 
HUDSON, D.B.; WIERENGA, P.J.; HILLS, R.G. Unsaturated hydraulic properties from upward flow into soil cores. Soil Science Society of America Journal, v.60, p.388-396, 1996.

IWATA, S.; TABUCHI, T.; WARKENTIN, B. P. Soil - water interactions: mechanisms and applications. 2.ed. New York: Marcel Dekker, 1994. cap.6, p.333-353: Heterogeneity of hydraulic conductivity in soil.

JHUN, M.; JEONG, H. Applications of bootstrap methods for categorical data analysis. Computational Statistics \& Data Analysis, v.35, p.83-91, 2000.

JONES, A.J.; WAGENET, R.J. In situ estimation of hydraulic conductivity using simplified methods. Water Resources Research, v.20, n.11, p.1620-1626, 1984.

JONES, T.A. Skewnessand kurtosis as criteria of normality in observed frequency distributions. Journal of Sedimentary Petrology, v.39, n.4, p.1322-1627, 1969.

JONG VAN LIER, Q.; LIBARDI, P.L. Variabilidade dos parâmetros da relação entre condutividade hidráulica e umidade do solo determinada pelo método do perfil instantâneo. Revista Brasileira de Ciência do Solo, v.23, p.10051014, 1999.

KACHANOSKI, R.G.; DE JONG, E. Scale dependence and the temporal persistence of spatial patterns of soil water storage. Water Resources Research, v.24, p.85-91, 1988. 
KLUTE, A. The determination of the hydraulic conductivity and diffusivity of unsaturated soils. Soil Science, v.113, n.4, p.264-276, 1972.

KLUTE, A.; DIRKSEN, C. Hydraulic conductivity and diffusivity: Laboratory methods. In: KLUTE, A. (Ed.) Methods of soil analysis. Madison: Soil Science Society of America, 1986. Pt. 1: Physical and mineralogical methods, cap.28, p.697-734.

KUTILEK, M.; NIELSEN, D.R. Soil hydrology. Berlin: Catena Verlag, 1994. 370p.

LAUREN, J.G.; WAGNENT, R.J. BOUMA, J.; WOSTEN, J.H.M. Variability of saturated hydrulic conductivity in a Glassaquic Hapludalf with macropores. Soil Science, v.145, n.1, p.20-28, 1988.

LEVINE, D.M.; BERENSON, M.; STEPHAN, D. Estatística: teoria e aplicações. Trad. de T.C.P. de Souza. Rio de Janeiro: LTC, 2000. 812p.

LIBARDI, P.L. Condutividade hidráulica do solo em condições de campo. Piracicaba, 1978. 113p. Tese (Doutorado) - Escola Superior de Agricultura “Luiz de Queiroz”, Universidade de São Paulo.

LIBARDI, P.L. Dinâmica da água no solo. 2.ed. Piracicaba: P. L. Libardi, 2000. 509p.

LIBARDI, P.L.; MANFRON, P.A.; MORAES, S.O.; TUON, R.L. Variabilidade da umidade gravimétrica de um solo hidromórfico. Revista Brasileira de Ciência do solo, v.20, p.1-12, 1996. 
LIBARDI, P.L.; PREVEDELlO, C.L.; PAULETTO, E.A.; MORAES, S.O. Variabilidade espacial da umidade, textura e densidade de partículas ao longo de uma transeção. Revista Brasileira de Ciência do Solo, v.210, n.2, p.8590, 1986.

LIBARDI, P.L.; REICHARDT, K.; NIELSEN, D.R.; BIGGAR, J.W. Simplified field methods for estimating the unsaturated hydraulic conductivity. Soil Science Society of America Journal, v.44, p.3-6, 1980.

LOGSDON, S.D.; JAYNES, D.B. Spatial variability of hydraulic conductivity in a cultivated field at different times. Soil Science Society of America Journal, v.60, p.703-709, 1996.

MAHESHWARI, B.L. Interrelations among physical and hydraulic parameters of non-cracking soils. Journal of Agricultural Engineering Research, v.68, p.297-309, 1997.

MALLANTS, D.; JACQUES D.; TSENG, P.; VAN GENUCHTEN, M.Th.; FEYEN, J. Comparison of three hydraulic property mesurement methods. Journal of Hydrology, v.199, p.295-318, 1997.

MATA, J.D.V. da. Variabilidade espacial de indicadores da compactação de terra roxa estruturada, sob dois sistemas de preparo, cultivada com feijão (Phaseolus vulgaris L.) irrigado. Piracicaba, 1997. 73p. Tese (Doutorado) Escola Superior de Agricultura "Luiz de Queiroz", Universidade de São Paulo. 
MIYAZAKI, T. Water flow in soils. New York: Marcel Dekker, 1993. cap.9, p.255-283: Heterogeneity of Soils in Fields.

MORAES, S.O. Heterogeneidade hidráulica de uma terra roxa estruturada. Piracicaba, 1991. 141p. Tese (Doutorado) - Escola Superior de Agricultura "Luiz de Queiroz", Universidade de São Paulo.

MULLA, D.J.; McBRARNEY, A.B. Soil spatial variability. In: SUMNER, M.E. (Ed.) Handbook of soil science. New York: CRC Press, 2000. Cap. 9, p.321-352.

NIELSEN, D.R.; BIGGAR, J.W.; ERH, K.T. Spatial variability of field measured soil water properties. Hilgardia, v.42, n.7, p.215-259, 1973.

OGATA, G.; RICHARDS, L.A. Water content changes following irrigation of bare-field soil that is protected from evaporation. Soil Science Society of America Proceedings, v.21, n.4, p.355-356, 1957.

OLIVEIRA, J.J.; CHAVES, L.H.G.; QUEIROZ, J.E.; LUNA, J.G. de. Variabilidade espacial de propriedades químicas em um solo salino-sódico. Revista Brasileira de Ciência do Solo, v.23, n.4, p.783-789, 1999.

OR, D.; WRAITH, J.M. Soil Water content and Water potential Relationships. In: SUMNER, M.E. Handbook of soil science. New York: CRC Press, 2000. Cap. 3, p.53-85.

PREVEDELLO, C.L. Física do solo com problemas resolvidos. Curitiba: C. L. Prevedello, 1996. 446p. 
PREVEDELLO, C.L.; REICHARDT, K.; CORDEIRO, D. G.; MELO, E.F.R.Q.; SCHEFFER, M. Gradiente unitário do potencial hidráulico como fonte de erro na obtenção da condutividade hidráulica em solo saturado. Pesquisa Agropecuária Brasileira, v.29, n.2, p.275-280, 1994.

QUEIROZ, J.E.; MENDONÇA, I.C. de; SANTOS, R.V. Um estudo comparativo entre dois procedimentos de cálculo da condutividade hidráulica. Revista Brasileira de Engenharia Agrícola e Ambiental, v.1, p.113-115, 1997.

RADCLIFFE, D.E.; RASMUSSEN, T.C. Soil water movement. In: SUMNER, M.E. Handbook of soil science. New York: CRC Press, 2000. Cap. 4, p.87127.

RAICE, R.C.; BOWMAN, R.S. Effect of sample size on parameter estimations in solute transport experiments. Soil Science, v.146, n.2, p.108-112, 1988.

REICHARDT, K. Dinâmica da matéria e da energia em ecossistemas. 2.ed. Piracicaba: ESALQ, 1996. 505p.

REICHARDT, K.; LIBARDI, P.L.; NIELSEN, D.R. Unsaturated hydraulic conductivity determination by a scaling technique. Soil Science, v.160, n.3, p.165-168, 1975.

REICHARDT, K.; VIEIRA, S.R.; LIBARDI, P.L. Variabilidade espacial de solos e experimentação de campo. Revista Brasileira de Ciência do Solo, v.10, n.1, p.1-6, 1986. 
REICHARDT, K.; LIBARDI, P.L.; SAUNDERS, L.C.U.; CADIMA, A. Dinâmica da água em solo cultivado com milho. Revista Brasileira de Ciência do Solo, v.3, n.1, p.1-5, 1979.

REYNOLDS, W.D.; ZEBCHUK, W.D. Hydraulic conductivity in a clay soil: Two measurement techniques and spatial characterization. Soil Science Society of America Journal, v.60, p.1679-1685, 1996.

RIBEIRO JUNIOR, P.J. Métodos geoestatísticos no estudo da variabilidade espacial de parâmetros do solo. Piracicaba, 1995. 99p. Tese (Mestrado) Escola Superior de Agricultura "Luiz de Queiroz", Universidade de São Paulo.

RICHARDS, L.A. The usefulness of capillary potential to soil moisture and plant investigators. Journal of Agricultural Research, v.37, p.719-742, 1928.

RICHARDS, L.A.; GARDNER, W.R.; OGATA, G. Physical processes determining water loss from soil. Soil Science Society of America Proceedings, v.20, p.310-314, 1956.

RICHARDS, S.J.; WEEKS, L.V. Capillary conductivity values from moisture yield and tension measurements on soil columns. Soil Science Society of America Proceedings, v.17, p.206-208, 1953.

RODRIGUES, J.B.T.; ZIMBACK, C.R.L. Variabilidade espacial da densidade do solo em latossolo roxo álico - Botucatu - SP (compact disc). In: CONGRESSO BRASILEIRO DE CIÊNCIA DO SOLO, 26., Rio de Janeiro, 1997. Anais. Rio de Janeiro: SBCS; CNPS, 1997. 
RUSSO, D.; BRESLER, E. Soil hydraulic as stochastic processes. I. An analysis of field spatial variability. Soil Science Society of America Journal, v.45, p.682-687, 1981.

SANTOS, H.L.; VASCONCELOS, C.A. Determinação do número de amostras de solo para análise química em diferentes condições de manejo. Revista Brasileira de Ciência do Solo, v.11, p.97-100, 1987.

STATISTICAL ANALYSIS SYSTEM INSTITUTE. SAS/STAT Procedure guide for personal computers. Version 5, SAS Inst. Cary, NC. 1991.

SCHAAP, M.G.; LEIJ, F.J. Using neural networks to predict soil water retention and soil conductivity. Soil \& Tillage Research, v.47, p.37-42, 1998.

SEYFRIED, M. Spatial variability constraints to modeling soil water at different scales. Geoderma, v.85, p.231-254, 1998.

SHOUSE, P.J.; SISSON, J.B.; ELLSWORTH, T.R.; JOBES, J.A. Estimating in situ unsaturated hydraulic properties of vertically heterogeneous soils. Soil Science Society of America Journal, v.56, p.1673-1679, 1992.

SILVA, A.P. Variabilidade espacial de atributos físicos do solo. Piracicaba, 1988. 105p. Tese (Doutorado) - Escola Superior de Agricultura "Luiz de Queiroz”, Universidade de São Paulo.

SILVA, A.P.; LIBARDI, P.L.; CAMARGO, O.A. Influência da compactação nas propriedades físicas de dois latossolos. Revista Brasileira de Ciência do Solo, v.10, p.91-95, 1986. 
SILVA, E.L.S.; GERVÁSIO, E.S. Uso do instrumento TDR para determinação do teor de água em diferentes camadas de um Latossolo Roxo Distrófico. Revista Brasileira de Engenharia Agrícola e Ambiental, v.3, n.3, p.417420, 1999.

SISSON, J.B.; WIERENGA, P.J. Spatial variability of steady-state infiltration rates as a stochastic process. Soil Science Society of America Journal, v.45, p.699-704, 1981.

SMITH, K.A.; MULLINS, C. E. Soil analysis-physical methods. New York: s.ed., 1991. 620p.

SOUSA, J.R.; QUEIROZ, J.E.; GHEYI, H.R. Variabilidade especial de características físico-hídricas e de água disponível em um solo aluvial no semiárido paraibano. Revista Brasileira de Engenharia Agrícola e Ambiental, v.3, n.2, p.140-144, 1999.

SOUZA, L.S. Variabilidade espacial do solo em sistemas de manejo. Porto Alegre, 1992. 162p. Tese (Doutorado) - Universidade Federal do Rio Grande do Sul.

SOUZA, L.S.; COGO, N.P.; VIEIRA, S.R. Variabilidade de propriedades físicas e químicas do solo em um pomar cítrico. Revista Brasileira de Ciência do Solo, v.21, n.3, p.367-372, 1997a. 
SOUZA, L.S.; PAIVA, A.Q.; RIBEIRO, A.C.; COSTA, L.M. da; SANTANA, M.B. Porosidade e condutividade hidráulica saturada em solos dos tabuleiros costeiros (compact disc). In: CONGRESSO BRASILEIRO DE CIÊNCIA DO SOLO, 26., Rio de Janeiro, 1997. Anais. Rio de Janeiro: SBCS/CNPS, 1997b.

SOUZA, M.L.P; LIBARDI, P.L.; REICHARDT, K. Propagação de erros na medida de água no solo em condições de campo. Revista Brasileira de Ciência do Solo, v.3, p.137-140, 1979.

SPIEGEL, M.R. Estatística: resumo da teoria. Trad. de P. Cosentino. Rio de Janeiro: Ao Livro Técnico, 1968. 580p.

STAT SOFT. Statistica for Windows [Eletronic manual index], v.4.3. Tulsa, 1993. $2 \mathrm{v}$.

THOMSEN, A.; HANSEN, B.; SCHELDE, K. Application of TDR to water level measurement. Journal of Hydrology, v.236, p.252-258, 2000.

TOMMASELLI, J.T.G. Influência de algumas características do solo sobre a calibração de um aparelho de TDR (Time-Domain Reflectometry). Piracicaba, 1997. 105p. Dissertação (Doutorado) - Centro de Energia Nuclear na Agricultura, Universidade de São Paulo.

TOMMASELLI, J.T.G.; BACCHI, O.O.S. Calibração de um equipamento de reflectometria de microondas para dois solos paulistas típicos. In: CONGRESSO BRASILEIRO DE CIÊNCIA DO SOLO, 25., Viçosa, 1995. Resumos expandidos. Viçosa: SBCS; UFV, 1995. p.24. 
TOMMASELLI, J.T.G.; BACCHI, O.O.S. Calibração de um TDR utilizando modelos empíricos para cinco solos paulistas (compact disc). In: CONGRESSO LATINO-AMERICANO DE CIÊNCIA DO SOLO, 13., Águas de Lindóia, 1996. Solo-suelo 96: trabalhos. Piracicaba: SBCS; SLCS, 1996.

TOPP, G.C.; REYNOLDS, W.D. Time domain reflectometry: a seminal technique for measuring mass and energy in soil. Soil \& Tillage Research, v.47, p.125-132, 1998.

TOPP, G.C.; DAVIS, J.L.; ANNAN, A.P. Electromagnetic determination of soil water content: Measurement in coaxial transmission lines. Water Resources Research, v.16, p.574-582, 1980.

TRANGMAR, B.B.; YOST, R.S.; UEHARA, G. Application of geostatistics to spatial studies of soil properties. In: BRADY, N.C. Advances in agronomy. Orlando: Academic Press, 1985. p.45-93.

VACHAUD, G.; PASSERAT DE SILANS, A.; BALABANIS, P. \& VAUCLIN, M. Temporal stability of spatially measured soil water probability density function. Soil Science Society of America Journal, v.49, p.822-827, 1985.

VAN GENUCHTEN, M.TH. A closed-form equation for predicting the hydraulic conductivity of unsaturated soils. Soil Science Society of America Journal, v.44, p.892-898, 1980. 
VAN WESENBEECK, I.J.; KACHANOSKI, R.G. \& ROLSTON, D.E. Temporal persistence of spatial patterns of soil water content in the tilled layer under a corn crop. Soil Science Society of America Journal, v.52, p.934-941, 1988.

VENKOVSKY, R.; DIAS, C.T.S.; DEMÉTRIO, C.G.B.; LEANDRO, R.A.; PIEDADE, S.M.S. Reamostragem por "bootstrap" na estimação de parâmetros baseados em marcadores genéticos. In: ENCONTRO SOBRE TEMAS DE GENÉTICA E MELHORAMENTO, 14., Piracicaba, 1997. Anais. Piracicaba: ESALQ, 1997. p.59-72.

VIEIRA, S.R. Variabilidade especial de argila, silte e atributos químicos em uma parcela experimental de um latossolo roxo de Campinas (SP). Bragantia, v.56, n.1, p.181-190, 1997.

VIEIRA, S.R.. Geoestatística em estudos de variabilidade espacial do solo. In: NOVAIS, R.F.; ALVAREZ; SCHAEFER, C.E.G.R (Ed.) Tópicos em ciência do solo. Viçosa: SBCS, 2000. Cap. 1, p.1-54.

VIEIRA, S.R.; LOMBARDI NETO, F. Variabilidade espacial do potencial de erosão das chuvas do estado de São Paulo. Bragantia, v.54, n.2, p.405-412, 1995.

VIEIRA, S.R.; CASTRO, O.M. de; TOPP, G.C. Spatial variability of some soil physical properties in three soils of São Paulo, Brazil. Pesquisa Agropecuária Brasileira, v.27, n.2, p.333-341, 1992. 
VIEIRA, S.R.; LOMBARDI NETO, F.; BURROWS, I.T. Mapeamento da chuva máxima provável para o Estado de São Paulo. Revista Brasileira de Ciência do Solo, v.15, n.1, p.93-98, 1991.

VIEIRA, S.R.; NIELSEN, D.R.; BIGGAR, J.W. Spatial variability of fieldmeasured infiltration rate. Soil Science Society of America Journal, v.45, p.1040-1048, 1981.

VIEIRA, S.R.; HATFIELD, J.L.; NIELSEN, D.R.; BIGGAR, J.W. Geostatistical theory and application to variability of some agronomical properties. Hilgardia, v.51, n.3, 1983. 73p.

VIEIRA, S.R.; TILLOTSON, PM.; BIGGAR, J.W; NIELSEN, D.R. Scaling of semivariograms and the kriging estimation of field-measured properties. Revista Brasileira de Ciência do Solo, v.21, p.525-533, 1997.

VILLAGRA, M.M.; MATSUMOTO, O.M.; BACCHI, O.O.S.; MORAES, S.O.; LIBARDI, P.L.; REICHARDT, K. Tensiometria e variabilidade espacial em Terra Roxa Estruturada. Revista Brasileira de Ciência do Solo, v.12, p.205$210,1988$.

WARRICK, A.W.; NIELSEN, D.R. Spatial variability of soil physical properties in the field. In: HILLEL, D. (Ed.) Applications of soil physics. New York: Academic Press, 1980. cap. 13, p.319-344.

WATSON, K.K. An instantaneous profile method for determining the hydraulic conductivity of unsaturated porous materials. Water Resources Research, v.2, p.709-715, 1966. 
WEBSTER, R. Optimally partitioning soil transects. Journal of Soil Science, v.29, p.388-402, 1978.

WENDROTH, O.; REYNOLDS, W.D.; VIEIRA, S.R.; REICHARDT, K.; WIRT, S. Statistical approaches to the analysis of soil quality data. In: GREGORICH, E.G.; CARTER, M.R. (Ed.) Soil quality: for crop production and ecosystem health. Amsterdam: Eselvier, 1997. Cap. 11, p.247-276. 
APÊNDICES 
APÊNDICE 1: Descrição do perfil do solo aberto no local do experimento.

\section{DESCRIÇÃO DO PERFIL}

\section{A. DESCRIÇÃO GERAL}

PERFIL - JF 01

DATA - 08/05/2001

CLASSIFICAÇÃO - Latossolo Vermelho Amarelo álico A moderado, textura média (Typic Hapludox).

LOCALIZAÇÃO - Lateral direita da cabeceira do aeroporto ESALQ - Fazenda Sertãozinho - Piracicaba - SP.

SITUAÇÃO - Trincheira

GEOLOGIA - Sedimentos arenosos não consolidados do Neocenozóico (Fm Rio Claro).

PEDREGOSIDADE - Não pedregosa

ROCHOSIDADE - Não rochosa

RELEVO LOCAL - Plano

REGIONAL - Suave ondulado

EROSÃO - Não aparente

DRENAGEM - Acentuada

USO ATUAL - Capim elefante (corte)

CLIMA - CWA pela classificação de Koëppen.

DESCRITO E COLETADO POR - T. O. Ferreira e R. E. Romero

\section{B. DESCRIÇÃO MORFOLÓGICA}

Ap $\quad 0-15 \mathrm{~cm}$, bruno-avermelhado-escuro (5YR 3/3, úmido); arenosa; moderada média e grande blocos subangulares; ligeiramente duro, friável, não plástico e ligeiramente pegajoso; transição clara e plana. 
AB

15-31 cm, bruno-avermelhado-escuro (5YR 3/3, úmido); arenosa; moderada média e grande blocos subangulares; duro, friável, ligeiramente plástico e ligeiramente pegajoso; transição clara e plana.

BA 31-50cm, bruno-avermelhado-escuro (5YR 3/3, úmido); arenosa; moderada média blocos subangulares; duro, muito friável, ligeiramente plástico e ligeiramente pegajoso; transição gradual e plana.

B1 50-78cm, bruno-avermelhado-escuro (5YR 3/4, úmido); média; moderada média blocos subangulares; duro, muito friável, ligeiramente plástico e ligeiramente pegajoso; transição gradual e plana.

B2 bruno-avermelhado-escuro (5YR 3/4, úmido); média; moderada a fraca média e pequena blocos subangulares; muito duro, muito friável, plástico e ligeiramente pegajoso; transição gradual e plana.

B3 bruno-avermelhado-escuro (5YR 3/4, úmido); média; moderada a fraca média e pequena blocos subangulares; ligeiramente duro, muito friável, plástico e ligeiramente pegajoso; transição gradual e plana.

RAíZES Poucas e finas em Ap, AB e BA e raras e finas em B1 e B2.

Observações Presença de camada adensada (pé-de-grade) a $31 \mathrm{~cm}$ de profundidade bem delimitada pelo acúmulo de matéria orgânica e carvão. Presença de mosqueado (pouco, pequeno e distinto) no horizonte $\mathrm{AB}$. 
APÊNDICE 2: Textura e granulometria dos horizontes descritos no perfil de solo da área experimental.

\begin{tabular}{|c|c|c|c|c|c|c|}
\hline \multirow[b]{2}{*}{ Horizonte } & \multirow[b]{2}{*}{ Argila } & \multirow[b]{2}{*}{ Silte } & \multicolumn{3}{|c|}{ Areia } & \multirow[b]{2}{*}{ Classificação } \\
\hline & & & Grossa & Fina & Total & \\
\hline \multicolumn{7}{|c|}{ 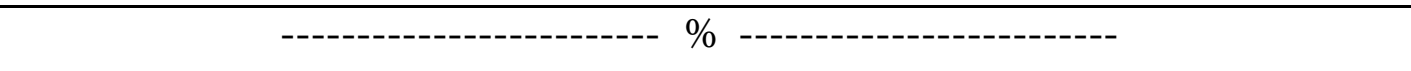 } \\
\hline Ap & 16,7 & 8,4 & 12,9 & 62,0 & 74,9 & F. arenoso \\
\hline $\mathrm{AB}$ & 18,6 & 6,2 & 14,8 & 60,4 & 75,2 & F. arenoso \\
\hline BA & 18,8 & 6,3 & 15,6 & 59,3 & 74,9 & F. arenoso \\
\hline B1 & 23,1 & 10,5 & 14,7 & 51,7 & 66,4 & F. arenoso \\
\hline B2 & 27,9 & 4,3 & 13,9 & 53,9 & 67,8 & $\begin{array}{l}\text { F. argilo } \\
\text { arenoso }\end{array}$ \\
\hline B3 & 25,4 & 6,4 & 13,6 & 54,6 & 68,2 & $\begin{array}{l}\text { F. argilo } \\
\text { arenoso }\end{array}$ \\
\hline
\end{tabular}


APÊNDICE 3: Valores de umidade nas diversas tensões (h) e profundidades (Z) do solo (Reichardt et al., 1979).

\begin{tabular}{cccccccccc}
\hline & \multicolumn{10}{c}{ Potencial matricial h (m) } \\
\cline { 2 - 10 } Prof $(\mathrm{Z})$ & 0 & 0,25 & 0,50 & 1,00 & 1,50 & 1,80 & 3,00 & 5,00 & 8,00 \\
\hline $\mathrm{m}$ & ------------------------- & $\theta$ & $\left(\mathrm{m}^{3} \mathrm{~m}^{-3}\right)$ & ----------------------------- \\
0,15 & 0,39 & 0,29 & 0,25 & 0,22 & 0,20 & 0,18 & 0,17 & 0,15 & 0,13 \\
0,30 & 0,40 & 0,35 & 0,32 & 0,28 & 0,26 & 0,25 & 0,20 & 0,19 & 0,18 \\
0,45 & 0,41 & 0,34 & 0,31 & 0,26 & 0,24 & 0,23 & 0,19 & 0,17 & 0,17 \\
0,60 & 0,43 & 0,38 & 0,33 & 0,27 & 0,25 & 0,23 & 0,17 & 0,16 & 0,15 \\
0,75 & 0,40 & 0,33 & 0,29 & 0,22 & 0,19 & 0,18 & 0,17 & 0,16 & 0,15 \\
0,90 & 0,38 & 0,32 & 0,29 & 0,23 & 0,21 & 0,19 & 0,17 & 0,16 & 0,15 \\
1,05 & 0,38 & 0,33 & 0,29 & 0,23 & 0,21 & 0,19 & 0,18 & 0,16 & 0,15 \\
1,20 & 0,40 & 0,35 & 0,31 & 0,24 & 0,21 & 0,20 & 0,17 & 0,15 & 0,14 \\
1,35 & 0,39 & 0,35 & 0,30 & 0,24 & 0,21 & 0,19 & 0,16 & 0,15 & 0,14 \\
\hline
\end{tabular}

Fonte: Reichardt et al. (1979) 